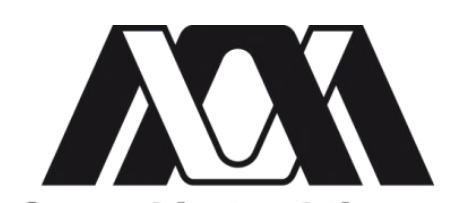

Casa abierta al tiempo

\title{
Estudio de la relación entre la subunidad G $\alpha$ Aga1 y el proceso de formación de artrosporas en Acremonium chrysogenum
}

\author{
TESIS \\ Para obtener el grado de \\ Maestro en Biotecnología
}

PRESENTA

Q. F. B. Jesús Eduardo Zúñiga León

DIRECTOR

Dr. Francisco Fierro Fierro ${ }^{1}$

ASESORES
Dr. Armando Mejía Álvarez ${ }^{1}$
Dr. Juan Esteban Barranco Florido ${ }^{2}$

${ }^{1}$ Departamento de Biotecnología, UAM-Iztapalapa

${ }^{2}$ Departamento de Sistemas Biológicos, UAM-Xochimilco 
“La Maestría en Biotecnología de la Universidad Autónoma Metropolitana está incluida en el Programa Nacional de Posgrados de Calidad (PNPC) del CONACYT, con la referencia 001465".

Esta tesis se realizó en el Laboratorio de Mejoramiento Genético de Microorganismos Industriales del Departamento de Biotecnología de la División de Ciencias Biológicas y de la Salud, Universidad Autónoma Metropolitana, Unidad Iztapalapa, bajo la dirección del Dr. Francisco Fierro Fierro. E1 trabajo fue financiado por CONACyT con el número de registro 105527. 
El H. Jurado designado por la

División de Ciencias Biológicas y de la Salud de la Unidad Iztapalapa aprobó la tesis:

Estudio de la relación entre la subunidad Ga Aga1 y el proceso de formación de artrosporas en Acremonium chrysogenum

Que presentó

Q.F. B. Jesús Eduardo Zúniga León

Comité Tutoral:

Director: Dr. Francisco Fierro Fierro

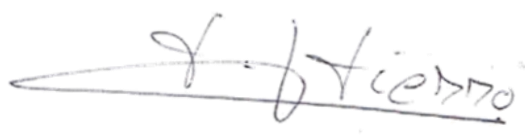

Asesor: Dr. Armando Mejía Álvarez

Asesor: Dr. Juan Esteban Barranco Florido

Jurado:

Presidente: Dr. Armando Mejía Álvarez

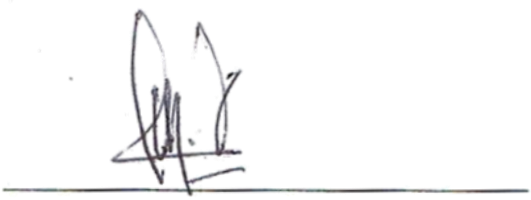

Secretario: Dr. Juan Esteban Barranco Florido

Vocal: Dra. Diana Verónica Cortés Espinosa

Vocal: M. en C. Ulises Carrasco Navarro

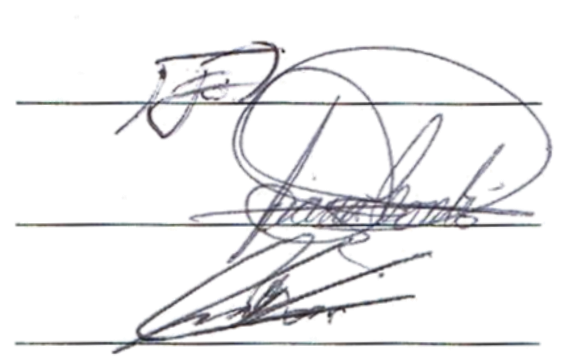




\title{
“Cada día sabemos más y entendemos menos”
}

\author{
Albert Einstein
}

\section{Agradecimientos}

A mi familia. Mamá, Papá les agradezco todo el esfuerzo que han hecho y todo el apoyo que me han demostrado a lo largo de mi vida. A mis hermanos, porque a pesar de todo, sé que siempre estarán ahí cuando lo necesite.

Al Dr. Francisco Fierro, a quien respeto, admiro y aprecio. Gracias por abrirme las puertas de su laboratorio y dejarme trabajar haciendo lo que más me gusta. Agradezco el tiempo que ha invertido en la dirección y corrección de mi tesis. Gracias por compartir de manera extraordinaria todo el conocimiento que posee.

A mis compañeros de laboratorio por apoyarme y crear un clima de trabajo agradable, y propicio para que el día a día fuera más ameno y tranquilo.

A mis mejores amigos Atonaltzin y Luciano, por el apoyo moral que he recibido de ellos durante todo este tiempo.

A mis revisores el Dr. Armando Mejía, Dr. Esteban Barrando y M. en C. Ulises Carrasco por sus consejos y sus contribuciones para la mejora de este trabajo.

Al Dr. Ramón García Rico por sus acertados comentarios hacia este trabajo.

A la Dra. Laura Ongay y Lupita que me han dado todas las bases de mi conocimiento y por el apoyo moral que he recibido de ellas. 


\section{RESUMEN}

Las proteínas $G$ heterotriméricas son elementos clave de las vías de transducción de señales en eucariotas. Estas proteínas responden a diversos estímulos ambientales mediante una respuesta celular que implica cambios en la actividad de enzimas y proteínas, y en la expresión de genes. Las proteínas $G$ heterotriméricas se componen de tres subunidades: $G \alpha, G \beta$ y $G \gamma$, las cuales regulan diferentes efectores en el interior de la célula. En los hongos filamentosos las subunidades $G \alpha$ se han clasificado en tres subgrupos diferentes, de los cuales el subgrupo I está implicado en la regulación de la patogenicidad, el metabolismo secundario, y procesos de diferenciación celular como la conidiación. Esta subunidad se ha estudiado en diferentes hongos como Penicillium chrysogenum, Penicillium roqueforti, Aspergillus nidulans, Neurospora crassa, Magnaporthe grisea, Cryphonectria parasitica, Cocbliobolus heterostrophus, Fusarium oxysporum, Fusarium fujikuroi, Gibberella zea, Trichoderma atroviride y Trichoderma virens. Acremonium chrysogenum es un hongo filamentoso de morfología simple y presenta únicamente cuatro estructuras morfológicas como parte de su diferenciación celular: hifas, artrosporas, conidióforos y conidios. Nuestro grupo previamente identificó y clonó el gen aga1 de $A$. chrysogenum, el cual codifica la subunidad G $\alpha$ Aga1 del subgrupo I. Con el fin de estudiar el efecto de Aga1 en la diferenciación de $A$. chrysogenum se obtuvieron transformantes con alelos de activación (aga ${ }^{\mathrm{G} 42 \mathrm{R}}$ y aga 1 $\left.{ }^{2} 204 \mathrm{~L}\right)$ e inactivación constitutiva (aga 1G203R). Los fenotipos mostraron claramente que Aga1 juega un papel importante en el desarrollo vegetativo del hongo, y su función es esencial para la formación de artrosporas, tipo morfológico relacionado con la producción de cefalosporina. La actividad constitutiva de la subunidad G $\alpha$ Aga1 (aga1Q204L) reprimió la producción de conidios, mientras que la ausencia de actividad (aga1G203R) la incrementó, por lo tanto se concluyó que Aga1 regula negativamente la conidiación. Nuestros resultados indican que la subunidad G $\propto$ Aga1 está implicada en varios procesos del desarrollo de $A$. chrysogenum.

\section{ABSTRACT}

Heterotrimeric G proteins are key components of signal transduction pathways in eukaryotes. These proteins respond to different environmental stimuli, triggering a cellular response that involves changes in the activity of enzymes and proteins, and in gene expression. Heterotrimeric $G$ proteins consist of three subunits: $G \alpha G \beta$ and $G \gamma$, which regulate multiple effectors inside the cell. In filamentous fungi, $\mathrm{G} \alpha$ subunits have been classified in three subgroups: I, II and III. Subgroup I G $\alpha$ subunits are involved in the regulation of pathogenicity and secondary metabolism, as well as cellular differentiation processes like conidiation. They have been studied in different filamentous fungi such as Penicillium chrysogenum, Penicillium roqueforti, Aspergillus nidulans, Neurospora crassa, Magnaporthe grisea, Cryphonectria parasitica, Cochliobolus heterostrophus, Fusarium oxysporum, Fusarium fujikuroi, Gibberella zea, Trichoderma atroviride y Trichoderma virens. Acremonium chrysogenum is a filamentous fungus of simple morphology which 
presents only four morphological structures as part of its cell differentiation: hyphae, arthrospores, conidiophores and conidia. Our group previously identified and cloned the aga 1 gene of $A$. chrysogenum, which encodes the subgroup I $\mathrm{G} \alpha$ subunit Aga1. In order to study the effect of the G $\alpha$ subunit Aga1 in differentiation of $A$. chrysogenum, transformants with constitutive activation (aga $1^{\mathrm{G} 42 \mathrm{R}}$ and $a g a 1^{\mathrm{Q} 204 \mathrm{~L}}$ ) and inactivation (aga 1G203R) alleles were obtained. The phenotypes clearly showed that Aga1 plays an important role in the vegetative development of the fungus, and is essential for the formation of arthrospores, a morphological type associated with the production of cephalosporin. The constitutive activity of Aga1 (aga1 $204 \mathrm{~L}$ ) suppressed conidia production, whereas the absence of Aga1 activity (aga 1G203R) increased it, thus we concluded that Aga1 negatively regulates conidiation. Our results indicate that the $\mathrm{G} \alpha$ subunit Aga1 is involved in several developmental processes in A. chrysogenum. 


\section{CONTENIDO}

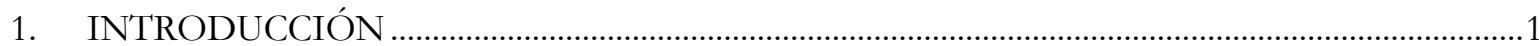

1.1 CARACTERÍSTICAS, TAXONOMÍA, MORFOLOGÍA Y DIFERENCIACIÓN DE $A$.

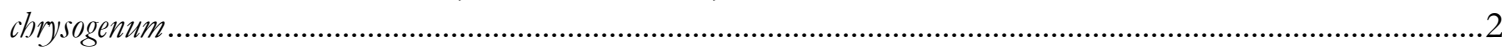

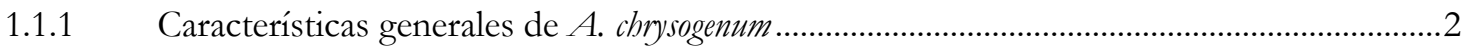

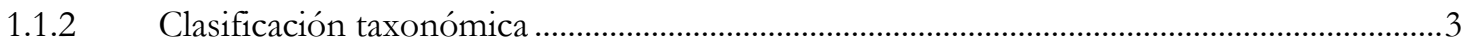

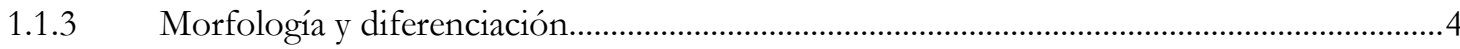

1.2 PRODUCCIÓN DE CEFALOSPORINA C EN A. chrysogenum …..............................................4

1.2.1 Ruta biosintética de cefalosporina $\mathrm{C}$ y transporte intracelular de intermediarios................4

1.2.2 Organización de los genes biosintéticos y de secreción de cefalosporina C .........................7

1.3 REGULADORES DE LA BIOSÍNTESIS DE CEFALOSPORINA Y DE LA

DIFERENCIACIÓN CELULAR EN $A$. chrysogenum …………..........................................................

1.4 PROTEÍNAS G HETEROTRIMÉRICAS ................................................................................

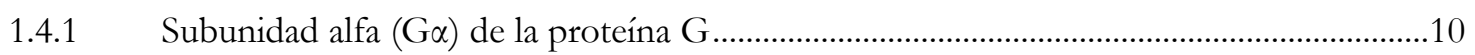

1.5 PROTEÍNAS G HETEROTRIMÉRICAS EN HONGOS FILAMENTOSOS ...................12

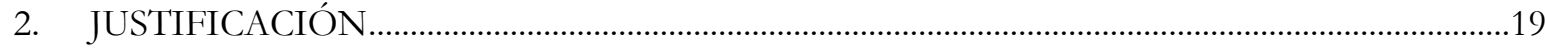

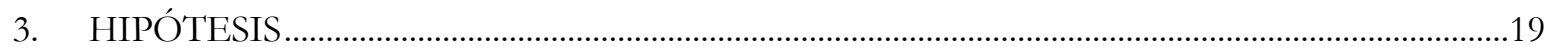

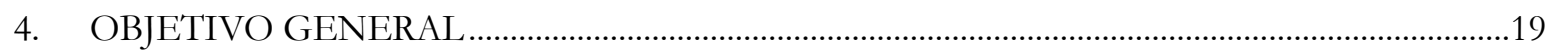

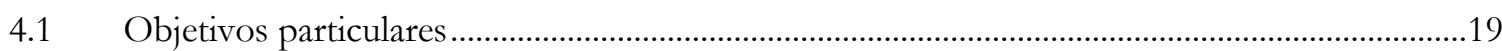

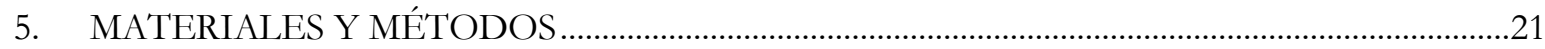

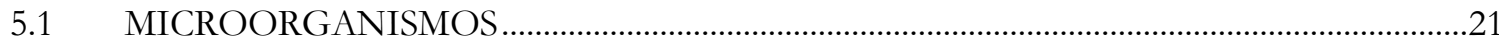

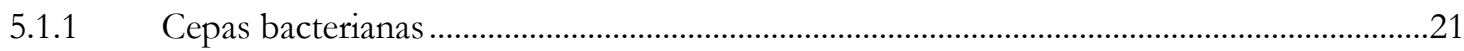

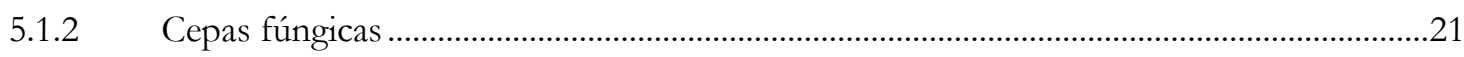

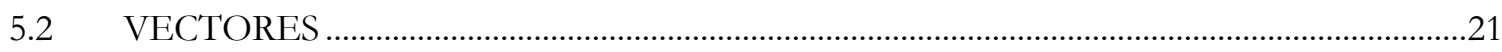

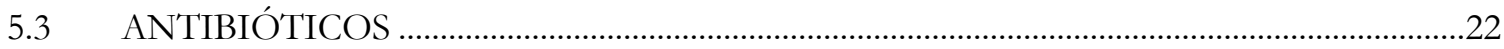

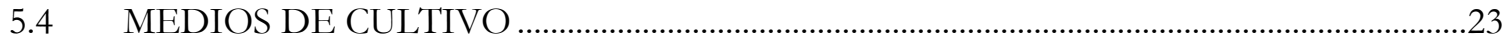

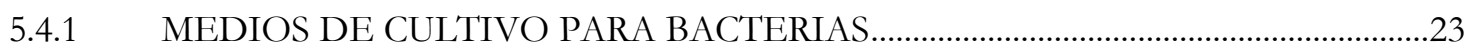

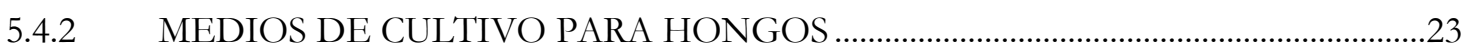

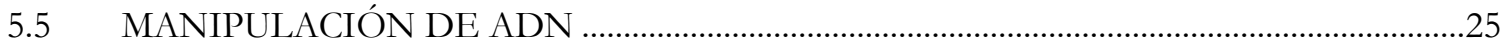

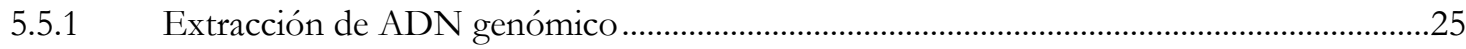

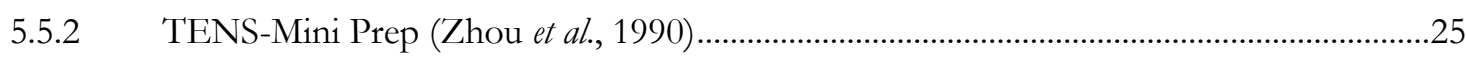

5.5.3 Megaprep por lisis alcalina y fenolización (método modificado) .........................................25

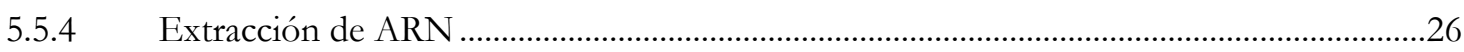

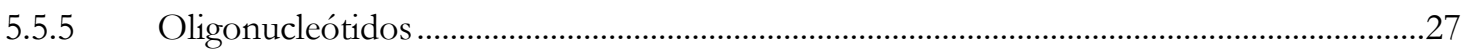

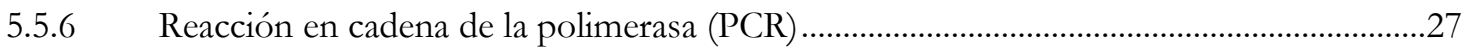

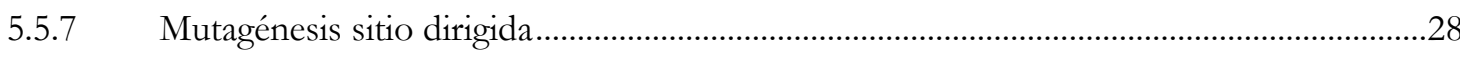

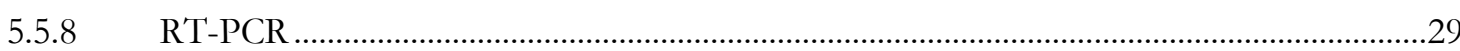


5.5.9 Digestiones enzimáticas. .29

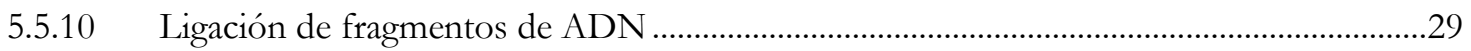

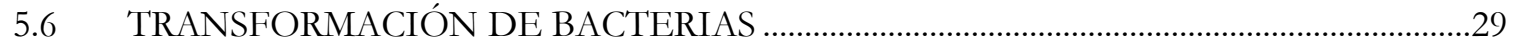

5.6.1 Preparación y transformación de células Ultra-competentes (Inoue et al., 1990; Hengen, 1996) 29

5.6.2 Transformación de bacterias por heat-shock ..........................................................................

5.7 TRANSFORMACIÓN DE A. chrysogenum POR PROTOPLASTOS.......................................30

5.7.1 Crecimiento del micelio .....................................................................................................

5.7.2 Obtención de protoplastos.................................................................................................

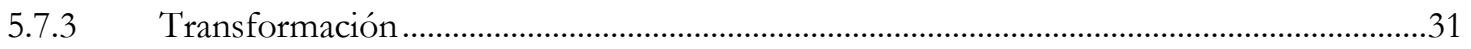

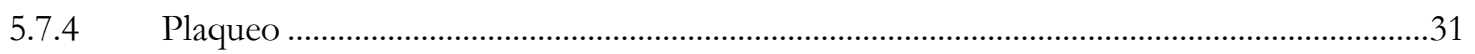

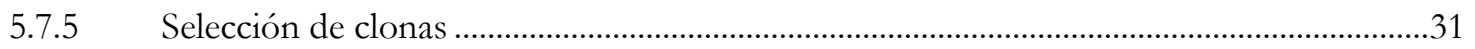

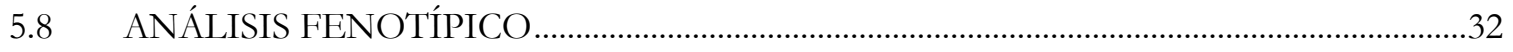

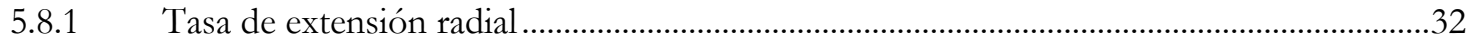

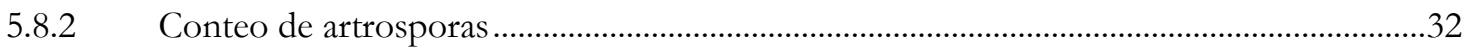

5.8.3 Determinación del peso seco ............................................................................................. 33

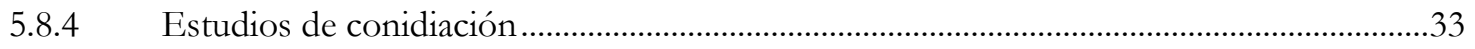

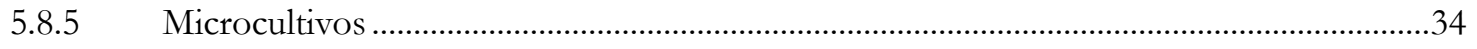

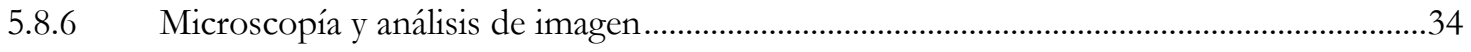

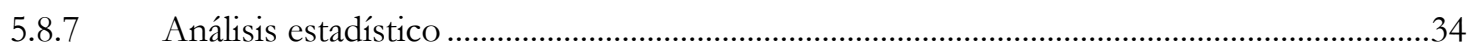

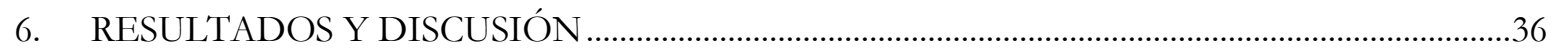

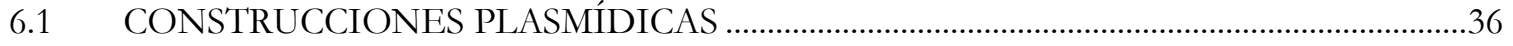

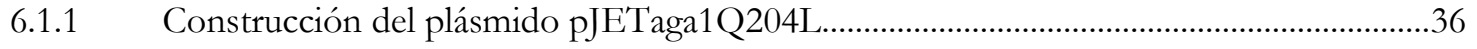

6.1.2 Construcción de los plásmidos integrativos pC43aga1G42R, pC43aga1G203R y

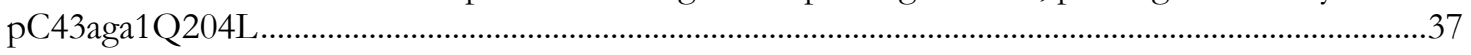

6.2 OBTENCIÓN DE MUTANTES DE A. chrysogemum ATCC 11550 CON LA

SUBUNIDAD G $\alpha$ Aga1 CONSTITUTIVAMENTE ACTIVA E INACTIVA.....................................39

6.2.1 Transformación y selección de los transformantes ..................................................................39

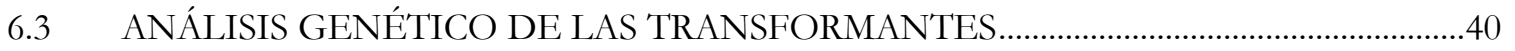

6.3.1 Comprobación de la integración de los alelos aga 1G42R, aga 1G203R y aga 1 $204 \mathrm{~L}^{\mathrm{G}}$ en las

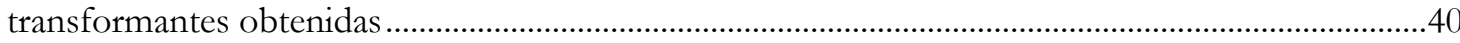

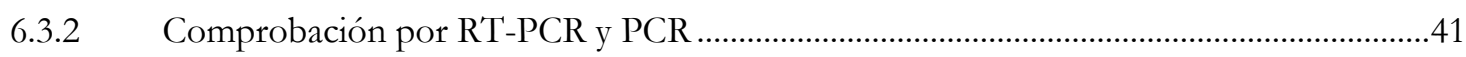

6.4 CARACTERIZACIÓN FENOTIÍPICA DE LAS CEPAS MUTANTES DE G $\alpha$ Aga1 .......42

6.4.1 TASA DE EXTENSIÓN RADIAL …………….................................................................

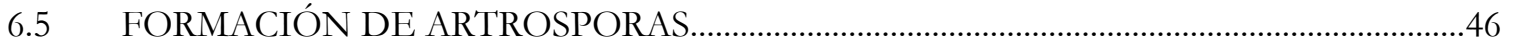

6.5.1 Efecto de la subunidad G $\propto$ Aga1 en la formación de artrosporas .......................................46

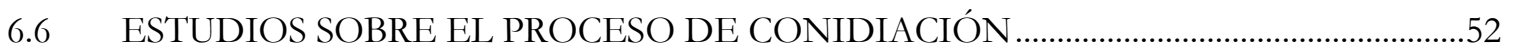

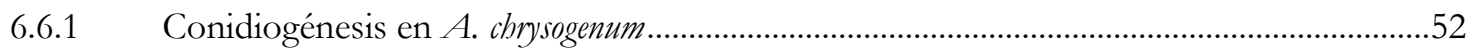


6.6.2 Estructuras conidiogénicas en las cepas G42R, G203R, Q204L y $\Delta$ aga1 ...........................53

6.6.3 Efecto de la subunidad $\mathrm{G} \alpha$ Aga1 en la conidiación .............................................................55

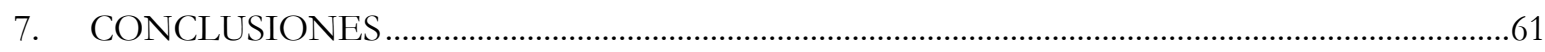

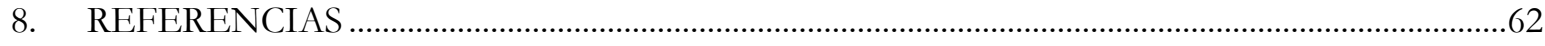

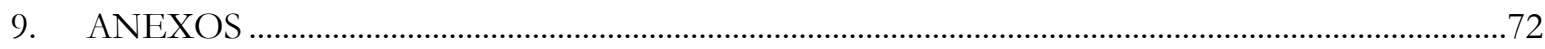

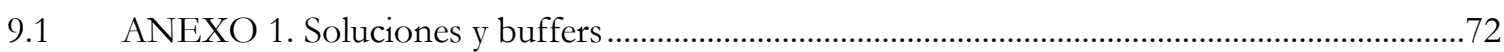

9.2 ANEXO 2. Medición de la extensión radial...................................................................................73

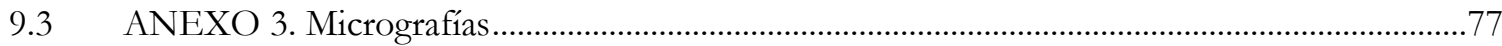

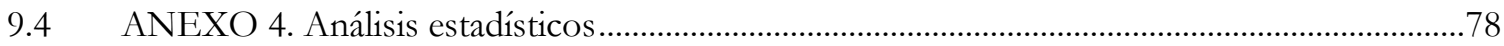


INTRODUCCIÓN 


\section{INTRODUCCIÓN}

La transducción de señales es un sistema mediante el cual una célula recibe señales de diferente naturaleza a través de receptores situados en la membrana celular y transfiere la información hacia el interior de la célula. Una característica de todos los organismos unicelulares y multicelulares es que exhiben varios comportamientos en respuesta a cambios en su entorno (Oldham y Hamm, 2008). Las células se encuentran equipadas con numerosos receptores de membrana que detectan cambios que ocurren a nivel extracelular (Oldham y Hamm, 2008). Dichos cambios pueden ser de naturaleza química, como cambios en la concentración de nutrientes u oxígeno, las cuales actúan como moléculas señalizadoras, o física, como temperatura y luz. Cuando alguna de estas moléculas se unen a los receptores, éstos cambian de conformación y se activan de tal modo que estimulan la transducción de señales (Sprang, 1997). El objetivo final de las vías de transducción es que la célula responda adecuadamente a las señales que recibe del entorno, permitiendo que se adapte a esas condiciones mediante una respuesta celular que implicará cambios en la actividad de enzimas y proteínas, y en la expresión de genes. La respuesta celular a las señales que recibe del exterior puede ir desde cambios en su metabolismo, biosíntesis de compuestos, hasta el desarrollo morfológico o la división celular (Malbon, 2005; Neer, 1995).

Existen muchas vías de transducción de señales en la célula, en las que participan efectores como adenilato ciclasa, mensajeros secundarios, entre otros. En varias vías de transducción de señal participan las denominadas proteínas $G$, las cuales tienen un ciclo de activación/desactivación en el que está involucrada una molécula de GTP y la actividad GTPasa intrínseca de estas proteínas (Rens-Domiano y Hamm, 1995). Las proteínas $G$ implicadas en vías de transducción de señal son de dos tipos: monoméricas y heterotriméricas. Las proteínas G monoméricas (small G proteins) consisten en una única unidad polipeptídica de alrededor de 200 residuos de aminoácidos, y entre sus funciones está el regular el tráfico vesicular, la reorganización del citoesqueleto y el transporte núcleo-citoplasma (Sprang, 1997). Por su parte, las proteínas $G$ heterotriméricas poseen tres subunidades: subunidad alfa (G $\alpha)$, beta $(G \beta)$ y gamma $(G \gamma)$. Éstas se activan tras la recepción de la señal por receptores de membrana del tipo GPCR (G Protein-Coupled Receptor), y regulan una gran variedad de procesos en la célula mediante la interacción de sus subunidades $(\mathrm{G} \alpha, \mathrm{G} \beta$ y $\mathrm{G} \gamma)$ con un número pequeño de efectores (Simon et al., 1991).

Las proteínas $G$ heterotriméricas de los hongos filamentosos están implicadas en procesos como el crecimiento, desarrollo y virulencia de especies patogénicas de animales y plantas. La mayoría de los hongos filamentosos caracterizados poseen tres tipos de subunidad $\mathrm{G} \alpha$ diferentes, mientras que sólo poseen un tipo de subunidad $G \beta$ y $G \gamma$. Cada uno de los tipos de subunidad $G \alpha$ corresponde a uno de 
los subgrupos definidos por Bolker (1998), denominados subgrupos I, II y III, de los cuales el subgrupo I está implicado en el metabolismo secundario, patogenicidad, y en procesos de diferenciación celular como el crecimiento, conidiación, desarrollo sexual y asexual (Schmitt et al., 2004a).

Recientemente, nuestro grupo identificó el gen aga1 en Acremonium chrysogenum, el cual codifica la subunidad $G \propto$ Aga1 del subgrupo I de las proteínas $G$ heterotriméricas, y del cual no se tienen reportes hasta el momento sobre su función en este hongo.

A. chrysogenum presenta varios tipos morfológicos en cultivo sumergido como parte de su diferenciación celular: hifas (filamentos finos septados), células yeast-like o artrosporas (productos de hifas fragmentadas), conidióforos, y conidios (de forma fusiforme), de los cuales las formación de artrosporas coincide con la máxima tasa de producción de cefalosporina (Nash y Huber, 1971).

Por otra parte, se ha encontrado que algunas proteínas desempeñan papeles importantes en mecanismos que, al parecer controlan la diferenciación celular de $A$. chrysogenum. Tal es el caso de CPCR1 (Schmitt et al., 2004b; Hoff et al., 2005; Hoff y Kück, 2005) que regula la expresión del gen pcbC de la ruta biosintética de cefalosporina y además está implicada en la formación de artrosporas, AcVEA (Dreyer et al., 2007) que controla la expresión de seis genes de la biosíntesis de cefalosporina y además juega un papel en la formación de artrosporas, AcSEPH (Long et al., 2013), la cual es requerida para una septación normal y una diferenciación celular íntegra, y por último CefM (Teijeira et al., 2009), un transportador de membrana localizado en peroxisomas esencial para el transporte de un intermediario de la ruta biosintética, y el cual también parece estar implicado en el proceso de fragmentación de las hifas.

Los mecanismos que regulan la diferenciación celular en $A$. chrysogenum son un tema activo de investigación, es por eso que hemos decidido estudiar el proceso de formación de artrosporas y de conidiación. La base de este proyecto ha sido la identificación y clonación del gen aga1, el cual ha dado pauta para investigar el papel que desempeña la subunidad $\mathrm{G} \alpha$ Aga1 en estos procesos de diferenciación.

\subsection{CARACTERÍSTICAS, TAXONOMÍA, MORFOLOGÍA Y DIFERENCIACIÓN DE $\boldsymbol{A}$. chrysogenum}

\subsubsection{Características generales de $\boldsymbol{A}$. chrysogenum}

La cepa original de Acremonium chrysogenum, denominada inicialmente Cephalosporium acremonium, fue aislada en 1945 por Giuseppe Brotzu de las aguas del mar de Cagliari en una zona próxima a una salida de aguas residuales (Brotzu, 1948). Brotzu demostró que dicho hongo secretaba una sustancia que inhibía el crecimiento de un gran número de bacterias gram-positivas y gram-negativas. 
A. chrysogenum es un hongo filamentoso perteneciente a los ascomicetos y sólo se conoce su fase asexual. Durante su metabolismo secundario es capaz de producir antibióticos beta-lactámicos como penicilina $\mathrm{N}$ y cefalosporina $\mathrm{C}$, junto con otros metabolitos de menor interés. Actualmente $A$. chrysogenum es el único microorganismo usado a nivel industrial para la producción de cefalosporina C (Abraham, 1990).

El género Acremonium es morfológicamente simple y habitualmente no se encuentra formando consorcios con otros microorganismos (Gams, 1971). Las especies de este género aparecen en sustratos tan diversos como el suelo, las raíces de plantas a las que puede atacar, los restos de materia vegetal o incluso en lagos (Guarro et al., 1999). Desde el punto de vista clínico, algunas especies de este género provocan infecciones en humanos como micetomas e infecciones oculares. Además causan enfermedades oportunistas debidas a la depresión del sistema inmune (Guarro et al., 1997).

\subsubsection{Clasificación taxonómica}

Un análisis del ADNr $18 \mathrm{~S}$ mostró que el género Acremonium es polifilético debido a la presencia de teleomorfos de esta especie en géneros de ascomicetos como Emericellopsis, Hapsidospora, Nectria, Nectriella, Neucomospora, Pronectria y Thielavia (Sordariales) (Glenn et al., 1996). Con estos estudios filogenéticos se ha logrado clasificar un gran número de especies de Acremonium, y se encontró que la mayoría de estas especies entran en el orden de los Hypocreales. Estos resultados han arrojado nueva luz sobre la biodiversidad de estos hongos morfológicamente simples que han ocasionado problemas en términos de clasificación e identificación de especies (Summerbell et al., 2011.) La clasificación taxonómica actual de $A$. chrysogenum se muestra en la tabla 1.

Tabla 1. Taxonomía de A. chrysogenum (National Center for Biotechnology Information).

\begin{tabular}{c}
\hline Taxonomía \\
Acremonium chrysogenum \\
\hline Super-reino: Eukatiota \\
Reino: Fungi \\
Filum: Ascomycota \\
Subfilum: Pezixomycotina \\
Clase: Sordariomycetes \\
Orden: Hypocreales \\
Familia: Hypocreomycetidae \\
Género: Acremonium \\
Especie: Acremonium chrysogenum \\
\hline
\end{tabular}

A. chrysogenum está clasificado en el orden de los Hypocreales, y está relacionado desde el punto de vista morfológico con especies de otros géneros del mismo orden como Fusarium, Trichoderma, Metarbizium, Nectria, Beauveria, Gibberella, Cordyceps y Claviceps. 


\subsubsection{Morfología y diferenciación}

A. chrysogenum presenta hifas septadas organizadas en compartimientos uninucleados. También, como parte de su desarrollo asexual produce conidios (esporas asexuales), los cuales son producidos en estructuras conidiales simples llamadas conidióforos (Peberdy, 1987).

Los conidios son hialinos tienen forma elíptica (fusiforme) de 25-50 $\mu \mathrm{m}$ de longitud y pueden ser en ocasiones ligeramente curvados (Peberdy, 1987). La conidiogénesis o esporulación del hongo es escasa, teniendo lugar de forma holoblástica para el primer conidio a partir de células especializadas llamadas conidiogénicas. Así este primer conidio se forma mediante la elongación de la parte apical del tallo de dicha célula conidiogénica. La formación del resto de los conidios tiene lugar de manera enteroblástica, es decir, se originan una cadena de conidios de manera fialídica. En este tipo de conidiogénesis enteroblástica, el sitio de salida del primer conidio queda como remanente un collar a través del cual se producen el resto de los conidios (Peberdy, 1987).

Se han observado cuatro tipos celulares de $A$. chrysogenum en cultivos sumergidos: hifas (filamentos finos con septos), artrosporas (formas altamente septadas, y simples), conidióforos y conidios (Nash y Huber, 1971). En A. chrysogenum se dan dos tipos de desarrollo morfogénico: por un lado se forman conidios hialinos de forma elíptica en la punta de las hifas conidiogénicas, los cuales se mantienen unidos formando pequeñas cabezas mucilaginosas. Este proceso de conidiación o esporulación asexual, se da tanto en medio sólido como en líquido (Bartoshevich et al., 1990).

Por otro lado, las hifas pueden también diferenciarse a artrosporas en un proceso conocido como fragmentación de hifas (Bartoshevich et al., 1990), el cual está asociado a la máxima tasa de producción de cefalosporina (Nash y Huber, 1971). Respecto a lo anterior, se creía que la diferenciación a artrosporas era determinante para la producción de cefalosporina (Nash y Huber, 1971), sin embargo, Queener y Ellis (1975) demostraron que no existe una relación entre ambos procesos.

\subsection{PRODUCCIÓN DE CEFALOSPORINA C EN $A$. chrysogenum}

\subsubsection{Ruta biosintética de cefalosporina $\mathrm{C}$ y transporte intracelular de intermediarios}

La biosíntesis de cefalosporinas y penicilinas en bacterias y hongos filamentosos comienza con la condensación no ribosomal de tres precursores aminoacídicos: ácido L- $\alpha$-aminoadípico, L-cisteína y Lvalina.

La formación del tripéptido $\delta$-(L- $\alpha$-aminoadipil)-L-cisteinil-D-valina (ACV) a partir de los tres aminoácidos precursores es catalizada por la ACV sintetasa, una enzima multimodular perteneciente a la familia de las péptido sintetasas y codificada por el gen $p c b A B$. A continuación ocurre la ciclación del tripéptido ACV para formar la isopenicilina $\mathrm{N}$ (IPN), reacción catalizada por la enzima isopenicilina $\mathrm{N}$ 
sintasa y codificada por el gen $p c b C$. Ambas enzimas se encuentran solubles en el citoplasma, por lo tanto, los productos a los que dan lugar están localizados también en el citoplasma (Schmitt et al., 2004a).

Estos dos primeros pasos son comunes en la biosíntesis de todos los antibióticos beta-lactámicos en los microorganismos productores de este tipo de antibióticos. En este punto se ramifica la ruta hacia la biosíntesis de penicilinas ( $\mathrm{G}$ y V) en Penicillium chrysogenum y Aspergillus nidulans, o bien hacia la biosíntesis de cefalosporina $\mathrm{C}$ en Acremonium chrysogenum (Fig. 1).

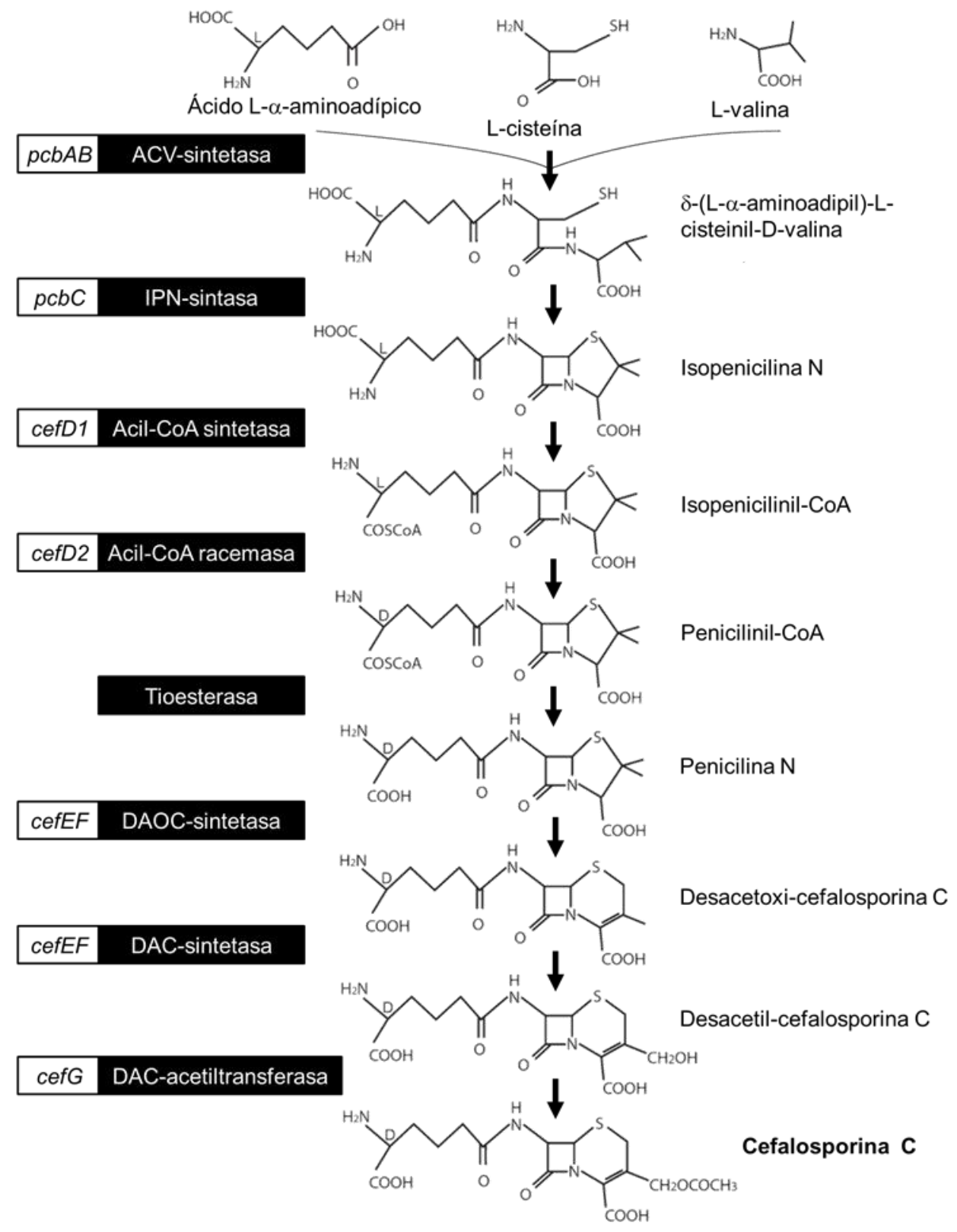

Fig. 1. Ruta biosintética de cefalosporina en A. chrysogenum. Detalle de los compuestos, genes participantes (rectángulos claros) y enzimas codificadas por estos genes (rectángulos sombreados), (Figura modificada de Schmitt et al., 2004a). 
El primer paso de la ruta específica que conduce a la biosíntesis de cefalosporina $\mathrm{C}$ comienza con la conversión de la isopenicilina $\mathrm{N}$ a penicilina $\mathrm{N}(\mathrm{PN})$ mediante un sistema de dos enzimas (Ullán et al., 2002a); una acil-CoA sintetasa de cadena larga codificada por el gen cefD1, y una acil-CoA racemasa codificada por el gen cefD2 (Ullán et al., 2004). Estas dos enzimas han sido localizadas en microcuerpos, lo que implica que el sustrato de las mismas, la isopenicilina $\mathrm{N}$, debe ser transportado al interior de dichos orgánulos para llevar a cabo la conversión de isopenicilina $\mathrm{N}$ a penicilina $\mathrm{N}$. Recientemente ha sido caracterizado el gen cefP, cuyo producto es una proteína transmembranal que se localiza en microcuerpos, y cuya función parece ser la de introducir el intermediario isopenicilina $\mathrm{N}$ en los microcuerpos para ser utilizado por el sistema CefD1-CefD2 (Ullán et al., 2010).

Posteriormente ocurre la conversión de penicilina $\mathrm{N}$ a desacetoxi-cefalosporina $\mathrm{C}$ (DAOC) por la enzima DAOC sintetasa (o expandasa), que convierte el anillo tiazolidínico característico de las penicilinas en un anillo dihidrotiazínico de seis miembros típico de cefalosporinas y cefamicinas. Para llevar a cabo este paso la penicilina $\mathrm{N}$ tiene que ser exportada de los microcuerpos hacia el citoplasma. Esta función la realiza la proteína transmembranal CefM codificada por el gen cefM (Teijeira et al., 2009) (Fig. 2).

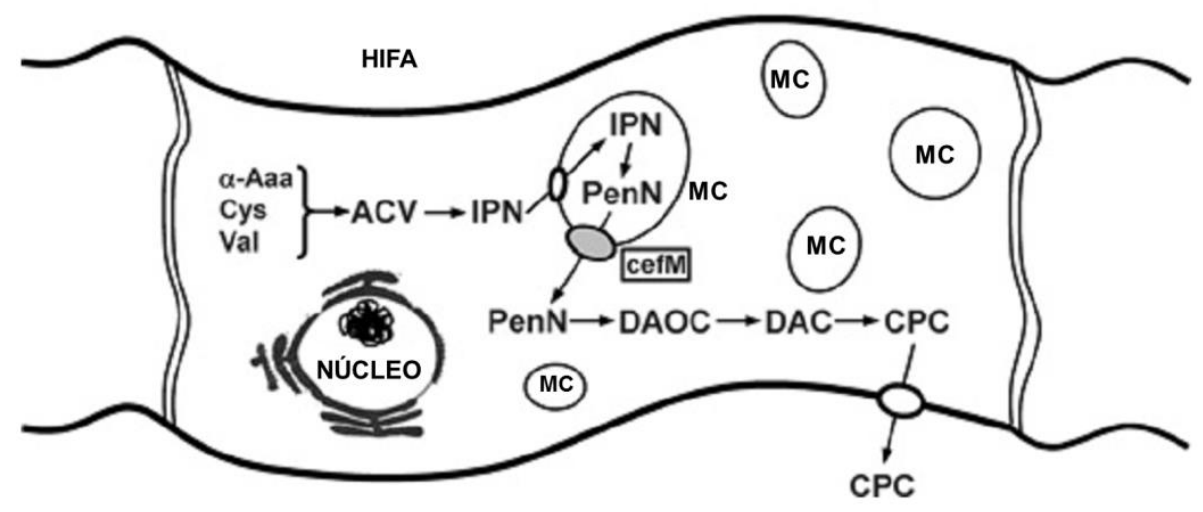

Fig. 2. Localización subcelular de los diferentes intermediarios de la ruta biosintética de cefalosporina en la hifa de $A$. chrysogenum, mostrándose la ubicación del transportador CefM en la membrana de microcuerpos (MC) (Figura modificada de Teijeira et al., 2009).

A partir de este punto todos los intermediarios se localizan en el citoplasma y dan continuidad a la parte final de la ruta biosintética. En el siguiente paso el grupo metilo del grupo C-3 de la DAOC es hidroxilado y oxidado a desacetil-cefalosporina C (DAC). Esta reacción es catalizada por la enzima DAOC sintetasa/DAC hidroxilasa, la cual es codificada por el gen cefEF (Samson et al., 1987).

El último paso de la ruta biosintética implica la transferencia de un grupo acetilo de la acetil-CoA a un grupo hidroxilo en el anillo sulfurado de la DAC llevando a la formación de cefalosporina C (CPC). Esta reacción es catalizada por la enzima acetil-CoA:DAC acetiltransferasa, la cual es codificada por el gen cefG (Gutiérrez et al., 1997). 
Se sabe que en $A$. chrysogenum la cefalosporina $C$ es secretada, sin embargo no se conoce con exactitud el o los sistemas de transporte que exportan la cefalosporina $\mathrm{C}$ al exterior celular, pero el producto del gen cefT parece estar involucrado en este proceso (Ullán et al., 2002b; Ullán et al., 2008).

\subsubsection{Organización de los genes biosintéticos y de secreción de cefalosporina $\mathrm{C}$}

$\mathrm{Al}$ igual que otros genes del metabolismo secundario en hongos, los genes de la biosíntesis de cefalosporina están agrupados en dos clusters diferentes: el "cluster temprano" y el "cluster tardío" (Fig. 3). En la mayoría de las capas el cluster temprano se encuentra en el cromosoma VI, y el cluster tardío se localiza en el cromosoma II (Skatrud y Queener, 1989). Por otra parte, en cepas de alta producción de cefalosporina, tal como la cepa C10, se encontró que los clusters tienen diferente localización, el cluster temprano se localiza en el cromosoma VII, mientras que el cluster tardío en el cromosoma I (Gutiérrez et al., 1999).

El cluster temprano agrupa los genes $p c b A B, p c b C$, cefD2 y cefD1, implicados en las primeras etapas de la biosíntesis de cefalosporinas. Además de los genes biosintéticos, se han encontrado otros genes en el cluster temprano probablemente implicados en la secreción de cefalosporina como los genes cefT ((Ullán et al., 2002b; Ullán et al., 2008)) y cefP (Ullán et al., 2010), y en la regulación de genes del mismo cluster como cefR (Teijeira et al., 2011).

Corriente arriba del gen $p c b A B$, se encuentran en el siguiente orden: el ORF3, que hipotéticamente codifica una deshidrogenasa, y el gen $c e f T$, que codifica una proteína que presenta similitud con la superfamilia de transportadores de multidrogas (MFS, Major Facilitator Superfamily) (Ullán et al., 2002b). Por otro lado, corriente abajo del gen $\operatorname{cefD} 1$ se localiza el gen $\operatorname{cef} M$, que codifica una proteína que de igual manera que cefT presenta similitud con la superfamilia MFS de transportadores de multidrogas (Teijeira et al., 2009).

En el cluster tardío se encuentran los genes $\operatorname{cefEF}$ y $\operatorname{cef} G$, responsables de los pasos finales de la biosíntesis (Fig. 3). Algunos autores reportan que estos genes se transcriben en dirección opuesta (Gutiérrez et al., 1999; Gupta y Ayyachamy, 2012), sin embargo no se sabe con exactitud la orientación de ambos genes en el cluster.
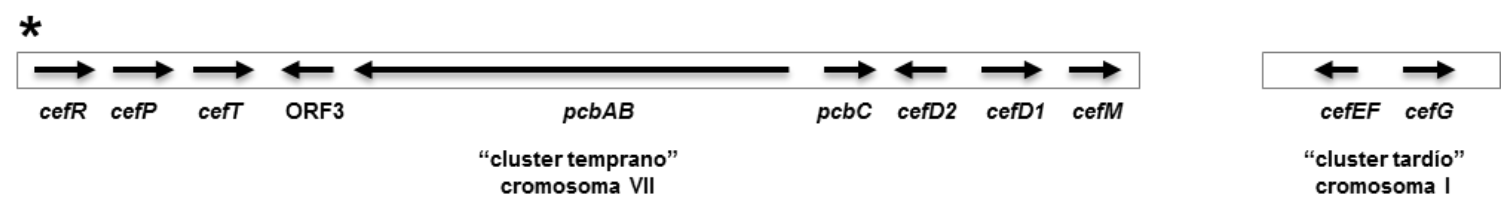

Fig. 3. Organización de los genes biosintéticos y de secreción de cefalosporina en $A$. chrysogenum C10 (*Figura modificada de Teijeira et al., 2011; Schmitt et al., 2004a). 


\subsection{REGULADORES DE LA BIOSÍNTESIS DE CEFALOSPORINA Y DE LA DIFERENCIACIÓN CELULAR EN A. chrysogenum}

Aunque no se tiene un conocimiento exhaustivo sobre la regulación de la ruta biosintética de cefalosporina y de la diferenciación celular en $A$. chrysogenum, se han caracterizado ya al menos siete proteínas implicadas en estos dos importantes procesos. Dos de estas proteínas son los reguladores globales PACC (Schmitt et al., 2001) y CRE1 (Jekosch y Kück, 2000a; Jekosch y Kück, 2000b), factores de transcripción que intervienen en la regulación al pH externo y a la disponibilidad de glucosa, y que tienen un papel importante en la regulación de la biosíntesis de otros antibióticos $\beta$-lactámicos y metabolitos secundarios en otros hongos filamentosos.

Por otro lado, en $A$. chrysogenum se encontró un factor transcripcional nombrado AcVEA, homólogo a VEA, el cual fue descrito como un regulador global de la morfogénesis en Aspergillus nidulans (Käfer, 1965; Mooney y Yager, 1990), y que forma parte del complejo denominado Velvet, junto con VelB y LaeA, esta última proteína se ha caracterizado como un regulador global del metabolismo secundario en varios hongos (Keller et al., 2005; Bok y Keller, 2004; Bok et al., 2005; Sugui et al., 2007; Bok et al., 2006; Shwab et al., 2007). AcVEA regula la expresión transcripcional de seis genes de la ruta biosintética de cefalosporina, y además está implicado en el desarrollo del hongo, de tal forma que su interrupción desrregula temporalmente el proceso de formación de artrosporas (Dreyer et al., 2007).

Otros dos factores de transcripción específicos de A. chrysogenum son AcFKH1 (Schmitt et al., 2004b) y CPCR1 (Schmitt y Kück, 2000), los cuales están implicados en la biosíntesis y la morfogénesis. AcFKH1 (Forkhead Transcription Factor 1 from A. chrysogenum) es un factor de transcripción Fork-head, el cual reconoce dos secuencias consenso dentro del promotor de los genes biosintéticos $p c b A B-p c b C$, y además parece estar implicado en la regulación morfológica junto con CPCR1, interaccionando con este último de forma directa (Schmitt et al., 2004b; Hoff et al., 2005; Hoff y Kück, 2005). CPCR1 (Cephalosporin C Regulator 1 from $A$. chrysogenum) es una proteína de unión a ADN que pertenece a la familia conservada de factores de transcripción de regulación de Factor X (RFX) de eucariotas (Schmitt y Kück, 2000). CPCR1 fue el primer factor de transcripción RFX identificado y caracterizado en hongos filamentosos y consta de 380 residuos de aminoácidos. Este factor posee dos dominios, un dominio de unión a ADN (N-Ter), y un dominio de dimerización (C-Ter) (Schmitt y Kück, 2000). El factor RFX5 en humanos, es esencial para activar genes del complejo principal de histocompatibilidad de clase II, por tanto, CPCR1 puede actuar como activador de genes de biosintéticos de cefalosporina (Schmitt y Kück, 2000). Schmitt

y colaboradores (2004c) demostraron que CPCR1 reconoce al menos dos secuencias de unión entre los genes $p c b A B$ y $p c b C$, localizados aproximadamente a 350 y 700 pb corriente arriba del sitio de inicio de la transcripción de $p c b C$. 
CPCR1 y AcFKH1 también están implicados en la morfogénesis de $A$. chrysogenum. Se ha demostrado que CPCR1 regula la fragmentación de hifas y en consecuencia la formación de artrosporas. El efecto fenotípico de una mutante $\Delta c p c \mathrm{R} 1$ es la ausencia hifas hinchadas o artrosporas unicelulares, incluso después de 168 horas de incubación en medio de cultivo líquido CCM. La sobreexpresión de cpcR1 (seis copias adicionales de $c p \mathrm{R} 1)$ resulta en una acelerada formación de artrosporas; presenta hifas hinchadas alrededor de las 48 horas (Hoff et al., 2005).

La presencia de CPCR1 es esencial para el control de la fragmentación de hifas en A. chrysogenum. Además, es posible que CPCR1 regule genes relacionados con la fragmentación de hifas tales como genes que codifiquen enzimas quitinolíticas o proteolíticas (Hoff et al., 2005).

Otra proteína relacionada con el desarrollo celular en $A$. chrysogenum, en concreto con el proceso de septación, y que ha sido identificada recientemente es AcSEPH. La interrupción del gen que codifica esta proteína provoca un crecimiento lento y la producción de cefalosporina cuatro veces menor a la cepa parental. AcSEPH es esencial para una septación normal y una diferenciación celular íntegra. También está implicada en la expresión de los genes biosintéticos $p c b C$, cefEF, cefD1 y cefD2 (Long et al., 2013). También recientemente se identificó una proteína serina/treonina cinasa (AcATG1) implicada en la autofagia, esencial para la formación del autofagosoma bajo limitaciones de nutrientes. La interrupción del gen Acatg1 ( $\triangle$ Acatg1) potenció la producción de cefalosporina y los resultados fueron consistentes con los niveles de expresión de genes biosintéticos. Además, el gen Acatg1 juega un papel importante en la conidiación, ya que su interrupción reduce significantemente la formación de conidios en un medio de esporulación (Wang et al., 2014).

\subsection{PROTEÍNAS G HETEROTRIMÉRICAS}

Las proteínas $G$ heterotriméricas son switches moleculares que encienden cascadas de señalización intracelulares en respuesta a estímulos externos en todos los organismos eucariotas (Oldham y Hamm, 2008). Por lo tanto, las proteínas $G$ tienen un papel crucial en la definición de las características específicas y temporales de la respuesta celular.

Estas proteínas transmiten las señales que se originan en receptores de membrana GPCR (G-proteincoupled receptors) a una variedad de efectores intracelulares (Neer, 1995), entre ellos la adenilato ciclasa, modificando así las concentraciones de AMP cíclico (cAMP).

Las proteínas $G$ heterotriméricas se componen de tres subunidades: $G \alpha, G \beta$ y $G \gamma$. Su función depende de la habilidad de la subunidad $\mathrm{G} \alpha$ para mantener el estado activo (heterotrímero desociado) o inactivo (heterotrímero) de la proteína (Simon et al., 1991).

La transducción de señales mediada por proteínas $G$ comienza a través de la activación de un receptor de membrana acoplado a proteína $G$ por un ligando (Fig. 4). La activación del receptor de membrana 
GPCR provoca un cambio conformacional en la subunidad G $\alpha$, la cual intercambia GDP por GTP resultando en la disociación de $G \alpha$ y $G \beta \gamma$, quedando entonces ambos activos para interaccionar con sus efectores específicos (Rens-Domiano y Hamm, 1995). Este mecanismo de señalización puede ser regulado por las proteínas RGS (Regulator of G Protein Signaling), las cuales estimulan la actividad GTPasa de las subunidades $\mathrm{G} \alpha$ provocando la reasociación de $\mathrm{G} \alpha$ con el dímero G $\beta \gamma$ para formar el heterotrímero inactivo (Simon et al., 1991).

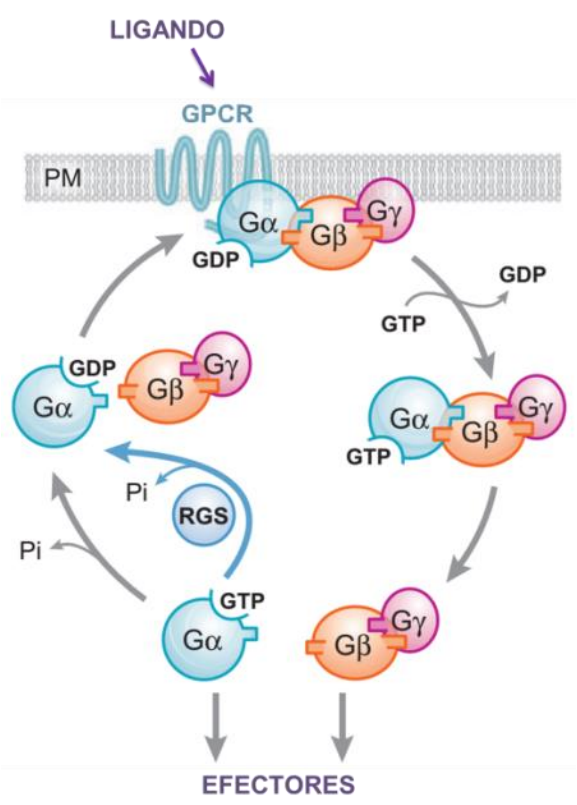

Fig. 4. Ciclo de activación/inactivación de las proteínas $G$ heterotriméricas. La inactivación se produce mediante la hidrólisis del GTP por una actividad GTP hidrolasa intrínseca de G $\alpha$ (Figura modificada de Li et al., 2007).

\subsubsection{Subunidad alfa $(\mathrm{G} \alpha)$ de la proteína $\mathrm{G}$}

En eucariotas superiores la subunidad $G \alpha$ se ha relacionado con la regulación del sistema visual, el metabolismo, canales iónicos, el transporte vesicular y la diferenciación celular (Barr et al., 1992; Wettschureck y Offermanns, 2005; Malbon, 2005). Se han identificado más de 20 diferentes subunidades $\mathrm{G} \alpha$ en mamíferos, las cuales corresponden a los productos de 16 genes. Estas subunidades $\mathrm{G} \alpha$ se han dividido en cuatro clases: $\mathrm{G} \alpha_{\mathrm{s}}, \mathrm{G} \alpha_{\mathrm{i}}, \mathrm{G} \alpha_{\mathrm{q}}$ y $\mathrm{G} \alpha_{12}$ (Tabla 2), en base a la similitud de su secuencia primaria (Sprang, 1997).

Los miembros de la familia de $\mathrm{G} \alpha_{i}$ parecen relacionarse con el desarrollo. Generalmente se clasifican por su habilidad para inhibir a la adenilato ciclasa $\left(G \alpha_{11}, G \alpha_{i 2}\right.$ y $\left.G \alpha_{i 3}\right)$, y parecen tener otras funciones que controlan los niveles intracelulares de cAMP (Malbon, 2005; García-Rico et al., 2011). 
Tabla 2. Subunidades $\mathrm{G} \alpha$ de las proteínas G heterotriméricas en mamíferos (Malbon, 2005).

\begin{tabular}{ll}
\hline Isoformas & Efectores \\
\hline Familia de las subunidades alfa $(\mathrm{G} \alpha)$ & \\
$\mathrm{G} \alpha_{\mathrm{i} 1 / \mathrm{i} 2 / \mathrm{i} 3}$ & Inhiben la adenililciclasa \\
$\mathrm{G} \alpha_{\mathrm{OA}, \mathrm{B} / \mathrm{z}}$ & Inhiben la adenililciclasa \\
$\mathrm{G} \alpha_{\mathrm{t} 1 / \mathrm{t} 2 / \text { gust }}$ & Activan PDE \\
$\mathrm{G} \alpha_{\mathrm{s} / \mathrm{olf} / \mathrm{sXL}}$ & Estimulan a la adenililciclasa \\
$\mathrm{G} \alpha_{\mathrm{q} / 11 / 14-16}$ & Estimulan PLC $\beta$ \\
$\mathrm{G} \alpha_{12 / 13}$ & Rho Factor de intercambio de nucleótidos de guanina \\
\hline PDE, fosfodiesterasa; PLC $\beta$, fosfolipasaC $\beta$. &
\end{tabular}

Estructuralmente todas las subunidades $\mathrm{G} \alpha$ tienen dos dominios, un dominio GTPasa que hidroliza GTP, y un dominio helicoidal único que encierra a GTP en el núcleo de la proteína (Milligan y Kostenis, 2006; Coleman et al., 1994).

El dominio GTPasa es estructuralmente homólogo al de la familia de proteínas G monoméricas, y está compuesto de 6 cadenas lámina $\beta$ rodeadas por 5 hélices $\alpha$. Este dominio tiene 5 loops (caja G-1 a G-5) altamente conservados, los cuales conforman el sitio de unión de GTP (Fig. 5 A y B). El loop de unión a GTP (P-loop o caja G-1) con la secuencia consenso GXXXXGK(S/T) ( $\underline{\mathbf{G}}$ AGES $\underline{G K S}$ para $\mathrm{G}_{\mathrm{i} \alpha}$ de bovino) conecta la lámina $\beta 1$ a la hélice $\alpha 1$, y contacta con los fosfatos $\alpha$ y $\beta$ de GTP. La caja G-2 está localizada en la región $\mathrm{N}$-Ter de la hoja $\beta 2$ (entre la hélice $\alpha 1$ y hoja $\beta 2$ ), contiene un sitio de unión a $\mathrm{Mg}^{2+}$ y tiene una secuencia consenso RVKTTGI para $\mathrm{G}_{\mathrm{i} \alpha}$ de bovino. La caja G-3 con la secuencia

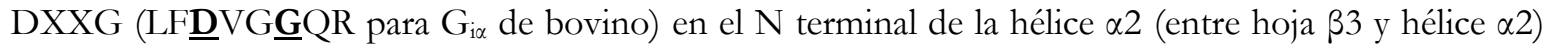
conecta los sitios de unión para $\mathrm{Mg}^{2+}$ y para el fosfato $\gamma$ de GTP. El loop G-4 (entre la hoja $\beta 5$ y la hélice $\alpha 4)$ con la secuencia conservada NKXD (FLNKKD para $G_{i \alpha}$ de bovino) reconoce el anillo de guanina. La caja G-5 con la secuencia consenso (T/G)(C/S)A (THFT $\underline{\text { CAT }}$ para $\mathrm{G}_{\mathrm{i} \alpha}$ de bovino), se localiza entre la hoja $\beta 6$ y hélice $\alpha 5$, y estabiliza a la guanina (Sprang, 1997; Oldham y Hamm, 2008). Este dominio también tiene tres loops flexibles cerca del sitio de unión al fosfato $\gamma$, llamados switches I, II y III, los cuales son conformacionalmente sensibles a la unión de GDP, y GTP $\gamma$ S un análogo no hidrolizable de GTP que es usado para estudiar la conformación e interacciones moleculares de G $\alpha$ activa. Este dominio contiene sitios de unión (switches I y II) al dímero G $\beta \gamma$, receptores helicoidales y proteínas efectoras corriente abajo (Oldham et al., 2006). 


\section{A}
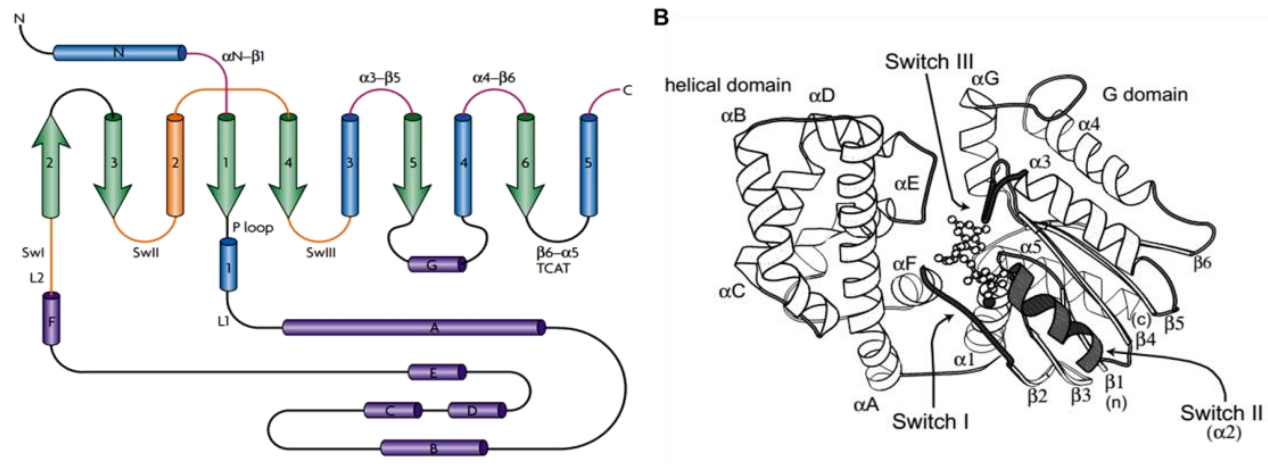

C

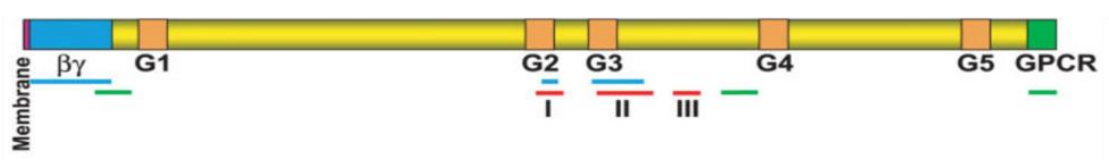

Fig. 5. (A) Estructura secundaria de la subunidad G $\alpha$. Los cilindros representan a las hélices $\alpha$ y las flechas a las láminas $\beta$. Las hélices $\alpha$ del dominio helicoidal se nombran con siete letras (A - G, cilindros color purpura). Las uniones 1 y 2 (L1 y L2) conectan al dominio helicoidal y al dominio GTPasa. Las regiones de los switches están en color naranja y los sitios de contacto con el receptor en

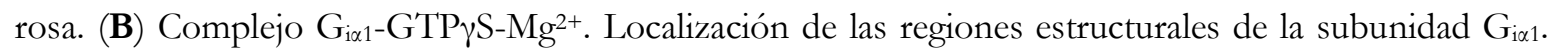
(C) Mapa lineal de la subunidad G $\alpha$. Las cajas coloreadas y las líneas representan diferentes regiones funcionales de la subunidad $\mathrm{G} \alpha$ : púrpura, sitio de acoplamiento a la membrana con lípidos modificados

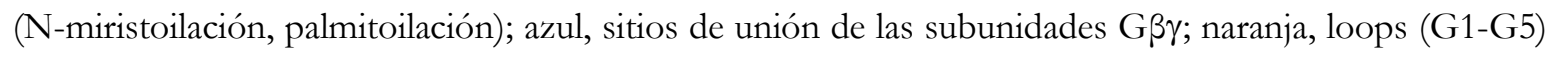
de unión del nucleótido de guanina; verde, sitio de unión del receptor acoplado a proteína G (GPCR); rojo, regiones de los switches I - III (Oldham y Hamm, 2008; Sprang, 1997).

El dominio helicoidal es único y está compuesto de 6 hélices $\alpha$ envueltas, las cuales forman cubierta en la cavidad del sitio de unión a nucleótido (Fig. 5 A). El dominio helicoidal incluye dos funciones importantes: incrementa la afinidad de $\mathrm{G} \alpha$ por el nucleótido guanina e incrementa la actividad hidrolítica de la proteína (Oldham et al., 2006; Oldham y Hamm, 2008).

\subsection{PROTEÍNAS G HETEROTRIMÉRICAS EN HONGOS FILAMENTOSOS}

Las proteínas $G$ heterotriméricas juegan un papel importante en la transducción de señales de varios estímulos ambientales y nutricionales en hongos filamentosos. Los primeros reportes sobre estas proteínas en hongos filamentosos demostraron que son esenciales para el crecimiento, el desarrollo y la virulencia de especies patogénicas en animales y plantas (Li et al., 2007; Liu y Dean, 1997).

Un análisis filogenético generado por alineamiento múltiple de proteínas $G$ de hongos reveló tres principales subgrupos (I-III) dentro de la familia de proteínas G $\alpha$. Los miembros de los subgrupos I y III pueden ser relacionados a las subunidades de las clases $G \alpha_{i}$ y $G \alpha_{s}$ de mamíferos, las cuales inhiben y 
estimulan, respectivamente, la actividad de la adenilato ciclasa, mientras que las subunidades del subgrupo II no tienen similitud con ninguna $\mathrm{G} \alpha$ de mamíferos que de pistas sobre su función (Bolker, 1998).

Las proteínas $\mathrm{G} \alpha$ del subgrupo I están altamente conservadas en la mayoría de los hongos filamentosos y regulan múltiples vías. Este subgrupo se ha implicado en la regulación de procesos como el crecimiento, conidiación, desarrollo sexual y asexual, patogenicidad y metabolismo secundario (Schmitt et al., 2004a).

Se han realizado múltiples estudios funcionales en varios hongos filamentosos con el fin de conocer el papel que desempeña la subunidad $G \alpha_{i}$ en el desarrollo. Como parte de dichos estudios se han generado cepas mutantes y cepas delecionadas $(\Delta G \alpha)$, en las cuales se han mostrado efectos pleiotrópicos provocando cambios fisiológicos importantes.

La primera subunidad $\mathrm{G} \alpha$ del subgrupo I fue identificada en el hongo filamentoso Neurospora crassa, Gna-1 (gna-1). Un análisis de secuencia indicó que Gna-1 pertenece a la superfamilia de proteínas $G \alpha_{i}$ de mamíferos mostrando una similitud del 55\%. Gna-1 contiene una secuencia consenso para miristoilación (MGXXXS) en el extremo amino terminal y un sitio de ADP-ribosilación dependiente de la toxina pertussis (CAAX) en el extremo carboxilo terminal que es conservado en la superfamilia de proteínas $G \alpha_{i}$ (Turner y Borkovich, 1993).

El primer estudio sobre la función de estas subunidades consistió en la interrupción del gen gna-1. La interrupción de gna-1 provocó una reducción de los niveles de cAMP, una morfología alterada de las colonias con una disminución en su extensión apical, una hiper-ramificación del micelio, y una reducción significativa en la acumulación de masa en medio sólido. Sin embargo, en medio líquido no se vio afectada la acumulación de biomasa. Esta diferencia se puede explicar por el fenotipo de la colonia mutante Agna-1 que puede afectar la asimilación de nutrientes en medio sólido, pero no en medio líquido (Ivey et al., 1996). Por otro lado, los alelos mutantes gna-1R178C y gna-1Q204L mostraron altos niveles de cAMP, bajos niveles de carotenoides y una conidiación reducida (Yang y Borkovich, 1999).

En $A$. nidulans se identificó el gen fadA el cual codifica la subunidad G $\alpha$ homóloga a gna-1 de N. crassa. Mediante un análisis funcional se identificaron dos mutaciones dominantes de este gen. Una conversión de la glicina 42 por arginina ( $f a d A^{\mathrm{G} 42 \mathrm{R}}$ ) resulta en un fenotipo muy similar a las mutantes de pérdida de función del gen flbA $(\Delta f l b A)$, el cual codifica una RGS (Regulator of G Protein Signaling) que estimula la actividad GTPasa de la subunidad G $\alpha$ FadA (Yu et al., 1996). La mutación G42R provoca que FadA pierda su actividad GTPasa, provocando una señalización constitutiva hacia la vía de proliferación, y bloqueando la vía de esporulación (conidiación). En este mutante la sobreexpresión de $f l b A$ no es capaz de activar la esporulación. Así mismo, la segunda mutación dominante, cambio de la glicina 203 por 
arginina (fad $A^{\mathrm{G} 203 \mathrm{R}}$ ), causó bajos niveles de cAMP intracelular, un crecimiento reducido y mayor esporulación. También se interrumpió fadA $(\Delta f a d A)$ y su comportamiento fue igual que la mutante fadAG203R (Yu et al., 1996). Por otro lado, también se han estudiado otras especies de Aspergillus, como A. fumigatus, en la cual se identificó el gen que codifica a la subunidad $\mathrm{G} \alpha_{\mathrm{i}} \mathrm{GpaA}$, y por análisis funcionales se han obtenido los mismos resultados que en $A$. nidulans (Mah y Yu, 2006).

Otro microorganismo en el que también ha sido ampliamente estudiada la vía de señalización mediada por proteínas $\mathrm{G}$ es el hongo filamentoso Penicillium chrysogenum. En este hongo también fue identificada una subunidad G $\alpha$ (Pga1) homóloga a GNA1 y FadA. La subunidad G $\alpha$ Pga1 está implicada en el crecimiento y en el proceso de conidiación. El alelo pga1G42R tuvo un efecto pleiotrópico, ya que provocó una conidiación reducida respecto a la cepa silvestre P. chrysogenum NRRL 1951, altos niveles de cAMP intracelular, afectó el crecimiento vegetativo en medio sólido, pero no afectó el crecimiento del micelio en cultivo líquido, y redujo la extensión apical en medio sólido formando colonias con diámetro pequeño (65\% y 67\% con respecto a la cepa silvestre después de 7 días de incubación), y además indujo una fuerte pigmentación en la parte inferior de la colonia (García-Rico et al., 2007). Por su parte, el alelo pga1G203R provocó altos niveles de conidiación comparado con la cepa silvestre, con formación de conidióforos y conidios en algunas hifas en cultivo sumergido, un color pálido que indica la baja producción de pigmento, y además redujo los niveles de cAMP (García-Rico et al., 2007; GarcíaRico et al., 2008a).

Las proteínas $G$ heterotriméricas se han estudiado en hongos como P. chrysogenum (García-Rico et al., 2007), P. roqueforti (García-Rico et al., 2009), A. nidulans (Yuet al., 1996), N. crassa (Ivey et al., 1996; Yang y Borkovich, 1999), Magnaporthe grisea (Fang y Dean, 2000), Cryphonectria parasitica (Segers y Nuss, 2003), Cocbliobolus heterostrophus (Horwitz et al., 1999), y además se han estudiado en algunas especies de Hypocreales, los cuales están más próximos filogenéticamente a A. chrysogenum, como Fusarium oxysporum, Fusarium fujikuroi, Gibberella zea y Trichoderma atroviride. Sin embargo, los estudios han sido limitados por la complejidad de la especie o la difícil manipulación genética.

En F. oxysporum se logró clonar el gen fga1. La disrupción de este gen ( $\Delta$ fga 1$)$ no tuvo un efecto apreciable en el crecimiento vegetativo, sin embargo produjo una morfología de colonia alterada. Por otro lado, $\Delta f g a 1$ presentó una conidiación reducida, menos del 50\% de conidios respecto a la cepa silvestre, y del mismo modo redujo su patogenicidad comparada con la cepa silvestre (Jain et al., 2002). En la especie F. füikkuroi se demostró que la biosíntesis de fusarubinas y bikaverinas es regulada negativa y positivamente por al menos dos subunidades G $\alpha$, FfG1 y FfG3. Además, la disrupción del gen ffg1 $(\Delta f f g 1)$ no tuvo un efecto apreciable en el crecimiento vegetativo (Studt et al., 2013). En Gibberella zea también se ha identificado una subunidad G $\alpha$ putativa del subgrupo I, nombrada GzGPA1, y mediante análisis funcionales se observó que esta proteína regula negativamente la producción de las micotoxinas 
deoxynivalenol (DON) y ZEA (zeavalenone), y tiene un ligero efecto en el crecimiento vegetativo (Yu et al., 2008). Por otro lado, la interrupción de tga1 (Atga1) en Trichoderma atroviride provocó una elevada esporulación, una drástica reducción del crecimiento comparado con la cepa silvestre, y redujo la producción de metabolitos secundarios (Reithner et al., 2005), datos que contrastan con los resultados obtenidos en F. oxysporum.

Gracias a las poderosas herramientas moleculares de hoy en día, recientemente nuestro grupo identificó y clonó el gen que codifica a la subunidad $\mathrm{G} \alpha$ de la proteína $\mathrm{G}$ de $A$. chrysogenum, el cual fue nombrado "aga1" (브remonium G-protein Alpha). Un alineamiento múltiple utilizando programa bioestadístico CLUSTAL W v2.1 (Larkin et al., 2007) demostró que el producto del gen aga1 (G $\alpha$ Aga1) pertenece al subgrupo I de las proteínas $\mathrm{G} \alpha$ (Fig. 6). Se observó un alto grado de identidad entre la proteína $\mathrm{G} \alpha$ Aga1 con subunidades $G \alpha_{i}$ de diferentes organismos, incluyendo la subunidad $G \alpha_{i}$ de mamíferos. La secuencia presenta las cinco cajas (G-1 a G-5) del dominio GTPasa altamente conservadas en otros hongos filamentosos.

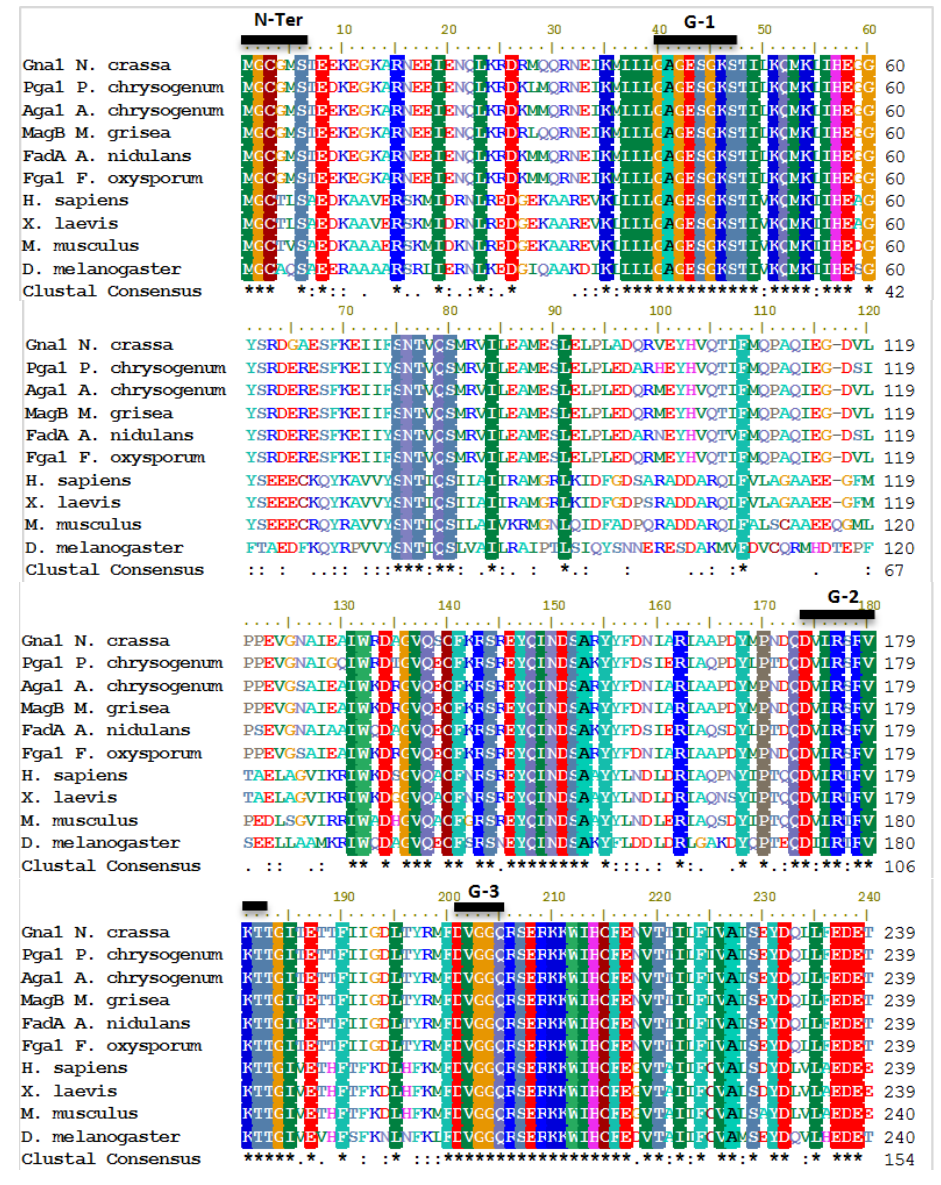




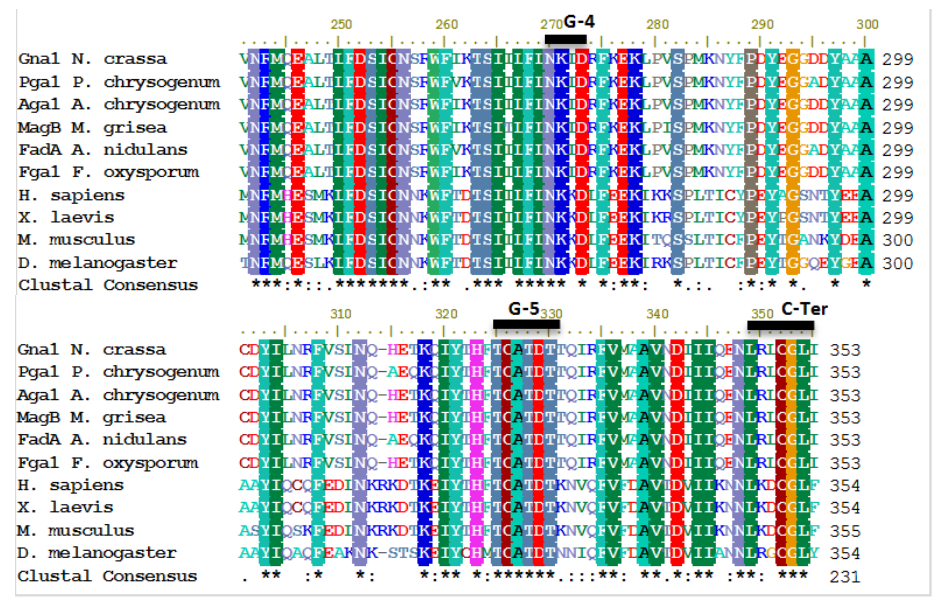

Fig. 6. Alineamiento de la subunidad $\mathrm{G} \alpha$ Aga1 de $A$. chrysogenum con otras subunidades $\mathrm{G} \alpha_{\mathrm{i}} \mathrm{de} N$. crassa, P. chrysogenum, A. chrysogenum, M. grisea, A. nidulans, F. oxysporium, Homo sapiens, Xenopus laevis, Mus musculus y Drosophila melanogaster. (*) Indica residuos idénticos. Las cinco cajas (G-1 - G-5) del dominio GTPasa se muestran encerradas en cuadros, así como los extremos amino y carboxilo conservados de este grupo de subunidades.

Con el fin de estudiar el papel que desempeña aga1 en el desarrollo de $A$. chrysogenum se construyeron tres alelos mutantes (Fig. 7). Los alelos mutantes generados fueron aga1G42R, aga 1G203R y aga 10204L; un cambio de glicina $(\mathrm{G})$ por arginina $(\mathrm{R})$ en la posición 42 y 203, y un cambio de glutamina (Q) por leucina (L) en la posición 204, respectivamente (Fig. 7 A). La glicina 42 se encuentra dentro de la caja G-1 (secuencia consenso $\mathrm{G}_{40} \mathrm{XX}_{42} \mathrm{XXG}_{45} \mathrm{~K}$ ), la cual está implicada en la unión de los fosfatos $\alpha$ y $\beta$ de

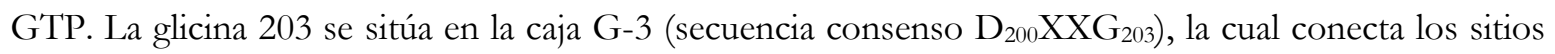
de unión para $\mathrm{Mg}^{2+}$ y para el fosfato $\gamma$ de GTP. Por último la glutamina 204 se localiza en seguida de la caja G-3 (D $\left.{ }_{200} \mathrm{XXG}_{203} \underline{\mathbf{Q}}_{204}\right)$ (Fig. 7 B) (Sprang, 1997; Oldham y Hamm, 2008).

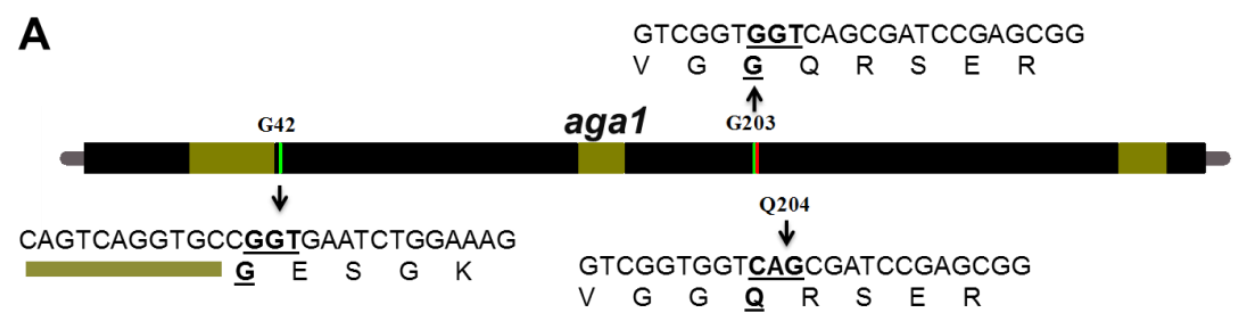

B

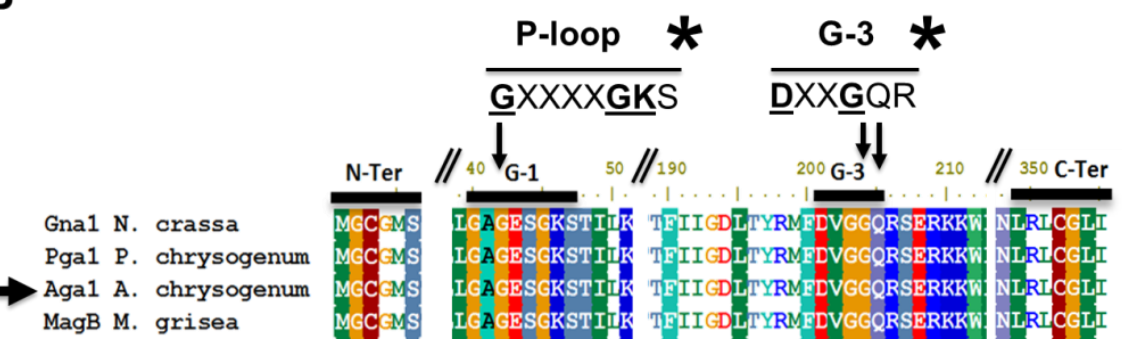


Fig. 7. (A) Posición espacial de los codones y aminoácidos que fueron mutados para generar los alelos mutantes en la secuencia de aga1. (B) Localización de las cajas G-1 y G-3 en la estructura primaria de $\mathrm{G} \alpha$ Aga1 donde se realizaron las mutaciones. (*) Señalan secuencias consenso de las cajas G1 (P-loop) y G3. Las letras en negrita y subrayadas indican residuos de aminoácidos altamente conservados en varios organismos (Sprang, 1997).

Se ha descrito en varios hongos filamentosos que los alelos aga $1^{\mathrm{G} 42 \mathrm{R}}$, aga $1^{\mathrm{Q} 204 \mathrm{~L}}$ generan una subunidad $\mathrm{G} \alpha$ constitutivamente activa, mientras que el alelo aga1G203R genera una subunidad $\mathrm{G} \alpha$ constitutivamente inactiva (Fig. 8). Se ha reportado en humanos que una mutante Ras G12V es deficiente en su actividad GTPasa, volviéndola constitutivamente activa (Campbell y Der, 2004), y una mutante G42V también reduce drásticamente su actividad GTPasa (Raw et al., 1997). Estudios estructurales de $\mathrm{G} \alpha_{\mathrm{i1}}(\mathrm{G} 42 \mathrm{~V})$ sugieren que la introducción de una valina previene estéricamente un posicionamiento apropiado de la glutamina 204, un residuo que coordina un ataque nucleofílico por una molécula de agua durante la hidrólisis de GTP (Raw et al., 1997). Esta glutamina es altamente conservada y crítica para la actividad GTPasa; su mutación a leucina (Q204L) en GTPasas tipo Ras o subunidades $G \alpha$ de proteínas $G$ heterotriméricas conlleva a una actividad constitutivamente activa (Berman et al., 1996; Campbell y Der, 2004). Por otro lado, la mutación dominante G203R provoca un cambio conformacional en el sitio de unión a GTP y previene la disociación del dímero G $\beta \gamma$, de tal forma que bloquea la señalización celular (Fang y Dean, 2000; Hicks et al., 1997).
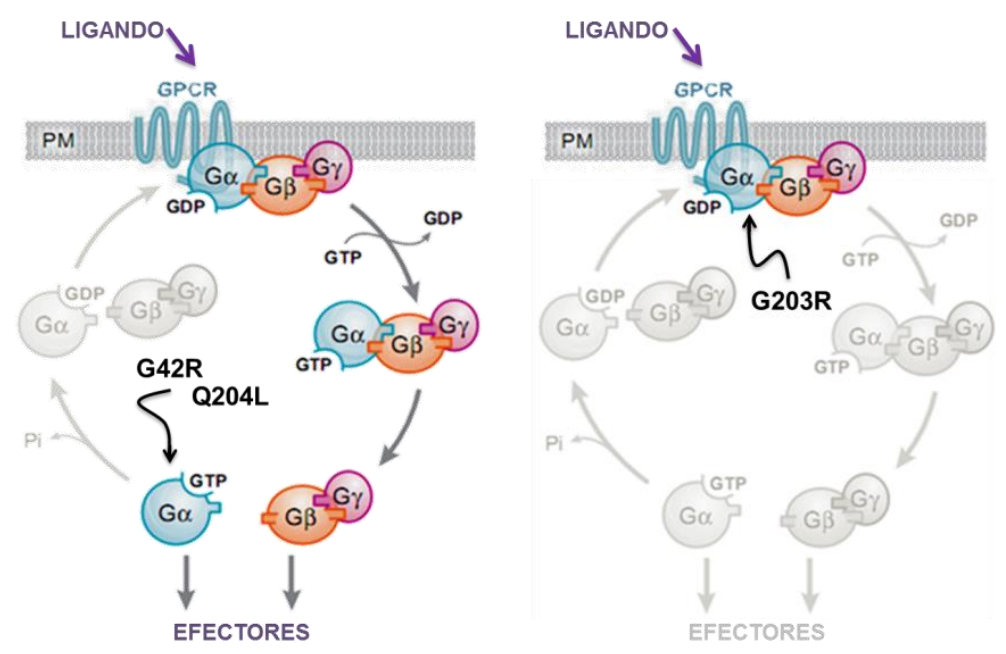

Fig. 8. Efecto de las mutaciones dominantes G42R, Q204L y G203R en una subunidad G $\alpha$. Lado izquierdo: subunidad $\mathrm{G} \alpha$ constitutivamente activa; lado derecho: subunidad $\mathrm{G} \alpha$ constitutivamente inactiva (Figura modificada de Li et al., 2007). 
Hasta el momento los estudios de la subunidad $G \alpha$ realizados en hongos filamentosos han descrito que la mutación G42R origina una subunidad G $\alpha$ sin actividad GTPasa. Sin embargo, recientemente el grupo de Bosch y colaboradores (2012) caracterizaron funcional y cristalográficamente el alelo magB $B^{\mathrm{G} 42 \mathrm{R}}$ en el hongo ascomiceto Magnaporthe oryzae, hongo responsable de una de las peores plagas del arroz (Zhang et al., 2011). En este trabajo mostraron aspectos importantes acerca de los efectos del alelo magBG42R. Demostraron que las mutantes $\mathrm{G} \alpha(\mathrm{G} 42 \mathrm{R})$ no son deficientes en su actividad GTPasa y tampoco son constitutivamente activas. Argumentaron que la arginina previene que la subunidad $G \alpha$ adopte un estado típico de transición para la hidrólisis del GTP. Por otro lado, Liu y colaboradores (2007) demostraron que las mutantes magB ${ }^{\mathrm{G} 42 \mathrm{R}}$ retienen actividad GTPasa.

También demostraron in vitro por resonancia de plasmón superficial (SPR: surface plasmon resonance) que la mutación G42R interrumpe la interacción de G $\alpha$ con la proteína RGS, lo que se ve reflejado en la inhabilidad para asociarse a RGS (Bosch et al., 2012). Este mismo efecto ya fue observado en tres miembros de las subunidades $\mathrm{G} \alpha$ de mamíferos: $\mathrm{G} \alpha_{\mathrm{i} 1}, \mathrm{G} \alpha_{\mathrm{oA}}, \mathrm{y} \mathrm{G} \alpha_{\mathrm{q}}$. Por este motivo decidimos incluir la mutación Q204L en este estudio funcional de la subunidad $\mathrm{G} \alpha$ Aga1 de A. chrysogenum. 


\section{JUSTIFICACIÓN}

El estudio de las proteínas $G$ heterotriméricas en varios hongos filamentosos ha ampliado el conocimiento de procesos como el metabolismo secundario y la diferenciación celular (Turner y Borkovich, 1993; Yang y Borkovich, 1999; Yu et al., 1996; García-Rico et al., 2007; Jain et al., 2002). En A. chrysogenum se ha caracterizado toda la ruta biosintética de cefalosporina, sin embargo, poco se conoce sobre su diferenciación. Apenas se han reportado algunas proteínas como CPCR1 (Schmitt et al., 2004b; Hoff et al., 2005; Hoff y Kück, 2005), AcVEA (Dreyer et al., 2007) y AcSEPH (Long et al., 2013), implicadas en procesos de su desarrollo morfológico como la formación de artrosporas, pero el conocimiento sigue siendo limitado. En este sentido, la caracterización funcional de la subunidad G $\alpha$ Aga1 nos permitirá estudiar el efecto en la formación de artrosporas, proceso ligado a la máxima tasa de producción de cefalosporina. Para esta propuesta deben generarse los alelos de activación (aga1G42R y aga 1 $204 \mathrm{~L}$ ) e inactivación constitutiva (aga1G203R), y observar los efectos a detalle. Los resultados ampliarán nuestro conocimiento sobre la función que desempeña la subunidad G $\alpha$ Aga1 en la formación de artrosporas y la conidiación, procesos de su diferenciación celular.

\section{HIPÓTESIS}

La subunidad $\mathrm{G} \alpha$ Aga1 de A. chrysogenum controla los procesos de formación de artrosporas, conidiación y crecimiento radial.

\section{OBJETIVO GENERAL}

Estudiar la relación entre la subunidad G $\alpha$ Aga1 y el proceso de formación de artrosporas en $A$. chrysogenum en medio sólido y medio líquido.

\subsection{Objetivos particulares}

- Obtención del alelo mutante aga19204L.

- Obtención de las cepas mutantes G42R, G203R y Q204L.

- Estudio de la tasa de extensión radial de las cepas G42R, G203R, Q204L y $\Delta a g a 1$ en medio sólido.

- Análisis de la formación de artrosporas en las cepas G42R, G203R, Q204L y $\Delta a g a 1$ en medio sólido y medio líquido.

- Estudio de la conidiación en las cepas G42R, G203R, Q204L y Daga1 en medio sólido. 


\section{MATERIALES Y MÉTODOS}




\section{MATERIALES Y MÉTODOS}

\subsection{MICROORGANISMOS}

\subsubsection{Cepas bacterianas}

Escherichia coli DH5 $\alpha$. Cepa no patógena y ampliamente usada para la manipulación de ADN. Tiene alta eficiencia de transformación (hasta $5 \times 10^{8}$ transformantes/ $\mu \mathrm{g}$ de ADN) y permite la selección por

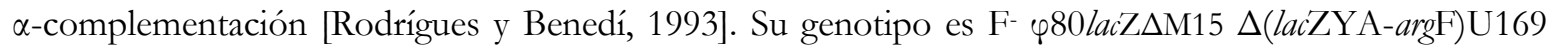
deoR recA1 endA1 bsdR17(rk, mk+) phoAsupE44 thi-1 gyrA96 relA1 $\lambda$.

Esta cepa fue utilizada para la amplificación de todas las construcciones plasmídicas. Su crecimiento se llevó a cabo en medio líquido y sólido Luria Bertani a $37^{\circ} \mathrm{C}$ durante $16 \mathrm{~h}$. Cuando se propagaron colonias transformantes resistentes a algún antibiótico, los medios fueron suplementados con el antibiótico correspondiente. Para conservar las diferentes cepas provenientes de colonias transformadas se almacenaron en glicerol al $40 \%$ a $-20^{\circ} \mathrm{C}$.

\subsubsection{Cepas fúngicas}

Acremonium chrysogenum ATCC 11550 (Brotzu, 1948). Cepa silvestre de A. chrysogenum, productora de cefalosporina C, desacetilcefalosporina C y penicilina N. Alcanza una producción de $200 \mu \mathrm{g} / \mathrm{mL}$ de cefalosporina en matraz.

\section{Crecimiento y mantenimiento}

El crecimiento y esporulación de $A$. chrysogenum se realizó en medio sólido CCM y LPE, respectivamente, incubado a $27^{\circ} \mathrm{C}$ de 5 a 7 días. Para el crecimiento de $A$. chrysogenum en medio líquido se utilizaron matraces de 250 y de $500 \mathrm{~mL}$, con 50 y $100 \mathrm{~mL}$ de medio, respectivamente, e incubados a $26^{\circ} \mathrm{C}$ de 5 a 7 días y con agitación a $150 \mathrm{rpm}$. El inóculo se preparó a partir de micelio macerado con perlas de vidrio o conidios (en el caso de las cepas con capacidad de conidiación). La conservación de las cepas de $A$. chrysogenum se realizó por siembra de esporas frescas en placas Petri, selladas con parafilm y conservadas a $4^{\circ} \mathrm{C}$ (3-4 semanas), o por suspensión de esporas en glicerol al $40 \%$ y almacenadas a $-20^{\circ} \mathrm{C}(1$ año).

\subsection{VECTORES}

pULC43. Contiene el gen de resistencia a fleomicina de Streptoalloteichus hindustanus expresado bajo el control de las regiones promotoras del gen $p c b C$ de P. chrysogenum (Fig. 9). Contiene también el 
terminador de la transcripción del gen yc1 de $S$. cerevisiae y un gen de resistencia a cloranfenicol (Gutiérrez et al., 1997).

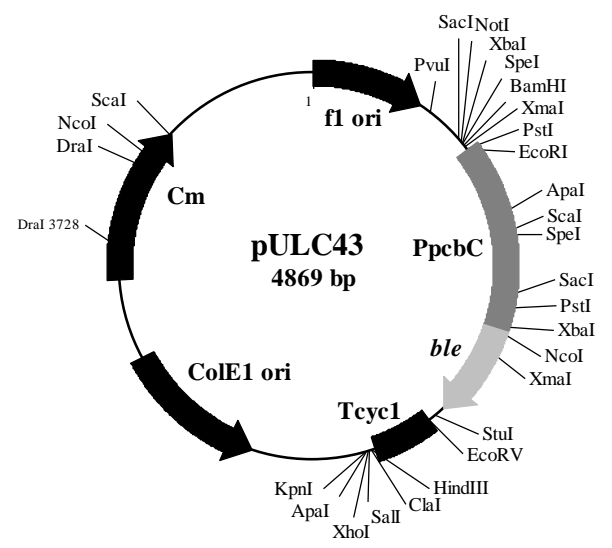

Fig. 9. Mapa circular de pULC43 (4869 pb). Plásmido de integración ectópica. Un fragmento de 1472 pb conteniendo el gen ble, el promotor de $p c b C$ y el terminador $y c 1$ fue insertado en el sitio EcoRV del vector pBC KS+ (Gutiérrez et al., 1997).

pJET1.2aga1. Contiene el gen aga1 bajo su propio promotor (Fig. 10). Porta el gen bla que codifica a una $\beta$-lactamasa, la cual confiere resistencia a ampicilina para seleccionar y mantener células recombinantes de E. coli. Este plásmido fue usado como templado para la mutagénesis dirigida.

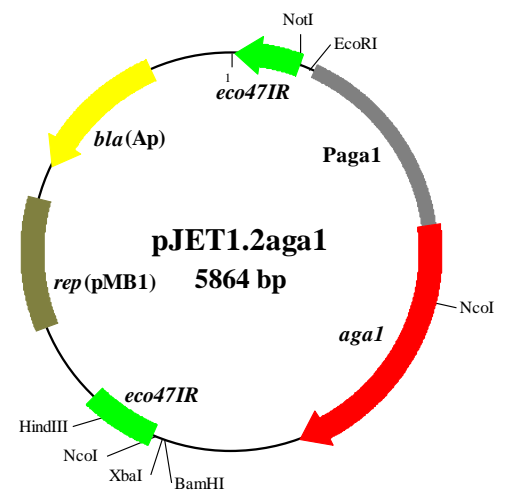

Fig. 10. Mapa circular de pJET1.2aga1 (5864 pb). Un fragmento de 2876 pb fue insertado en los sitios BamHI y EcoRI del vector pJET1.2/blunt interrumpiendo el gen letal eco47IR, el cual permite una selección positiva de colonias recombinantes.

\subsection{ANTIBIÓTICOS}

Ampicilina: Se preparó una solución de $100 \mathrm{mg} / \mathrm{mL}$. Se utilizó agua inyectable para su preparación y finalmente fue esterilizada por filtración a través de una membrana de $0.22 \mu \mathrm{m}$ de diámetro de poro. Se usó para la selección de transformantes de E. coli a una concentración final de $100 \mu \mathrm{g} / \mathrm{mL}$. La solución fue almacenada a $-20^{\circ} \mathrm{C}$. 
Cloranfenicol: Se preparó una solución de $10 \mathrm{mg} / \mathrm{mL}$ de etanol absoluto. Se utilizó etanol absoluto para su preparación y finalmente fue esterilizada por filtración a través de una membrana de $0.22 \mu \mathrm{m}$ de diámetro de poro. Fue utilizada para la selección de transformantes de E. coli a una concentración final de $30 \mu \mathrm{g} / \mathrm{mL}$. La solución fue almacenada a $-20^{\circ} \mathrm{C}$.

Fleomicina: Se preparó un stock de $20 \mathrm{mg} / \mathrm{mL}$ en solución acuosa. Se utilizó agua o Buffer HEPES $(\mathrm{pH}$ 7.25) para su preparación y finalmente fue esterilizada por filtración a través de una membrana de $0.22 \mu \mathrm{m}$ de diámetro de poro. Fue utilizada para la selección de transformantes de A. chrysogenum a una concentración de $30 \mu \mathrm{g} / \mathrm{mL}$. Se conservó a $-20^{\circ} \mathrm{C}$.

\subsection{MEDIOS DE CULTIVO}

\subsubsection{MEDIOS DE CULTIVO PARA BACTERIAS}

\section{Medio Luria-Bertani}

Bacto-Triptona $10 \mathrm{~g}$

Extracto de levadura $5 \mathrm{~g}$

$\mathrm{NaCl} \quad 10 \mathrm{~g}$

Agua destilada $1 \mathrm{~L}$

$\mathrm{pH} 7.0$

Para medio sólido se añadió agar al $2 \%$.

\subsubsection{MEDIOS DE CULTIVO PARA HONGOS}

\section{Medio CCM (medio complejo de cultivo)}

Sacarosa

Medio TSB ((Triptic Soy Broth)

Extracto de carne (Difco)

Extracto de levadura

Glucosa

$\mathrm{NaCl}$

$\mathrm{K}_{2} \mathrm{HPO}_{4}$

$\mathrm{MgSO}_{4} \cdot 7 \mathrm{H}_{2} \mathrm{O}$

$\mathrm{FeSO}_{4}$

Agua destilada hasta

$\mathrm{pH} 7.0$

Para medio sólido se añadió agar al $2 \%$.
$3 g$

$5 \mathrm{~g}$

$1 \mathrm{~g}$

$1 \mathrm{~g}$

$15 \mathrm{~g}$

$0.5 \mathrm{~g}$

$0.5 \mathrm{~g}$

$0.5 \mathrm{~g}$

$0.018 \mathrm{~g}$

$1 \mathrm{~L}$

\section{Medio TSB.}

Peptona de caseína

$10 \mathrm{~g}$

Peptona de soya

$3 \mathrm{~g}$

Glucosa

$2.5 \mathrm{~g}$

$\mathrm{NaCl}$

$\mathrm{K}_{2} \mathrm{HPO}_{4}$

Agua destilada

pH 7.0

$6 \mathrm{~g}$

$2.5 \mathrm{~g}$

hasta 1 litro 
Medio MMC (Medio definido de crecimiento; modificado de Queener et al., 1985).

$\begin{array}{ll}\text { Sacarosa } & 31.6 \mathrm{~g} \\ \text { Glucosa } & 2.2 \mathrm{~g} \\ \text { Sólidos de maceración del maíz } & 0.5 \mathrm{~g} \\ \text { L-Asparagina } & 7.5 \mathrm{~g} \\ \text { Acetato amónico } & 0.22 \mathrm{~g} \\ \mathrm{KH}_{2} \mathrm{PO}_{4} & 15 \mathrm{~g} \\ \mathrm{~K}_{2} \mathrm{HPO}_{4} & 21 \mathrm{~g} \\ \mathrm{Na}_{2} \mathrm{SO}_{4} & 0.75 \mathrm{~g} \\ \mathrm{MgSO}_{4} \cdot 7 \mathrm{H}_{2} \mathrm{O} & 0.18 \mathrm{~g} \\ \mathrm{CaCl}_{2} & 0.06 \mathrm{~g} \\ \text { Solución de sales } & 1 \mathrm{~mL} \\ \text { Agua destilada hasta } & 1 \mathrm{~L}\end{array}$

Composición de la solución de sales en gramos por litro:

$\begin{array}{ll}\mathrm{Fe}\left(\mathrm{NH}_{4}\right)_{2}\left(\mathrm{SO}_{4}\right)_{2} \cdot 6 \mathrm{H}_{2} \mathrm{O} & 15 \mathrm{~g} \\ \mathrm{MnSO}_{4} \cdot 4 \mathrm{H}_{2} \mathrm{O} & 3 \mathrm{~g} \\ \mathrm{ZnSO}_{4} \cdot 7 \mathrm{H}_{2} \mathrm{O} & 3 \mathrm{~g} \\ \mathrm{CuSO}_{4} \cdot 5 \mathrm{H}_{2} \mathrm{O} & 0.8 \mathrm{~g}\end{array}$

Medio LPE (Medio de esporulación y mantenimiento; modificado de Le Page y Campbell, 1946).

Glucosa

Extracto de levadura

$\mathrm{NaCl}$

$\mathrm{CaCl} 2$

Agar

Agua destilada hasta 1 litro

pH 6.8

Para medio sólido se añadió agar al $2 \%$.
$1 \mathrm{~g}$

$2 \mathrm{~g}$

$1.5 \mathrm{~g}$

$10 \mathrm{~g}$

$20 \mathrm{~g}$

\section{Medio TSAS.}

Medio TSB (Triptic Soy Broth)

Sacarosa

Agar (Difco)

Agua destilada

$\mathrm{pH} 7.0$

$30 \mathrm{~g}$

$103 \mathrm{~g}$

$30 \mathrm{~g}$

$1 \mathrm{~L}$

\section{Medio PDA (BIOXON)}

Infusión de papa

Dextrosa

Agar

$\mathrm{pH}$ final $5.6+/-0.2$
$4 \mathrm{~g}$

$20 \mathrm{~g}$

$15 \mathrm{~g}$ 


\subsection{MANIPULACIÓN DE ADN}

\subsubsection{Extracción de ADN genómico}

Las extracciones de ADN genómico de las cepas fúngicas se realizaron usando el Promega DNA Purification Kit siguiendo las especificaciones del proveedor.

\subsubsection{TENS-Mini Prep (Zhou et al., 1990)}

Se tomó una colonia bacteriana proveniente de una placa de agar LB con ampicilina con 12 - 16 h de crecimiento y se dejó crecer en una placa nueva a $37^{\circ} \mathrm{C}$ toda la noche. Se tomó un botón celular con un palillo y se resuspendió en $50 \mu \mathrm{L}$ de agua estéril. Se adicionaron $300 \mu \mathrm{L}$ de Buffer TENS (Ver ANEXO 1) y se resuspendió perfectamente con un vórtex durante $2-5 \mathrm{~s}$. Se adicionaron $100 \mu \mathrm{L}$ de acetato de sodio $3.0 \mathrm{M}$, pH 5.2, y se resuspendió perfectamente con un vórtex de 2 - 5 s. Se centrifugó a 14000 rpm durante 2 min y el sobrenadante se transfirió a un microtubo de $1.5 \mathrm{~mL}$. Se le adicionaron $900 \mu \mathrm{L}$ de etanol absoluto frío y se mezcló por inversión. Se centrifugó durante 2 min y se retiró el sobrenadante. El botón se lavó 2 veces con $1 \mathrm{~mL}$ de etanol al 70\%, se centrifugó durante 2 min y se retiró el sobrenadante. Se dejó secar al aire durante 10 min y el botón se resuspendió con $100 \mu \mathrm{L}$ de agua estéril. Se analizaron $10 \mu \mathrm{L}$ de la muestra en un gel de agarosa al 1\%.

\subsubsection{Megaprep por lisis alcalina y fenolización (método modificado)}

Se inocularon $100 \mathrm{~mL}$ de medio $\mathrm{LB} /$ antibiótico con la cepa transformante, y se incubó toda la noche a $37^{\circ} \mathrm{C}$ con agitación constante. Se recuperaron las células por centrifugación a $4500 \mathrm{rpm}$ durante $10 \mathrm{~min}$ a temperatura ambiente (en tubos de $50 \mathrm{~mL}$ ). Se resuspendió el pellet de bacterias con 4 ó $5 \mathrm{~mL}$ de Buffer P1 (Ver ANEXO 1). Se adicionaron 4 - 5 mL de Buffer P2 (Ver ANEXO 1), y se mezcló completamente por inversión 4 - 6 veces (no vórtex). Se incubó a temperatura ambiente durante 5 min. En seguida se le adicionaron 4 ó $5 \mathrm{~mL}$ de Buffer P3 (Ver ANEXO 1), luego se mezcló por inversión 4 - 6 veces, y se mantuvo en hielo por $15 \mathrm{~min}$. Se centrifugó a $4500 \mathrm{rpm}$ por $30 \mathrm{~min}$, y se transfirió el sobrenadante a un tubo nuevo. En seguida se adicionaron 3 volúmenes de etanol absoluto y 0.1 volúmenes de acetato de sodio. El $\mathrm{ADN}$ se dejó precipitando a $-20^{\circ} \mathrm{C}$ toda la noche. Se centrifugó a 4500 rpm durante 30 min y se desechó el sobrenadante. Se lavó el botón con 1 mL de etanol al 70 \% y se transfirió la suspensión a un microtubo de $1.5 \mathrm{~mL}$. Después se centrifugó a $13000 \mathrm{rpm}$ durante 5 min, se retiró el sobrenadante y finalmente se resuspendió el pellet con $500 \mu \mathrm{L}$ de agua estéril libre de ADNasas.

Se adicionó ARNasa $(100 \mu \mathrm{g} / \mathrm{mL})$ a la muestra anterior y se incubó a $37^{\circ} \mathrm{C}$ durante $1 \mathrm{~h}$. Se agregó un volumen de fenol:cloroformo:alcohol isoamílico 25:24:1 (Sigma Aldrich Co.) y se mezcló brevemente 
hasta formar una emulsión. Se centrifugó a $13000 \mathrm{rpm}$ por 3 - 5 min a temperatura ambiente para separar la fase acuosa de la fase orgánica. La fase acuosa (superior) fue transferida a un tubo nuevo. Se repitieron los pasos desde la adición de fenol. En seguida se retiraron los restos de fenol con un volumen de cloroformo. Se centrifugó a $13000 \mathrm{rpm}$ por 3 - 5 min y la fase acuosa se transfirió a un tubo nuevo. Finalmente el ADN se precipitó con etanol.

\subsubsection{Extracción de ARN}

Después de 48 y 96 h de cultivo se centrifugó la biomasa a 4000 rpm durante 15 min. Se retiró el sobrenadante y se lavó el micelio con $10 \mathrm{~mL}$ de $\mathrm{NaCl}$ 0.9\%. En seguida el micelio se congeló con nitrógeno líquido y se maceró en un mortero estéril, se tomaron aproximadamente $100 \mathrm{mg}$ de macerado y se depositaron en microtubos de $1.5 \mathrm{~mL}$ previamente congelados en nitrógeno.

A cada tubo con macerado se le adicionó $1 \mathrm{~mL}$ de Trizol (Sigma-Aldrich) y se homogeneizó vigorosamente en vórtex para posteriormente dejar reposar 5 min a temperatura ambiente, después de lo cual se adicionaron $200 \mu \mathrm{L}$ de cloroformo y se mezcló vigorosamente por $15 \mathrm{~s}$ en vórtex, incubando 3 min a temperatura ambiente. Se centrifugó a $14000 \mathrm{rpm}, 15$ min a $4{ }^{\circ} \mathrm{C}$, después de lo cual se transfirió la fase acuosa a tubos nuevos. El ARN presente en la fase acuosa se precipitó con $500 \mu \mathrm{L}$ de isopropanol, mezclando por inversión y almacenando a $-20^{\circ} \mathrm{C}$ toda la noche. Posteriormente se centrifugó a $14000 \mathrm{rpm}, 30 \mathrm{~min}$ a $4^{\circ} \mathrm{C}$, descartando el sobrenadante. El precipitado se lavó con $1 \mathrm{~mL}$ de etanol al 70\% y se centrifugó a $8000 \mathrm{rpm}, 5$ min a $4^{\circ} \mathrm{C}$ para desechar el sobrenadante y el precipitado se dejó secar de 5 a 10 min a temperatura ambiente.

El ARN se resuspendió en $20 \mu \mathrm{L}$ de agua DEPC estéril (libre de ARNasas) y se colocó en un baño de hielo durante $10 \mathrm{~min}$, y a continuación se incubó a $65^{\circ} \mathrm{C}$ por $10 \mathrm{~min}$ con agitación constante. Finalmente se almacenó a $-70^{\circ} \mathrm{C}$ hasta su uso.

Con el fin de verificar la integridad del ARN obtenido se realizó una electroforesis en gel de agarosa en condiciones desnaturalizantes usando formaldehído al 37\% (12.3 M), el cual permite una separación dependiente de tamaño. 


\subsubsection{Oligonucleótidos}

Los oligonucleótidos fueron adquiridos de la Unidad de Servicio del Instituto de Biotecnología de la UNAM. En la tabla 3 se describen los oligonucleótidos utilizados y sus respectivas funciones.

Tabla 3. Oligonucleótidos empleados en este trabajo.

\begin{tabular}{|c|c|c|}
\hline Oligonucleótido & Secuencia & Función \\
\hline Q204L-F & 5'-TTCGATGTCGGTGGTCTCCGATCCGAGCGG-3' & \multirow{2}{*}{ Mutagénesis } \\
\hline Q204L-R & 5'-CCGCTCGGATCGGAGACCACCGACATCGAA-3' & \\
\hline RTG42R-F & 5'-ATGCTGCTCCTGGGTGCCCGC-3' & \multirow{5}{*}{ RT-PCR } \\
\hline RTG42R-R & 5'-CTTCTTCCGCTCGGATCGCTGACC-3' & \\
\hline RTG203R-F & 5'-GATGCTGCTCCTGGGTGCCGGT-3' & \\
\hline RTG203R-R ${ }^{a}$ & 5'-CTTCCGCTCGGATCGCTGGCG-3' & \\
\hline RT-AGAWT-R & 5'-CACCGCCCTCGTAGTCTGGGAAG-3' & \\
\hline Paga1-F & 5'-AGCCTTTGACACCTCTCGTCCTTTG-3' & \multirow{3}{*}{ PCR } \\
\hline P2aga1-F & 5'-CGTTGCCATCCATCGTCACTTTG-3' & \\
\hline G42R-R & 5'-GATGGTCGACTTTCCAGATTCG-3' & \\
\hline Aga1-840R & 5'-AAGTAGTTCTTCATBGGGCTRA-3' & Secuenciación \\
\hline
\end{tabular}

\subsubsection{Reacción en cadena de la polimerasa (PCR)}

Este método se usó para la amplificación de secuencias plasmídicas y genómicas. Se usó la enzima Taq DNA Polymerase, Recombinant (Thermo Scientific). Las condiciones de reacción se muestran en la tabla 4. La mezcla de reacción se muestra en la tabla 5.

Tabla 4. Condiciones de reacción de la PCR.

\begin{tabular}{l|l|ll}
\hline \multicolumn{4}{c}{ Condiciones de reacción } \\
\hline \multirow{6}{*}{30 Ciclos } & Desnaturalización inicial & $94^{\circ} \mathrm{C}$ & $3 \mathrm{~min}$ \\
& Desnaturalización & $94^{\circ} \mathrm{C}$ & $45 \mathrm{~s}$ \\
& Alineamiento & $50-72^{\circ} \mathrm{C}$ & $45 \mathrm{~s}$ \\
& Extensión & $72^{\circ} \mathrm{C}$ & $2 \mathrm{~min}$ \\
& Extensión final & $72^{\circ} \mathrm{C}$ & $7 \mathrm{~min}$ \\
\hline
\end{tabular}

Tabla 5. Componentes de la mezcla de reacción para la PCR y sus respectivas concentraciones

\begin{tabular}{|c|c|}
\hline Componente & Concentración final \\
\hline 10X Pfx Buffer & $1 \mathrm{X}$ \\
\hline $\mathrm{MgSO}_{4}(25 \mathrm{mM})$ & $1.5 \mathrm{mM}$ \\
\hline dNTP's (10 mM) & $0.2 \mathrm{mM}$ \\
\hline Oligo $\mathrm{F}(10 \mu \mathrm{M})$ & $0.5 \mu \mathrm{M}$ \\
\hline Oligo $\mathrm{R}(10 \mu \mathrm{M})$ & $0.5 \mu \mathrm{M}$ \\
\hline$P f x$ ADN pol $(5 \mathrm{U} / \mu \mathrm{L})$ & $0.5 \mathrm{U}$ \\
\hline DNA $(10 \mathrm{ng} / \mu \mathrm{L})$ & $0.4 \mathrm{ng} / \mu \mathrm{L}$ \\
\hline Agua esterilizada & $\mathrm{cbp}$ \\
\hline Total & $25 \mu \mathrm{L}$ \\
\hline
\end{tabular}




\subsubsection{Mutagénesis sitio dirigida}

Con el fin de obtener el alelo mutante aga $1^{\mathrm{Q} 204 \mathrm{~L}}$ de $A$. chrysogenum se introdujo un cambio de glutamina por leucina en la posición 204 de la subunidad $\mathrm{G} \alpha$ Aga1 mediante la técnica de mutagénesis sitio dirigida (Quick-change Site-directed Mutagenesis Kit).

La mutagénesis sitio dirigida es un método simple, rápido y eficiente para realizar mutaciones puntuales usando la técnica de PCR en combinación con la digestión del ADN parental con DpnI, y de esta forma obtener alelos mutantes que expresan proteínas donde se ha reemplazado o insertado uno o varios residuos de aminoácidos.

La reacción básica de mutagénesis consiste en mezclar un plásmido circular, dos oligonucleótidos complementarios y ADN polimerasa. Este método se realizó usando la enzima PfuUltra II Fusion HS DNA Polymerase (Agilent Technologies). Esta polimerasa replica ambas hebras del plásmido con alta fidelidad asegurando que se produzca únicamente la mutación introducida en los oligonucleótidos. Tras una serie de ciclos con las condiciones óptimas de amplificación se logra modificar el plásmido original. $\mathrm{Al}$ finalizar la amplificación se realiza un tratamiento con la endonucleasa DpnI, la cual es específica (secuencia blanco: 5'-Gm6ATC-3') para ADN metilado y hemimetilado. De esta manera se puede digerir el ADN parental y seleccionar el ADN sintetizado que porta la mutación deseada. La mayoría de las cepas de E. coli producen ADN metilado, esto hace que sea susceptible a la digestión por DpnI. Posteriormente el producto de reacción se introduce en la bacteria, la cual convierte al plásmido lineal recién sintetizado en un plásmido circular. Finalmente las bacterias transformadas con el plásmido modificado crecerán en un medio de selección, sin embargo no todas tendrán el plásmido modificado. Este protocolo se realizó usando 25 ng de ADN, y 125 pmol de cada oligonucleótido. Los dNTP's fueron agregados a una concentración de $0.2 \mathrm{mM}$. Por último, se agregaron $0.32 \mu \mathrm{L}$ de PfuUltra II Fusion HS DNA Polymerase $(2.5 \mathrm{U} / \mu \mathrm{L})$. Las condiciones de PCR se muestran en la tabla 6.

Después de la amplificación, a la mezcla de reacción se le adicionó $1 \mu \mathrm{L}$ de $\mathrm{DpnI}(10 \mathrm{U} / \mu \mathrm{L})$ y se incubó durante $2 \mathrm{~h}$ a $37^{\circ} \mathrm{C}$. Posteriormente se transformaron células $\mathrm{DH} 5 \alpha$ ultracompetentes con $1 \mu \mathrm{L}$ de la mezcla, en seguida fueron sembradas en placas con medio LB/ampicilina, y finalmente se incubaron durante $12-16 \mathrm{~h}$ a $37^{\circ} \mathrm{C}$. Se seleccionaron pocas colonias y se caracterizaron los plásmidos. La mutación deseada fue confirmada por secuenciación usando $100 \mathrm{ng} / \mu \mathrm{L}$ del plásmido purificado. Los resultados fueron analizados con el programa BioEdit v7.1.9. 
Tabla 6. Condiciones de reacción de mutagénesis.

\begin{tabular}{l|l|ll}
\hline \multicolumn{4}{c}{ Condiciones de reacción } \\
\hline \multirow{4}{*}{25 Ciclos } & Desnaturalización inicial & $95^{\circ} \mathrm{C}$ & $3 \mathrm{~min}$ \\
& Desnaturalización & $95^{\circ} \mathrm{C}$ & $30 \mathrm{~s}$ \\
& Alineamiento & $55-65^{\circ} \mathrm{C}$ & $30 \mathrm{~s}$ \\
& Extensión & $68^{\circ} \mathrm{C}$ & $6 \mathrm{~min}$ \\
& Extensión final & $68^{\circ} \mathrm{C}$ & $7 \mathrm{~min}$ \\
\hline
\end{tabular}

\subsubsection{RT-PCR}

La técnica RT-PCR consiste en un par de reacciones que se llevan a cabo en el mismo tubo, en primer lugar una transcripción reversa y a continuación una amplificación por PCR, comúnmente se le denomina reacción “one-step”. El procedimiento se realizó con el QIAGEN OneStep RT-PCR Kit, siguiendo las especificaciones del proveedor.

\subsubsection{Digestiones enzimáticas}

Las digestiones se realizaron con el fin de obtener fragmentos específicos de ADN y para caracterizar vectores por análisis de restricción. Las digestiones se llevaron a cabo siguiendo las especificaciones del proveedor (Thermo Scientific).

\subsubsection{Ligación de fragmentos de ADN}

La ligación de fragmentos de ADN provenientes de productos de PCR y de digestión se realizó con T4 ADN ligase (Thermo Scientific) siguiendo las especificaciones del proveedor.

\subsection{TRANSFORMACIÓN DE BACTERIAS}

\subsubsection{Preparación y transformación de células Ultra-competentes (Inoue et al., 1990; Hengen,} 1996)

Se inocularon $25 \mathrm{~mL}$ de medio $\mathrm{LB}$ con 10 - 12 colonias de células $\mathrm{DH} 5 \alpha$, se incubaron a $37^{\circ} \mathrm{C}$ durante 8 - 10 h. Se inocularon $250 \mathrm{~mL}$ de LB (en un matraz de $2 \mathrm{~L}$ ) con $2.5 \mathrm{~mL}$ del preinóculo. Se dejaron crecer con agitación constante $(180-250 \mathrm{rpm})$ a $18^{\circ} \mathrm{C}$ durante aproximadamente dos días hasta alcanzar una densidad óptica de 0.5 - 0.6 a $600 \mathrm{~nm}$. Se transfirió el matraz a un baño de hielo y se mantuvo durante $10 \mathrm{~min}$. Se centrifugó el medio a $4000-5000 \mathrm{rpm}$ por $10 \mathrm{~min}$ a $4^{\circ} \mathrm{C}$. El pellet se resuspendió en $80 \mathrm{~mL}$ de Buffer TB (Ver ANEXO 1) frío, y se mantuvo en hielo durante $10 \mathrm{~min}$. Se centrifugó a 4000 - $5000 \mathrm{rpm}$ por $10 \mathrm{~min}$ a $4^{\circ} \mathrm{C}$. El pellet se resuspendió en $20 \mathrm{~mL}$ de TB más $1.4 \mathrm{~mL}$ de DMSO (Ver ANEXO 1), y se mantuvo en hielo durante 10 min. El volumen final se repartió en 
alícuotas de $100 \mu \mathrm{L}$ en microtubos de $1.5 \mathrm{~mL}$, y se sumergieron inmediatamente en nitrógeno líquido. Se almacenaron a $-70^{\circ} \mathrm{C}$ para su uso.

\subsubsection{Transformación de bacterias por heat-shock}

Se tomaron $50 \mu \mathrm{L}$ de células ultra-competentes y se depositaron en un microtubo de $1.5 \mathrm{~mL}$. Se le adicionaron $10 \mu \mathrm{L}$ de plásmido, se resuspendió suavemente y se mantuvo en hielo durante $30 \mathrm{~min}$. Se transfirió la mezcla a un baño de agua a $42^{\circ} \mathrm{C}$ durante 2 min y se enfrió rápidamente en hielo. Se adicionaron $800 \mu \mathrm{L}$ de medio LB, se mezcló por inversión y se incubó a $37^{\circ} \mathrm{C}$ durante $1 \mathrm{~h}$. Se sembró una alícuota de $100 \mu \mathrm{L}$ en la superficie de una placa con LB/agar y con el antibiótico específico. Se incubó toda la noche a $37^{\circ} \mathrm{C}$.

\subsection{TRANSFORMACIÓN DE A. chrysogenum POR PROTOPLASTOS}

\subsubsection{Crecimiento del micelio}

Se inocularon $100 \mathrm{~mL}$ de medio MMC con micelio procedente de cinco cajas de medio LPE incubadas previamente durante 5 días a $28^{\circ} \mathrm{C}$. El cultivo se incubó a $28^{\circ} \mathrm{C}$ a $200 \mathrm{rpm}$ durante $20 \mathrm{~h}$. Una vez transcurrido el tiempo de incubación se recogió el micelio por centrifugación a 8000 rpm durante 30

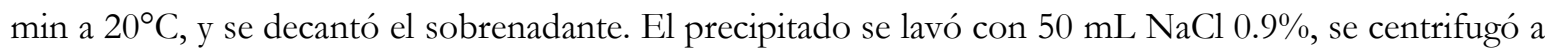
4000 rpm durante 15 min.

\subsubsection{Obtención de protoplastos}

El micelio se resuspendió en $100 \mathrm{~mL}$ de TPC (Ver ANEXO 1) suplementado con Ditiotreitol (DTT) $0.1 \mathrm{M}$ y se incubó a $28^{\circ} \mathrm{C}$ a $250 \mathrm{rpm}$ durante $2 \mathrm{~h}$. La incubación con DTT permite reducir las uniones disulfuro de las proteínas de la pared celular, facilitando la liberación posterior de protoplastos. En seguida se recuperó el micelio correspondiente a $20 \mathrm{~mL}$ por centrifugación a $4000 \mathrm{rpm}$ durante 10 min, y después se lavó el micelio tratado con $20 \mathrm{~mL}$ de TPC. En seguida el micelio se resuspendió en $20 \mathrm{~mL}$ TPC que contiene enzimas líticas de Trichoderma harzianum (Sigma-Aldrich Co.) a una concentración final de $10 \mathrm{mg} / \mathrm{mL}$. La mezcla se colocó en un matraz de $250 \mathrm{~mL}$ y se incubó el tiempo necesario para la liberación de protoplastos (no más de $5 \mathrm{~h}$ a $28^{\circ} \mathrm{C}$ con agitación constante a $100 \mathrm{rpm}$ ). La liberación de los protoplastos se observó en un microscopio cada hora.

Una vez observada la liberación de protoplastos en la producción adecuada, se filtró la suspensión protoplastos en una membrana de nylon de $30 \mu \mathrm{m}$ de diámetro de poro (Nytal, Suiza) previamente colocada sobre un embudo (todo esterilizado), con el fin de separar los protoplastos de los restos de micelio. En seguida se recuperaron los protoplastos por centrifugación a $2500 \mathrm{rpm}$ durante 4 min a 
temperatura ambiente. El agregado celular obtenido se lavó con $5 \mathrm{~mL}$ de $\mathrm{NaCl} 0.8 \mathrm{M}$, recuperándose por centrifugación en las condiciones mencionadas anteriormente; el lavado con $\mathrm{NaCl}$ se repitió tres veces consecutivas. Luego se lavó el agregado celular con $5 \mathrm{~mL}$ de Buffer NCM (Ver ANEXO 1) y se centrifugó de la misma manera. Los protoplastos se resuspendieron en NCM a una concentración de 1 x $10^{8}$ protoplastos/mL (aproximadamente 5 veces el volumen del precipitado) y se añadió $1 / 10$ del volumen del Buffer CCM (Ver ANEXO 1). Se mezcló suavemente y la suspensión de protoplastos se mantuvo en hielo hasta el momento de transformación.

\subsubsection{Transformación}

En un tubo de $15 \mathrm{~mL}$ se mezclaron $100 \mu \mathrm{L}$ de la suspensión de protoplastos con $10 \mu \mathrm{g}$ de plásmido. Se mezcló por inversión y se mantuvieron en hielo durante 20 min. A la mezcla anterior se le añadieron $500 \mu \mathrm{L}$ de Buffer CCM, se mezcló suavemente y se mantuvo a temperatura ambiente durante 20 min más. Luego se agregaron $600 \mu \mathrm{L}$ de Buffer NCM con el fin de disolver el polietilenglicol presente en el Buffer CCM. La mezcla de transformación se mantuvo a temperatura ambiente hasta el momento del plaqueo.

\subsubsection{Plaqueo}

Se prepararon las bases de las placas de transformación, extendiendo $7 \mathrm{~mL}$ de medio TSAS con fleomicina (a una concentración final de $30 \mu \mathrm{g} / \mathrm{mL}$ ) en cajas Petri de $60 \mathrm{~mm}$ de diámetro. La mezcla de transformación se repartió en 4 tubos de $15 \mathrm{~mL}$, en volúmenes de $300 \mu \mathrm{L}$. Posteriormente a cada tubo se le añadieron $7.5 \mathrm{~mL}$ del medio TSAS $\left(\mathrm{a} 48^{\circ} \mathrm{C}\right.$ ) con fleomicina. Por último, la mezcla se añadió como cobertera sobre la base de las placas de transformación, que se incubaron durante 7 días a $28^{\circ} \mathrm{C}$. Para los controles positivo y negativo solamente se plaquearon $100 \mu \mathrm{L}$ de las suspensión de protoplastos en medio TSAS sin fleomicina y $100 \mu \mathrm{L}$ de protoplastos en medio TSAS con fleomicina, respectivamente.

\subsubsection{Selección de clonas}

Las colonias transformantes que aparecieron durante el tiempo de incubación fueron resembradas por punción en placas de medio TSAS con el doble de concentración de fleomicina $(60 \mu \mathrm{g} / \mathrm{mL})$. La resiembra se realizó dos veces para asegurar que las colonias obtenidas se trataran de verdaderas transformantes (expresando la resistencia a fleomicina). Para asegurar la obtención de transformantes verdaderas se aislaron conidios de las cepas, ya que los conidios son mononucleados este principio ayudó a obtener homocariontes. Los conidios se sembraron en la superficie de placas con medio TSAS/fleomicina y después de 10 días de incubación se picaron colonias aisladas provenientes de conidios resistentes a fleomicina. 


\subsection{ANÁLISIS FENOTÍPICO}

\subsubsection{Tasa de extensión radial}

El crecimiento en medio sólido de los hongos filamentosos se lleva a cabo de manera radial. A nivel germinal las hifas vegetativas se extienden radialmente avanzando sobre el medio de cultivo hasta colonizar toda su superficie formando un círculo. La velocidad a la que se extiende el radio de este círculo sobre el medio es una medida directa del crecimiento vegetativo del hongo.

Para medir la tasa de extensión radial se inocularon $0.5 \mu \mathrm{L}$ de una suspensión de conidios de 1x106 conidios/mL, en el centro de una placa de Petri de $50 \mathrm{~mm}$ de diámetro con el medio de cultivo a probar. Se incubó a $26^{\circ} \mathrm{C}$ durante 7 días. A lo largo del tiempo se midió el diámetro de la colonia, tomando como referencia el frente de la placa. Se tomaron dos medidas perpendiculares entre sí, por colonia. Las mediciones se realizaron hasta las $168 \mathrm{~h}$ cada $24 \mathrm{~h}$ a partir de las $48 \mathrm{~h}$ de incubación. Los datos fueron procesados y se determinó la tasa de extensión radial en $\mathrm{mm} / \mathrm{h}$. Se ensayaron los medios CCM, LPE y PDA.

La medición de los diámetros se llevó a cabo usando el programa ImageJ (Ver ANEXO 2). Para esto fueron capturadas las imágenes de las colonias a cada tiempo con una cámara digital Samsung ST80 acoplada a un Estereoscopio Southern Precision Instrument Modelo 1839. Las imágenes obtenidas fueron analizadas en ImageJ usando una escala constante de $2 \mathrm{~mm}$ de longitud, donde se obtuvieron los diámetros, promedios y desviaciones estándar de todas las mediciones.

\subsubsection{Conteo de artrosporas}

La fragmentación es una forma de reproducción asexual que ocurre cuando el micelio de un hongo es físicamente descompuesto o fragmentado. En $A$. chrysogenum la fragmentación da lugar a cadenas de artrosporas, también llamadas "yeast-like", las cuales son células metabólicamente activas enriquecidas de orgánulos intracelulares y vacuolas que contienen lípidos (Long et al., 2013).

Con el fin de observar si la subunidad G $\alpha$ Agal tiene un efecto en el proceso de fragmentación de las hifas, se monitoreó la formación de artrosporas a lo largo del tiempo.

Se sembraron las cepas de $A$. chrysogenum en placas con medio CCM sólido, y se incubaron durante 5 días a $26^{\circ} \mathrm{C}$. Una vez transcurrido el tiempo de incubación se lavó la superficie de la placa con $5 \mathrm{~mL}$ de PBS-Tween 80 (Ver ANEXO 1) para remover la mayor cantidad posible de conidios. Después se recolectó el micelio húmedo con una espátula metálica y se depositó en un tubo de $50 \mathrm{~mL}$ conteniendo $30 \mathrm{~mL}$ de medio líquido CCM. En seguida se maceró el micelio con perlas de vidrio y agitación fuerte, y se estimó el peso seco en $\mathrm{mg} / \mathrm{ml}$ (a partir del macerado). Una vez conocido el peso, se inocularon 100 $\mathrm{mL}$ de medio líquido CCM con un volumen equivalente a $10 \mathrm{mg}$ de micelio tomado del tubo con el 
macerado. Los matraces inoculados se dejaron crecer durante 7 días a $26^{\circ} \mathrm{C}$ con agitación constante (150 rpm).

El conteo de artrosporas se realizó cada 24 h hasta las 168 h de cultivo. Al mismo tiempo también se determinó el peso seco para obtener una relación directa entre la cantidad de artrosporas y los mg de micelio. Las artrosporas fueron visualizadas en un microscopio óptico Olympus CH30RF100 y el conteo se realizó con una cámara de Neubauer Improved. El número de artrosporas se determinó usando la fórmula descrita abajo. Los datos fueron procesados, analizados y finalmente representados como como número de artrosporas por mg de micelio.

$$
\text { 1) } \frac{\text { Art }}{\text { Cuadro }} \times 25 \times 1000 \times \mathrm{FD}=\mathrm{Art} / \mathrm{mL} \quad \text { 2) } \frac{\mathrm{Art} / \mathrm{mL}}{\mathrm{mg} / \mathrm{mL}}=\mathrm{Art} / \mathrm{mg}
$$

Donde Art/Cuadro corresponde al promedio de artrosporas contadas en cinco cuadros; 25 corresponde al total de cuadros centrales (equivalente a $0.1 \mathrm{~mm}^{3}$ ); 1000 corresponde a una equivalencia $(1000 \mu \mathrm{L} / \mathrm{mL})$; FD corresponde al factor de dilución de la muestra; $\mathrm{mg} / \mathrm{mL}$ (peso seco en $\mathrm{mg} / \mathrm{mL}$ ).

\subsubsection{Determinación del peso seco}

La densidad del crecimiento en medio líquido se cuantificó mediante la determinación del peso seco por volumen de medio de cultivo.

Se tomó una muestra de $2 \mathrm{~mL}$ del cultivo cada $24 \mathrm{~h}$, desde las $0 \mathrm{~h}$. Cada muestra fue depositada en microtubos de $2 \mathrm{~mL}$ previamente pesados. Se centrifugó la muestra a $13000 \mathrm{rpm}$ durante $10 \mathrm{~min} \mathrm{a} 4^{\circ} \mathrm{C}$. Se retiró cuidadosamente el sobrenadante. Se lavó el precipitado en $1 \mathrm{~mL}$ de $\mathrm{HCl} 0.1 \mathrm{M}$, se resuspendió y centrifugó a $13000 \mathrm{rpm}$ durante $10 \mathrm{~min}$. Se descartó el sobrenadante y se repitió en las mismas condiciones el lavado con $1 \mathrm{~mL}$ de $\mathrm{NaCl} 0.9 \%$. Se desechó el sobrenadante y las muestras se colocaron en un horno durante $48 \mathrm{~h} \mathrm{a} 60^{\circ} \mathrm{C}$. Se pesaron los tubos y se determinó el peso seco (en $\mathrm{mg} / \mathrm{mL}$ ) por la diferencia del peso vacío y con biomasa.

\subsubsection{Estudios de conidiación}

Se estudió la conidiación en las cepas A. chrysogenum ATCC 11550, G42R, G203R, y Daga1.

Para el estudio de conidiación se propagaron $25 \mu \mathrm{L}$ de una suspensión de 1x106 conidios en la superficie de placas de Petri de $50 \mathrm{~mm}$ con medio CCM, LPE y PDA. Las placas fueron incubadas a $26^{\circ} \mathrm{C}$ durante 7 días. Con la ayuda de un sacabocado se extrajeron cilindros de las placas cuya área fue de $95 \mathrm{~mm}^{2}$. Cada cilindro de agar se depositó en un tubo de $15 \mathrm{~mL}$ y se le agregó $2 \mathrm{~mL}$ de Buffer NT (Ver ANEXO 1). Se agitó el tubo vigorosamente durante 2 min para desprender los conidios de los cilindros de agar. 
Los conidios fueron visualizados en un microscopio óptico Olympus CH30RF100 y el conteo se realizó con una cámara de Neubauer Improved. El número de conidios $/ \mathrm{mm}^{2}$ se determinó usando las fórmulas descritas abajo.

$$
\text { 1) } \frac{\text { Con }}{\text { Cuadro }} \times 25 \times 1000 \times \mathrm{FD}=\mathrm{Con} / \mathrm{mL} \quad \text { 2) } \frac{\mathrm{Con} / \mathrm{mL}}{47.5 \mathrm{~mm}^{2} / \mathrm{mL}}=\mathrm{Con} / \mathrm{mm}^{2}
$$

Donde Con/Cuadro corresponde al promedio de conidios contadas en cinco cuadros; 25 corresponde al total de cuadros centrales (equivalente a $0.1 \mathrm{~mm}^{3}$ ); 1000 corresponde a una equivalencia (1000 $\mu \mathrm{L} / \mathrm{mL}$ ); FD corresponde al factor de dilución de la muestra; $47.5 \mathrm{~mm}^{2} / \mathrm{ml}$ (área $95 \mathrm{~mm}^{2} / 2 \mathrm{~mL}$ de Buffer NT).

\subsubsection{Microcultivos}

Los microcultivos se realizaron en placas de Petri de $50 \mathrm{~mm}$ con medio LPE. Una vez vertido el medio dentro de la caja de Petri se dejó gelificar, y en seguida se insertó en el agar de manera inclinada un cubreobjetos estéril, de tal forma que su inclinación no impida cerrar la caja. Una vez insertado el cubreobjetos se inocularon $5 \mu \mathrm{L}$ de una suspensión de conidios $\left(1 \times 10^{6}\right.$ conidios $\left./ \mathrm{mL}\right)$ justo en el corte del agar y el cubreobjetos. El medio se incubó a $26^{\circ} \mathrm{C}$ durante 168 h. Se preparó un portaobjetos con $5 \mu \mathrm{L}$ de azul de lactofenol y enseguida se levantó el cubreobjetos de la placa con una pinza cuidando de no estropear las estructuras morfológicas, y se colocó sobre el portaobjetos. Posteriormente se observaron las estructuras al microscopio.

\subsubsection{Microscopía y análisis de imagen}

La morfología de las cepas fue analizada a diferentes tiempos de cultivo (48 - $168 \mathrm{~h}$ ) usando un microscopio Olympus CH30RF100. Las imágenes fueron capturadas con una cámara digital SAMSUNG ST80 y procesadas con el programa Adobe Photoshop v7.0. Para observar estructuras conidiogénicas las muestras fueron teñidas con azul de bromofenol y observadas al microscopio a 40X y 100X (usando aceite de inmersión). Para el estudio de extensión radial se usó un Estereoscopio Southern Precision Instrument Modelo 1839 acoplado a una cámara. Las imágenes fueron analizadas con el programa ImageJ.

\subsubsection{Análisis estadístico}

La extensión radial y la conidiación se analizaron estadísticamente para observar las posibles diferencias entre las cepas mutantes. Los datos obtenidos fueron sometidos a un análisis de varianza (ANOVA) de un factor "cepa" con cuatro niveles "cepas", y se compararon las medias de los tratamientos mediante la prueba de Tukey ( $\mathrm{p} \leq$ 0.05) (Hayter, 1984). El análisis estadístico se realizó mediante el paquete estadístico SPSS (PASW Statistics v18.0, SPSS Inc). 


\section{RESULTADOS Y DISCUSIÓN}




\section{RESULTADOS Y DISCUSIÓN}

\subsection{CONSTRUCCIONES PLASMÍDICAS}

\subsubsection{Construcción del plásmido pJETaga1Q204L}

Hasta el momento se tenían los plásmidos pJETaga1G42R y pJETaga1G203R, los cuales contienen los

alelos aga1G42R y aga1G203R de activación e inactivación constitutiva, respectivamente. Por lo tanto, se construyó el plásmido pJETaga1Q204L, el cual porta el alelo aga1Q204L de activación constitutiva según lo reportado en otros hongos filamentosos como N. crassa (Yang y Borkovich, 1999), M. grisea (Liu et al., 2007), A. fumigatus (Mah y Yu, 2006) y A. nidulans (Yu et al., 1999).

El alelo aga1Q204L se obtuvo mediante mutagénesis sitio dirigida (Fig. 11) a partir del plásmido pJET1.2aga1 usando el par de oligonucleótidos Q204L-F y Q204L-R (Tabla 3). Estos oligonucleótidos introdujeron un cambio de una glutamina (Q) por leucina (L) en la posición 204 de subunidad $\mathrm{G} \alpha$ Aga1. Después de la reacción de mutagénesis se realizó una electroforesis en gel de agarosa para visualizar la integridad de los amplicones generados en la reacción. En el gel se observaron bandas inespecíficas amplificadas en menor proporción respecto a la banda de interés (5864 pb). Las bandas de $5864 \mathrm{pb}$ fueron purificadas a partir del gel de agarosa, mismas que se usaron para transformar células de E. coli DH5 $\alpha$. Una vez que se obtuvieron colonias recombinantes con el plásmido pJETaga1Q204L, éste fue aislado y confirmado por secuenciación (Fig. 11). Las condiciones de reacción de la mutagénesis permitieron amplificar satisfactoriamente el plásmido completo y obtener el alelo aga1Q204L. Cabe señalar que estas condiciones fueron aplicadas para introducir mutaciones puntuales en otros genes obteniendo resultados favorables. 

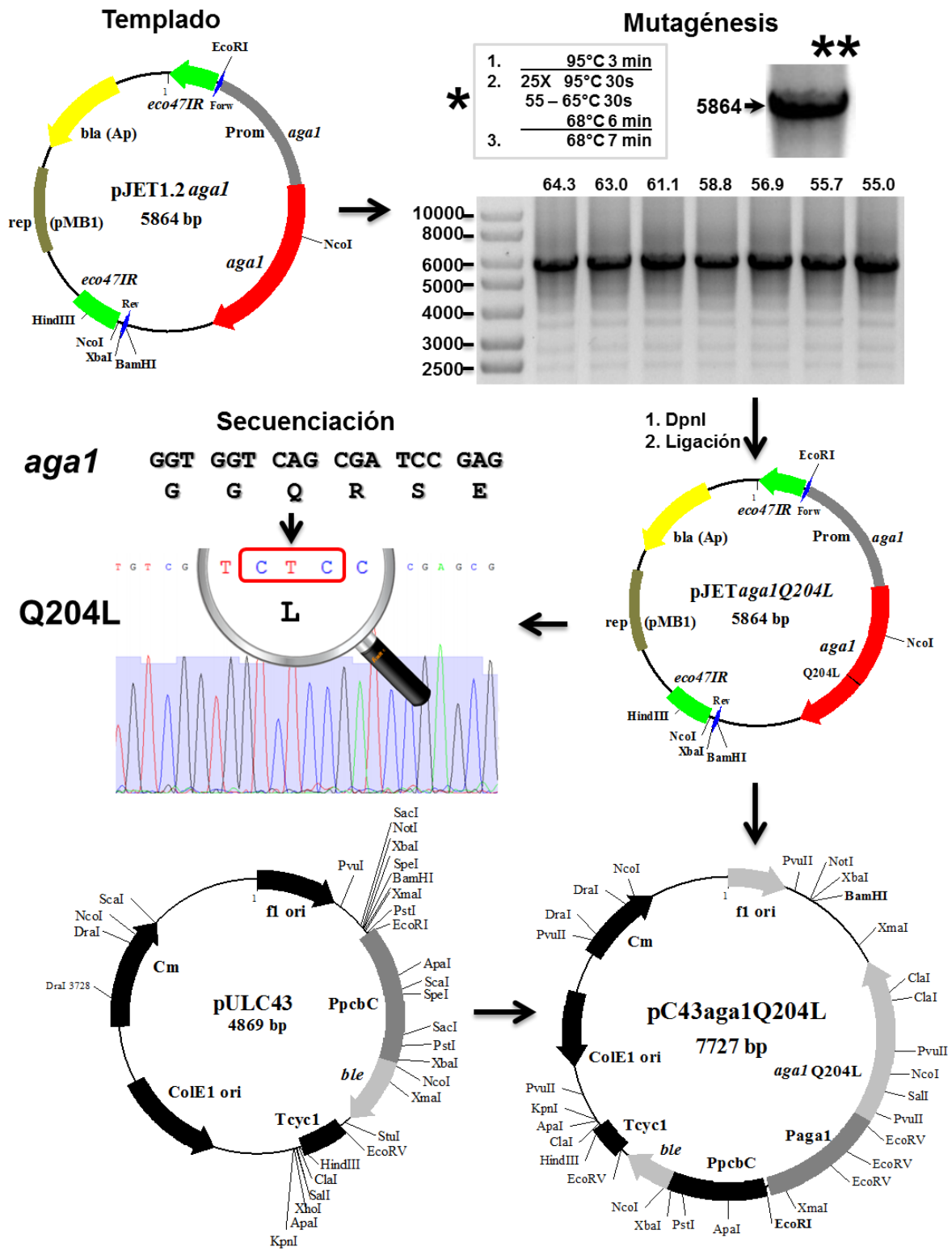

Fig. 11. Construcción de los plásmidos pJETaga1Q204Ly pC43aga1Q204L. Mapas circulares de los plásmidos mostrando la ubicación de algunos sitios de restricción. Parte superior derecha: muestra el análisis electroforético del gradiente de temperatura en la reacción de mutagénesis. (*) Indica las condiciones de PCR para la mutagénesis. (**) Indica el tamaño de banda esperado.

\subsubsection{Construcción de los plásmidos integrativos pC43aga1G42R, pC43aga1G203R y} pC43aga1Q204L

Una vez obtenidos los plásmidos pJETaga1G42R, pJETaga1G203R y pJETaga1Q204L, se procedió a clonar cada fragmento EcoRI-BamHI de 2876 pb en pULC43, para obtener los plásmidos pC43aga1G42R, pC43aga1G203R (Fig. 12 A), y pC43aga1Q204L (Fig. 11). Los plásmidos fueron 
confirmados por análisis de restricción usando las endonucleasas de restricción ApaI, HindIII y XhoI (Fig. 12. B), y por secuenciación (Fig. 12. C).

A

A
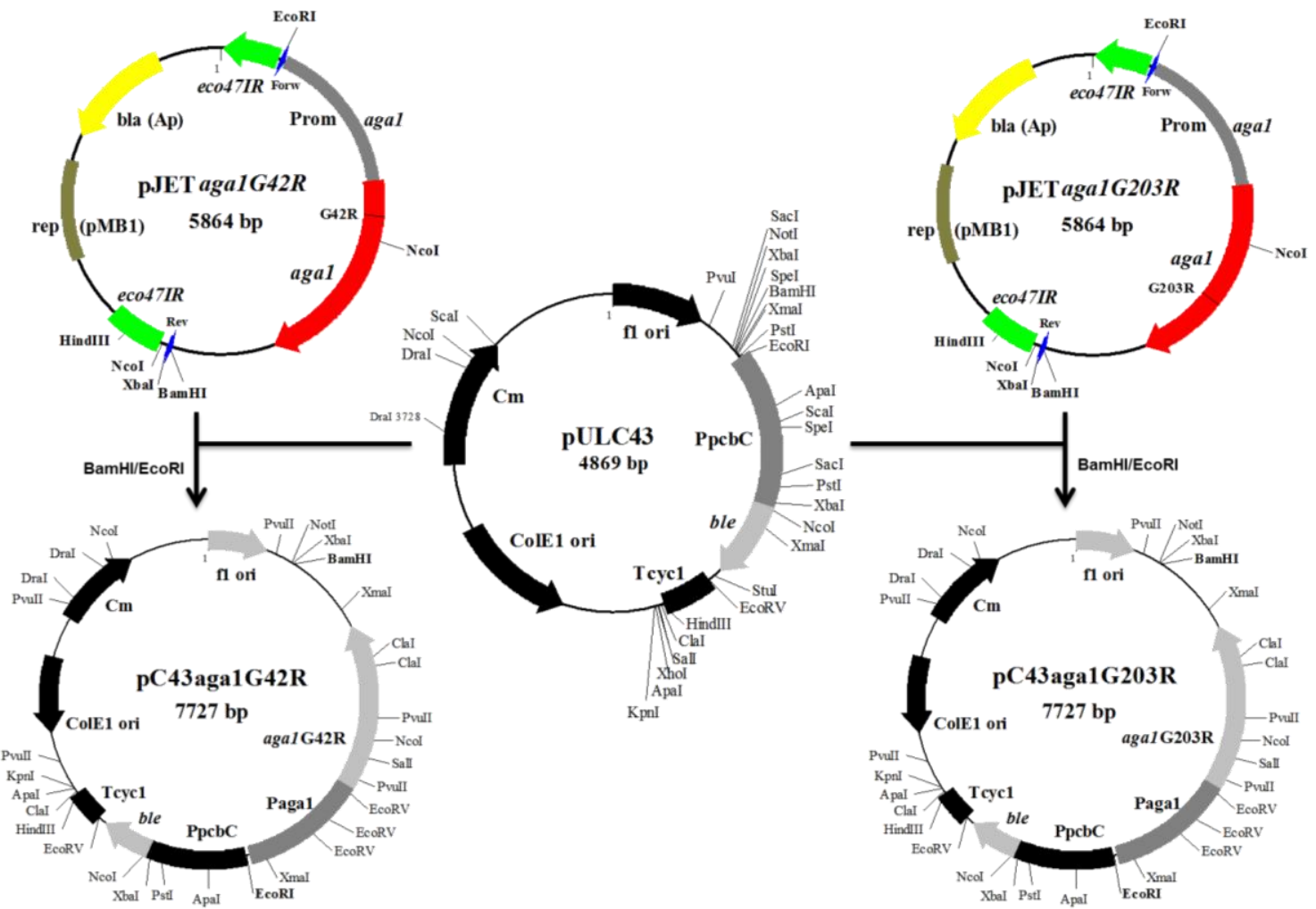

B
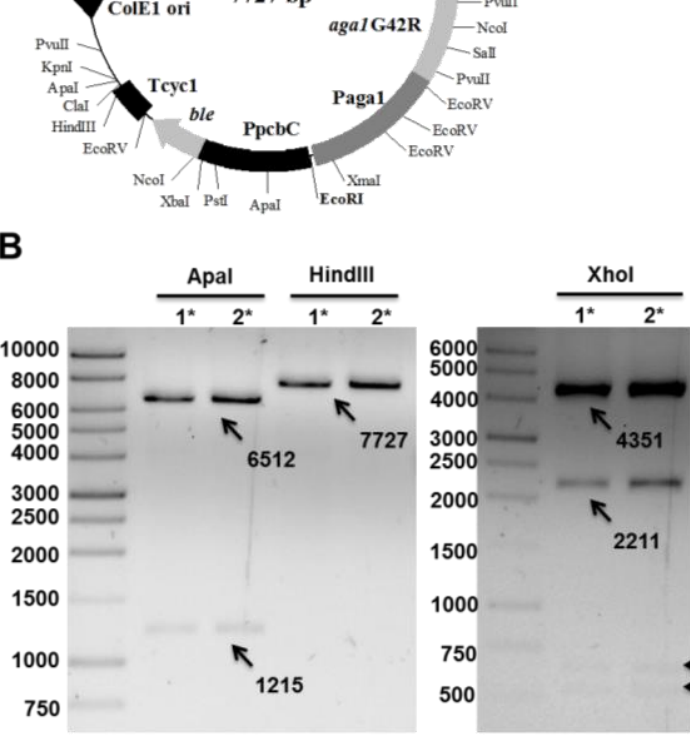

C

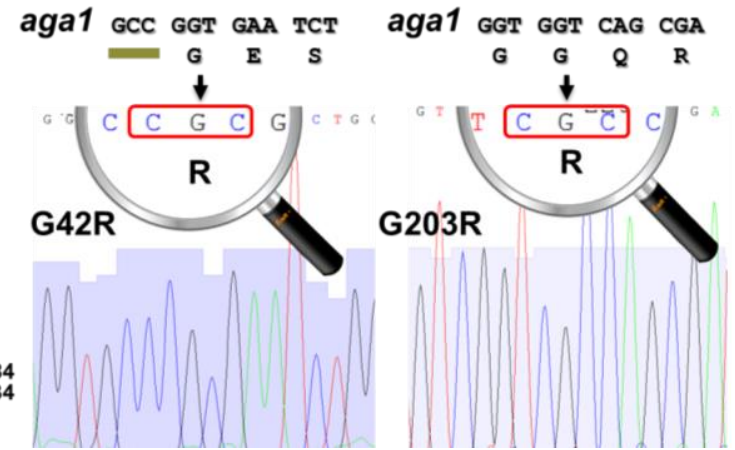

Fig. 12. Construcción de los plásmidos pC43aga1G42R y pC43aga1G203R. (A) Mapas detallados de los plásmidos mostrando regiones específicas y sitios de restricción dentro de su secuencia. (B) Análisis de restricción con endonucleasas mostrando los fragmentos de tamaños esperados. 1*: pC43aga1G42R; 2*: pC43aga1G203R. (C) Electroferogramas de los plásmidos pJETaga1G42R y pJETaga1G203R mostrando la mutación deseada (Para la secuenciación se usó el oligonucleótido Aga1-840R). 


\subsection{OBTENCIÓN DE MUTANTES DE $A$. chrysogenum ATCC 11550 CON LA SUBUNIDAD G $\alpha$ Aga1 CONSTITUTIVAMENTE ACTIVA E INACTIVA}

\subsubsection{Transformación y selección de los transformantes}

Para estudiar el papel que desempeña la subunidad $\mathrm{G} \alpha$ Aga1 en $A$. chrysogenum, se obtuvieron los alelos dominantes aga 1G42R, aga1 ${ }^{\mathrm{Q} 204 \mathrm{~L}}$ y aga1G203R, los dos primeros de activación constitutiva, y el último de inactivación constitutiva.

La transformación de $A$. chrysogenum se realizó por la técnica de protoplastos. Se evaluó la resistencia del hongo al antibiótico fleomicina, y se seleccionaron transformantes resistentes después de dos pases en placas con el doble de concentración de fleomicina $(60 \mu \mathrm{g} / \mathrm{mL})$ para asegurar el crecimiento exclusivo de transformantes verdaderas (Fig. 13 A).
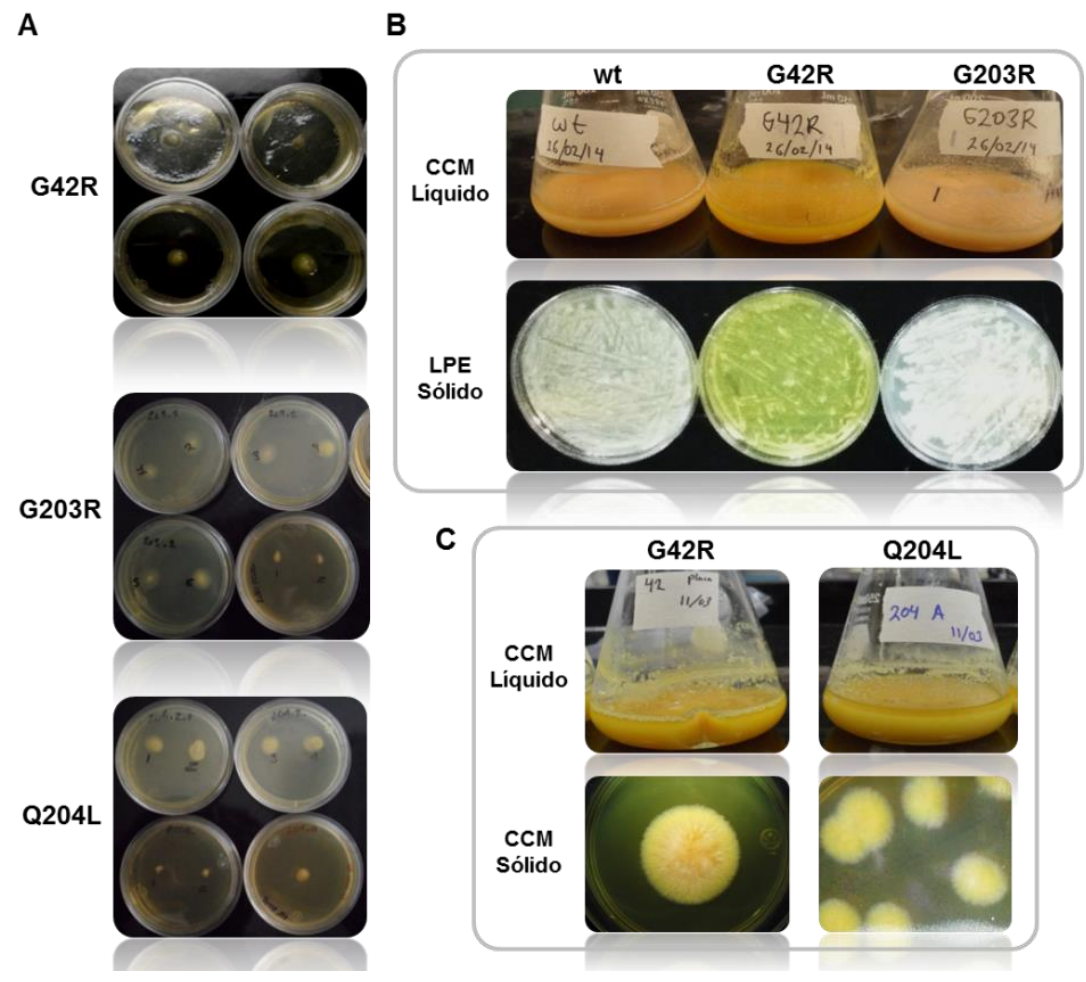

Fig. 13. (A) Transformantes obtenidas en primer pase de fleomicina. (B) Diferencias fenotípicas entre la cepa parental y las cepas mutantes G42R y G203R en medio líquido y sólido. (C) Cepas mutantes G42R y Q204L mostrando fenotipos similares en medio líquido y sólido.

Las transformantes mostraron ligeras diferencias fenotípicas (Fig. 13 B, C). La cepa parental y la cepa G203R no mostraron diferencias físicas apreciables en medio líquido y medio sólido (Fig. 13 B). Sin embargo, la mutante G42R mostró una producción de un pigmento amarillo en medio líquido y medio sólido después de las 48 horas (Fig. 13 B). Estos resultados coinciden con los reportados en la mutante 
G $\alpha(\mathrm{G} 42 \mathrm{R})$ de $P$. chrysogenum la cual produce grandes cantidades de un pigmento amarillo llamado crisogenina. Además, se reportó que la actividad de $\mathrm{G} \alpha(\mathrm{G} 42 \mathrm{R})$ estimula la producción de dos metabolitos secundarios (crisogenina y roquefortina) (García-Rico et al., 2008). Al igual que la cepa G42R, la cepa Q204L (alelo de activación constitutiva) también presentó abundante producción de pigmento amarillo en medio líquido después de las $72 \mathrm{~h}$ de crecimiento. En medio sólido ambas cepas (G42R y Q204L) tornaron la colonia de color amarillo, lo cual indica que posiblemente comparten el mismo fenotipo (Fig. 13 C). Por otra parte, el micelio de la cepa Q204L le dio una apariencia viscosa al medio de cultivo en los primeros días $(1-3$ días $)$ de crecimiento, comportamiento que no mostraron el resto de las cepas.

\subsection{ANÁLISIS GENÉTICO DE LAS TRANSFORMANTES}

\subsubsection{Comprobación de la integración de los alelos aga1 ${ }^{\mathrm{G} 42 \mathrm{R}}$, aga1 ${ }^{\mathrm{G} 203 \mathrm{R}}$ y aga1204L en las} transformantes obtenidas

La integración de los alelos aga1G42R, aga1G203R y aga19204L se comprobó mediante RT-PCR y PCR convencional. Para ello se diseñaron oligonucleótidos específicos de tal manera que las últimas 2 - 4 bases de su extremo 3'-OH reconozca el cambio de uno o dos nucleótidos correspondientes a las mutaciones introducidas en la secuencia del gen aga1 (Fig. 14 A y B).

A

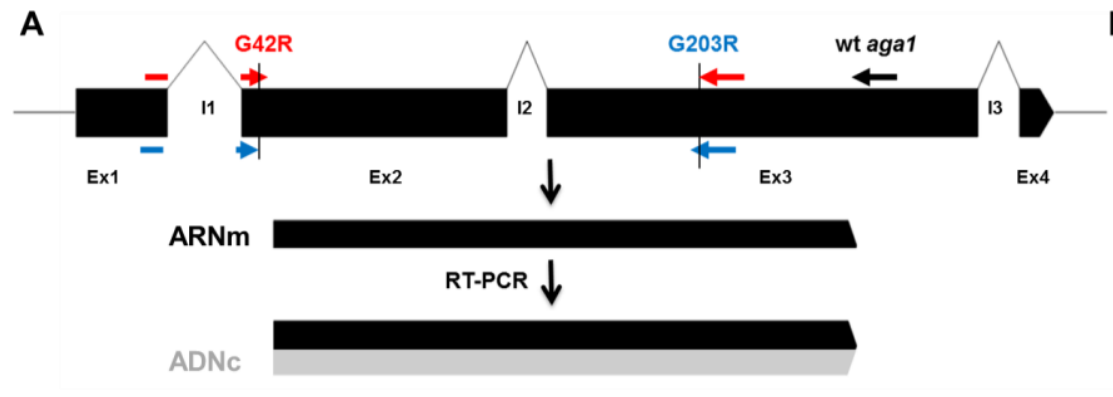

B

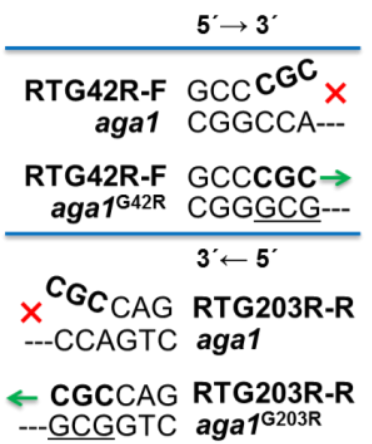

Fig. 14. Diseño de oligonucleótidos. (A) Mapa lineal de los alelos aga $1^{\mathrm{G} 42 \mathrm{R}}$ y aga ${ }^{\mathrm{G} 203 \mathrm{R}}$, y reconocimiento de oligonucleótidos a secuencias específicas de ARN mensajero (se aplicó el mismo principio para reconocer secuencias de ADN). Flechas rojas: oligonucleótidos específicos para G42R; flechas azules: oligonucleótidos específicos para G203R. Flecha negra: oligonucleótido usado como control positivo (B) Alineamiento específico de los oligonucleótidos RTG42R-F y RTG203R-R a sus alelos correspondientes. 


\subsubsection{Comprobación por RT-PCR y PCR}

Inicialmente sólo se les extrajo ARN a las cepas transformantes con los alelos aga ${ }^{\mathrm{G} 42 \mathrm{R}}$ y aga ${ }^{\mathrm{G} 203 \mathrm{R}}$ para comprobar la presencia de mutación (aún no se contaba con el alelo aga19204L). La RT-PCR se realizó usando tres temperaturas de alineamiento $\left(50,55\right.$ y $\left.60^{\circ} \mathrm{C}\right)$, logrando amplificación de bandas a 50 y $55^{\circ} \mathrm{C}$. Con esta técnica no se logró comprobar satisfactoriamente la presencia de los alelos aga1G42R y aga1G203R, ya que se obtuvieron bandas inespecíficas (Fig. 15 A). Se esperaban bandas de 525 y 523 pb para las cepas G42R y G203R, respectivamente. Sólo en la transformante G42R aparece una banda intensa cercana a las $500 \mathrm{pb}$ (banda esperada de $525 \mathrm{pb}$ ), posiblemente correspondiente al alelo aga 1G42R (Fig. 15 A). La transformante G203R presentó bandas inespecíficas a $50^{\circ} \mathrm{C}$, mientras que a $55^{\circ} \mathrm{C}$ no tuvo amplificación. Posiblemente las bandas inespecíficas fueron consecuencia de la temperatura de alineamiento o la calidad del ARN. Con el fin de mejorar la amplificación de bandas específicas se propone diseñar nuevos oligonucleótidos, mejorar la calidad del ARN, incrementar la temperatura de alineamiento (superior a $55^{\circ} \mathrm{C}$ ) y optimizar las condiciones de PCR.

Debido a que los resultados no fueron contundentes con la técnica RT-PCR se optó por realizar una PCR convencional con oligonucleótidos específicos. Se realizó un gradiente de temperaturas de alineamiento, logrando amplificación a $65.6^{\circ} \mathrm{C}$. Se obtuvieron bandas de 416 y $950 \mathrm{pb}$, las cuales corresponden a los alelos aga $1^{\mathrm{G} 42 \mathrm{R}}$ y aga $1 \mathrm{G} 203 \mathrm{R}$, respectivamente (Fig. 15 B). Cabe señalar que los controles negativos no mostraron bandas, lo cual indica que los oligonucleótidos funcionaron de manera específica contra la mutación.
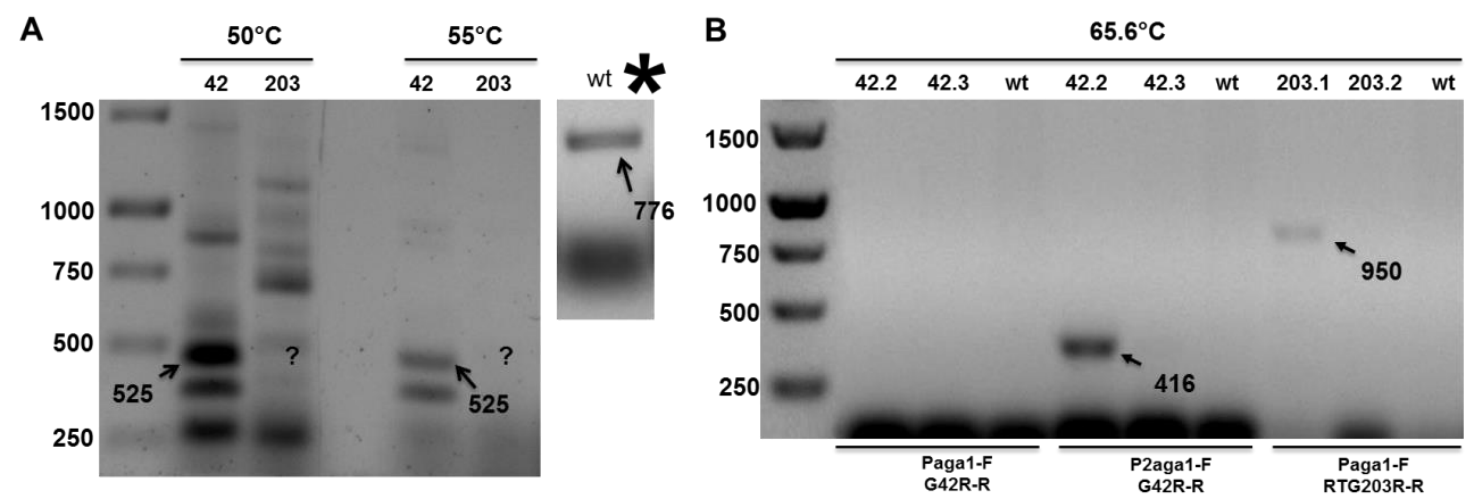

Fig. 15. (A). RT-PCR de las cepas transformantes G42R y G203R. (*) Control positivo (wt: $A$. chrusogenum) usando los oligonucleótido RTG203R-F y RT-AGAW'T-R. (B) PCR de cepas transformantes G42R y G203R. Oligonucleótidos usados Paga1-F, G42R-R, P2aga1-F y RTG203R-R (ver tabla 3).

Con respecto a la cepa Q204L, al realizar pruebas de PCR no se logró confirmar la presencia de la mutación, incluso realizando gradientes de temperatura seguían apareciendo bandas inespecíficas (datos 
no mostrados). Sin embargo, se harán más pruebas para confirmar la presencia del alelo en la cepa, utilizando en esta ocasión una Platinum Taq polimerasa en lugar de Taq polimerasa convencional, con el fin de hacer la reacción más específica y eficiente. No obstante, al mostrar todas las transformantes Q204L un fenotipo similar al esperado para una subunidad G $\alpha$ Aga1 constitutivamente activa, se decidió continuar trabajando con esta cepa.

\subsection{CARACTERIZACIÓN FENOTÍPICA DE LAS CEPAS MUTANTES DE G $\alpha$ Aga1}

\subsubsection{TASA DE EXTENSIÓN RADIAL}

\subsubsection{Estudio de la extensión radial de las cepas A. chrysogenum ATCC 11550, G42R, G203R y Aaga1}

La subunidad $\mathrm{G} \alpha$ del subgrupo I, en la mayoría de los hongos filamentosos, regula el crecimiento, por ello se decidió evaluar la tasa de extensión radial de las cepas G42R y G203R en diferentes medios sólidos. Este ensayo tiene como objetivo comprobar si la presencia de una mutación afecta el crecimiento y desarrollo del hongo a lo largo del tiempo en un medio sólido. En este estudio también se incluyó una cepa con el gen aga1 delecionado ( $\Delta a g a 1$ obtenida en nuestro laboratorio). La cepa Q204L se descartó para esta prueba debido a que no produce suficientes conidios $\left(<10\right.$ conidios $\left./ \mathrm{mm}^{2}\right)$, y por lo tanto resultó imposible llegar a un número suficiente de éstos para igualar las condiciones de las demás cepas.

Todas las cepas fueron analizadas en los medios de cultivo sólidos CCM, PDA y LPE, los cuales son comúnmente usados en $A$. chrysogenum.

Las cepas mutantes mostraron ligeras diferencias significativas en las tasas de extensión radial en los tres medios probados al compararse con la cepa parental (Fig. 16. Ver ANEXO 4).

Las cepas G42R, G203R y $\Delta a g a 1(0.053,0.051$ y $0.052 \mathrm{~mm} / \mathrm{h}$, respectivamente) no mostraron diferencias significativas entre sí en medio CCM, sin embargo, la cepa parental mostró una diferencia $(0.056 \mathrm{~mm} / \mathrm{h})$ ligeramente por arriba de la media de cepas mutantes $\left(\overline{\mathbf{x}}_{\text {mutantes }} 0.052 \mathrm{~mm} / \mathrm{h}\right)$. Por otro lado, las cepas G42R y $\Delta a g a 1$ no mostraron diferencias en PDA, mientras que la cepa parental y G203R presentaron diferencias significativas respecto al resto de las cepas. Cabe señalar que en general todas las cepas tuvieron una reducción drástica de la tasa de crecimiento en PDA $\left(\overline{\mathbf{x}}_{\text {cepas }} 0.0165 \mathrm{~mm} / \mathrm{h}\right)$, correspondiente al 30\% del observado en CCM ( $\left.\overline{\mathrm{x}}_{\text {cepas }} 0.0537 \mathrm{~mm} / \mathrm{h}\right)$.

Del mismo modo, en LPE se observaron algunas diferencias (Fig. 16). La cepa parental y la cepa G203R no presentaron diferencias ( 0.053 y $0.051 \mathrm{~mm} / \mathrm{h}$, respectivamente), mientras que G42R y $\Delta$ aga1 fueron significativamente diferentes respecto al resto de las cepas. La cepa G42R mostró una reducción en la tasa de crecimiento, correspondiente al 79\% de la cepa parental. 
Estos resultados indican que $A$. chrysogenum tiene un crecimiento lento en medio sólido, con una tasa de crecimiento que oscila entre 0.02 a $0.06 \mathrm{~mm} / \mathrm{h}$. Peberdy (1987) demostró que la velocidad de crecimiento de $A$. chrysogenum es lenta, alcanzando un diámetro de $8-15 \mathrm{~mm}$ tras 10 días de incubación (aproximadamente $0.033-0.0625 \mathrm{~mm} / \mathrm{h}$ ) en medio MEA (extracto de malta con agar), lo cual corresponde a los resultados obtenidos. Por otro lado, algunos hongos filamentosos como $P$. chrysogenum y P. roqueforti (García-Rico et al., 2007) presentan un crecimiento más acelerado (aproximadamente 0.3 a $0.6 \mathrm{~mm} / \mathrm{h}$ ) que $A$. chrysogenum. Cabe mencionar que $A$. chrysogenum fue originalmente aislado de un medio acuoso (Brotzu, 1948), por lo tanto parece estar especialmente más adaptado a este medio.

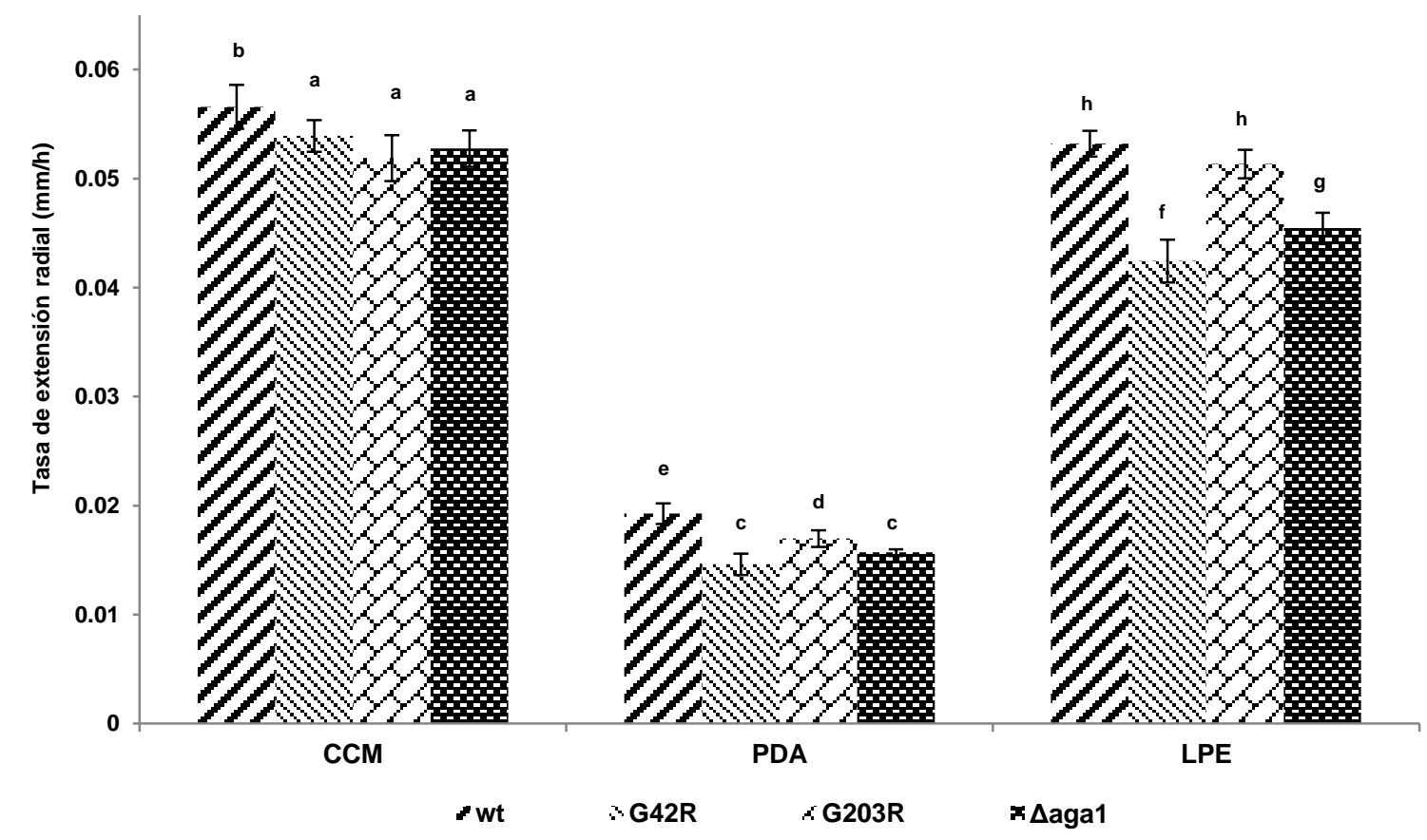

Fig. 16. Tasa de extensión radial de las cepas A. chrysogenum ATCC 11550 (wt), G42R, G203R y $\Delta a g a 1$ en los medios de cultivo sólido: CCM, PDA y LPE, después de 7 días de incubación. Las barras de error representan la desviación estándar de cuatro réplicas. Diferentes letras por medio de cultivo indican diferencias significativas $(P<0.05)$.

En general las cepas G42R, G203R y $\Delta a g a 1$ mostraron diferencias significativas respecto a la cepa parental (Ver ANEXO 4). De acuerdo a los análisis estadísticos el alelo aga1G42R afectó significativamente el crecimiento de la colonia en los medios probados respecto a la cepa parental. Este efecto se ha observado en cepas mutantes $\mathrm{G} \alpha(\mathrm{G} 42 \mathrm{R})$ de P. chrysogenum y P. roqueforti que portan el alelo aga1G42R (García-Rico et al., 2007). Sin embargo, contrastan con los reportados en A. nidulans (Yu et al., 1996; Shimizu y Keller, 2001) y M. grisea (Fang y Dean, 2000), donde no se mostraron diferencias entre las mutantes $\mathrm{G} \alpha(\mathrm{G} 42 \mathrm{R})$ respecto a la parental. 
La mutante G203R presentó diferencias significativas con respecto a la cepa parental en CCM y PDA, sin embargo, en LPE no mostraron diferencias. En la mutante $\mathrm{G} \alpha(\mathrm{G} 203 \mathrm{R})$ de $A$. nidulans se observó un efecto reducido en la tasa de crecimiento, sin embargo, en P. chrysogenum (García-Rico et al., 2007) у M. grisea (Fang y Dean, 2000) no se observaron diferencias con respecto a la cepa parental.

La cepa $\Delta a g a 1$ mostró una tasa de crecimiento siempre por debajo de la cepa silvestre. Un efecto similar se observó en la mutante $\Delta$ cpg-1 de C. parasitica, donde el diámetro de las colonias fue el 65 - 70\% de la parental (Gao y Nuss, 1996). Por otro lado, los resultados obtenidos en el ensayo contrastan con los reportados en otros hongos filamentosos como F. oxysporum (Jain et al., 2002), F. fujikuroi (Studt et al., 2013) у T. virens (Mukherjee et al., 2004), en los cuales no se observó ninguna diferencia en la tasa de crecimiento al realizar las respectivas interrupciones de los genes que codifican las subunidades $\mathrm{G} \alpha$ del subgrupo I.

Además de la tasa de extensión radial, también se evaluó la morfología de colonia de las cepas mutantes (Fig. 17). Se observaron pequeñas diferencias en el tamaño y morfología de colonia entre algunas cepas y en los diferentes medios de cultivo tras $168 \mathrm{~h}$ de crecimiento, lo cual indica que las cepas mutantes sufrieron ligeras alteraciones en su desarrollo. Las diferencias morfológicas se describen a detalle en el ANEXO 2.

En CCM la cepa parental presentó una coloración blanca en gran parte de la colonia y una ligeramente coloración amarilla la cual corresponde a un pigmento producido por $A$. chrysogenum (Fig. 17). Este pigmento amarillo es parte de su metabolismo secundario (Peberdy, 1987), como se reporta en el hongo de su misma especie A. citrinum (Giraldo et al., 2014), y en P. chrysogenum (García-Rico et al., 2007). Las cepas G42R, G203R y $\Delta a g a 1$ presentaron la misma pigmentación en el centro de la colonia, sin embargo la cepa G42R tuvo más pigmentada su superficie. En LPE las cepas mostraron un micelio ralo, y visto al microscopio era fino y de textura vellosa. La mutante G42R presentó una colonia ligeramente pequeña y de aspecto compacto. En PDA las cuatro cepas mostraron una apariencia levaduriforme con pequeñas elevaciones de aspecto crateriforme. 

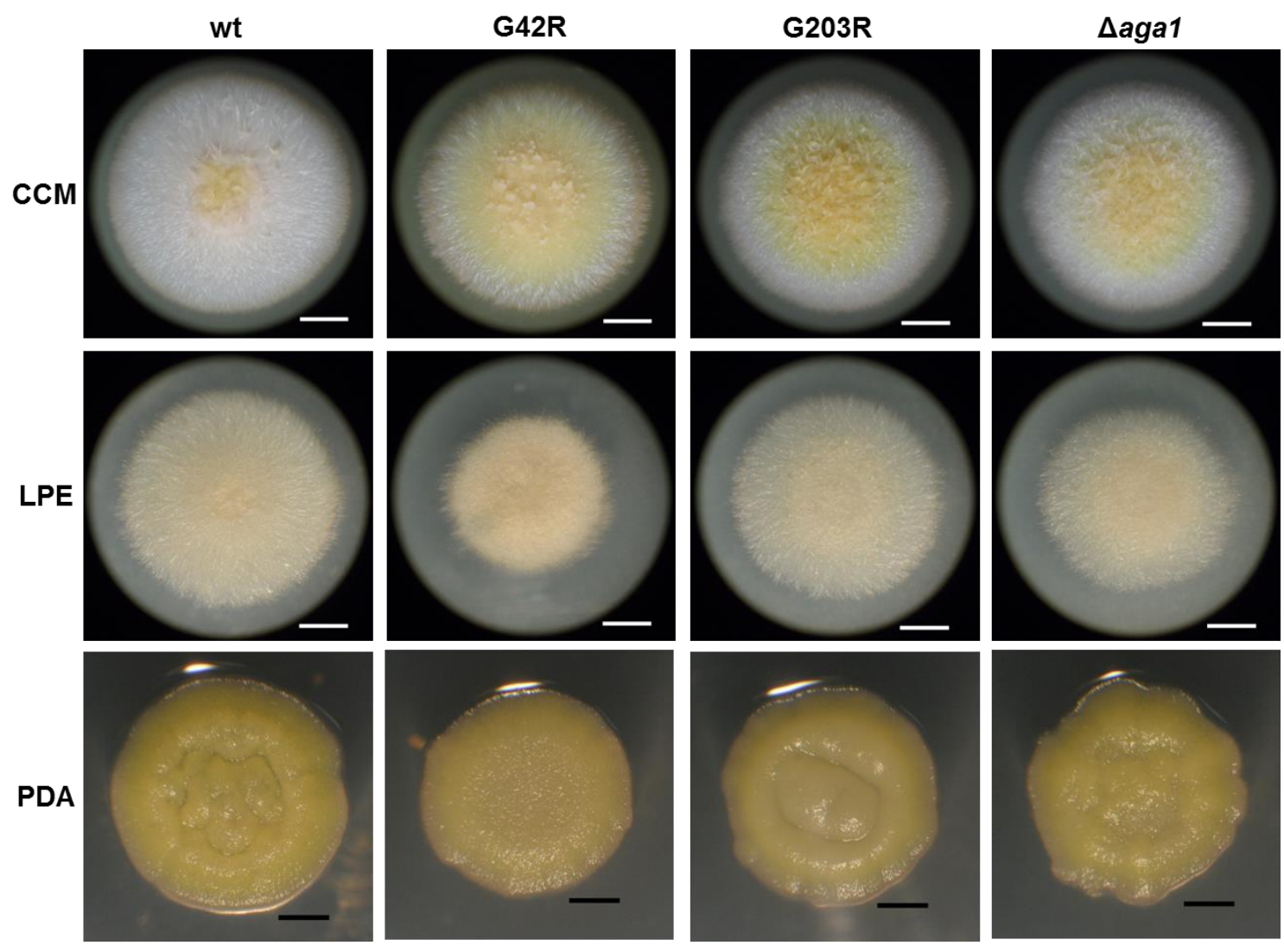

Fig. 17. Morfología de colonia de las cepas A. chrysogenum ATCC 11550 (wt), G42R, G203R y $\Delta$ aga1 en los medios de cultivo sólido CCM, LPE y PDA, tras 168 horas de crecimiento. Barras blancas: 2 mm; Barras negras: $1 \mathrm{~mm}$.

Con el fin de analizar la morfología de colonia más a detalle y observar el efecto de los alelos mutantes en las cepas G42R, G203R y $\Delta a g a 1$, se dejaron crecer en CCM durante 15 días. Aparentemente no se observaron diferencias en cuanto al tamaño de las colonias, no obstante las características fenotípicas fueron diversas (Fig. 18). La cepa silvestre y G42R compartieron un aspecto crateriforme y una textura aterciopelada, mientras que las cepas G203R y $\Delta a g a 1$ tuvieron un aspecto plano y una textura granulosa. Al ser observadas al microscopio las cepas G203R y $\Delta a g a 1$ mostraron un aspecto compacto y una textura cremosa en su superficie. Por otro lado la cepa parental tuvo una textura vellosa y aterciopelada, mientras que G42 mostró una textura cremosa en el centro de la colonia. Cabe señalar que la cepa G42R tuvo una coloración amarilla en toda la colonia, efecto característico de este alelo mutante. El pigmento amarillo fue producido en medio sólido al igual que en medio líquido por la cepa G42R (Fig. 13 B y C), por lo tanto, parece ser que su biosíntesis está regulada positivamente por la subunidad $\mathrm{G} \alpha$ Aga1. Este mismo efecto fue observado en una mutante $\mathrm{G} \alpha(\mathrm{G} 42 \mathrm{R})$ de P. chrysogenum al producir crisogenina, entre otros metabolitos secundarios (García-Rico et al., 2008). 

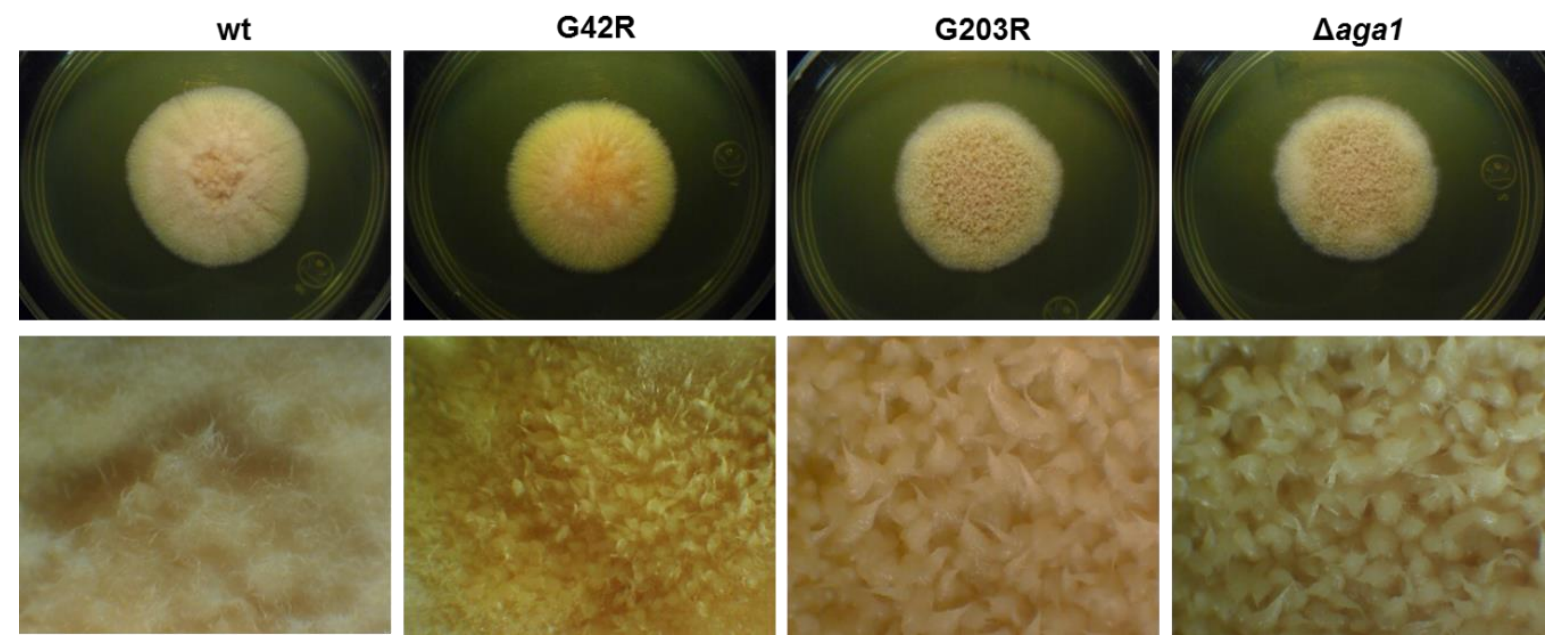

Fig. 18. Morfología de colonia de las cepas A. chrysogenum ATCC 11550 (wt), G42R, G203R y $\Delta$ aga1 en medio CCM a los 15 días de incubación.

\subsection{FORMACIÓN DE ARTROSPORAS}

\subsubsection{Efecto de la subunidad G $\alpha$ Aga1 en la formación de artrosporas}

En los hongos filamentosos se pueden distinguir dos fases importantes de crecimiento, la fase log y la fase estacionaria (Meletiadis et al., 2001). En la fase log los ápices de las hifas sufren una elongación continua debido a la incorporación de nuevo material en la pared celular (Steinberg, 2007). Durante la fase estacionaria cesa la elongación de las hifas, se producen metabolitos secundarios, y el hongo sufre cambios morfológicos importantes como la formación de artroconidios (artrosporas) a partir de hifas preexistentes (Fischer y Kües, 2006). Las artrosporas, junto con los conidióforos, son estructuras que regularmente tienen lugar durante el ciclo asexual de muchos hongos filamentosos (Martín et al., 2012). Existe una amplia variedad de hongos que forman artrosporas como parte de su diferenciación celular, por ejemplo Mucor spp. (Bartnicki y Nickerson, 1962a; Bartnicki y Nickerson, 1962b), Coccidioides spp., Trichosporon spp. (Alexopoulos y Mims, 1979), Trichophyton spp. (Bibel et al., 1977), Oidiodendron spp., Geotrichum spp., Sporendonema spp. (Cole y Kendrick, 1969), y Acremonium spp. (Bartoshevich et al., 1990; Hoff et al., 2005; Jicinska, 1974; Schell y Perfect, 1996; Summerbell et al., 2011).

A. chrysogenum presenta una fase de crecimiento vegetativo durante la fase exponencial, la cual es seguida por la fase estacionaria donde tiene lugar un proceso de diferenciación morfológica, en el cual las hifas se hinchan y forman células yeast-like o artrosporas (Karaffa et al., 1997). Esta fase de diferenciación en artrosporas coincide con la máxima tasa de producción de cefalosporina (Nash y Huber, 1971). La 
fragmentación de hifas (Fig. 19) es un proceso activo de la diferenciación celular de A. chrysogenum la cual se produce en condiciones con bajo aporte de nutrientes (Bartoshevich et al., 1990; Hoff et al., 2005). La fragmentación viene acompañada de la formación de artrosporas altamente vacuoladas y de gran tamaño a causa del consumo de la fuente de carbono (Karaffa et al., 1997; Hoff et al., 2005). Hasta el momento se desconocen los mecanismos moleculares que controlan la fragmentación de las hifas y formación de artrosporas (Martín et al., 2012).
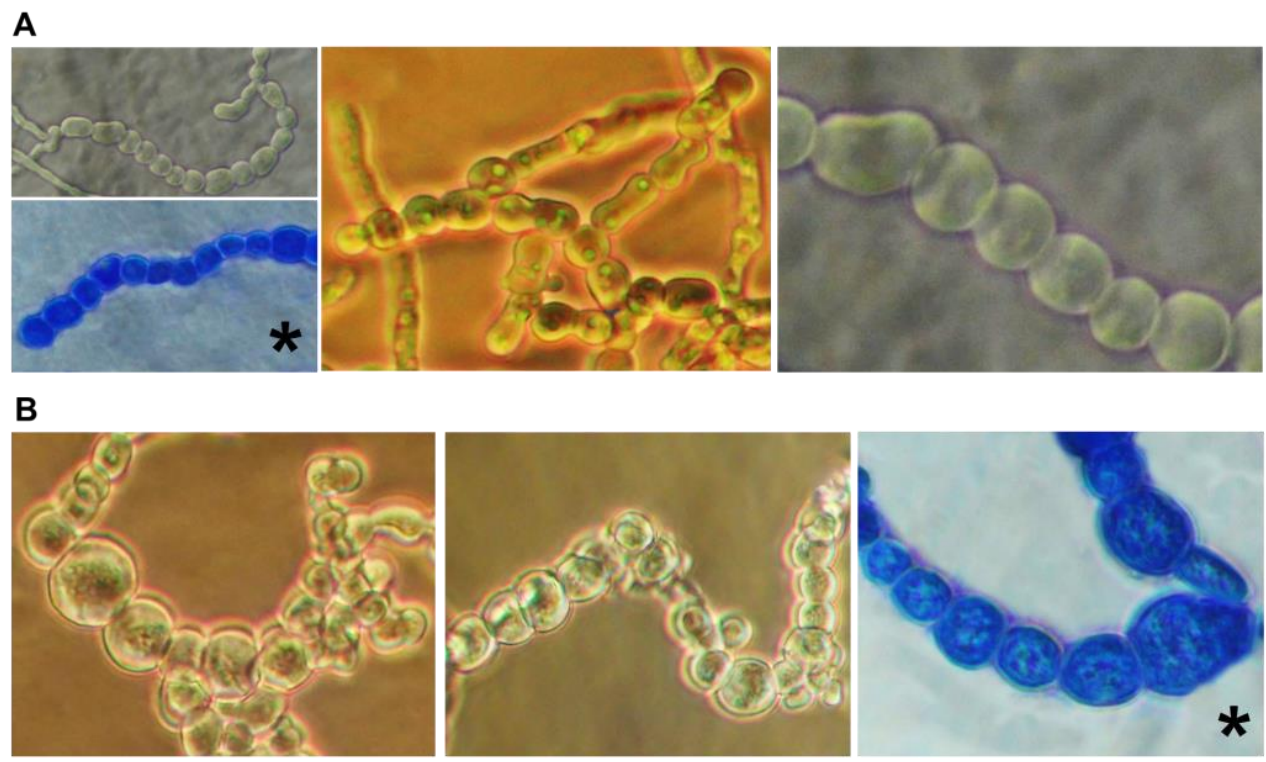

Fig. 19. Formación de artrosporas en $A$. chrysogenum ATCC 11550. Cadenas de artrosporas generadas a las $72-96$ h (A) y a las 192 h (B) en medio de cultivo líquido CCM. Los asteriscos indican cadenas de artrosporas teñidas con azul de lactofenol. Micrografías obtenidas a 100X.

En A. chrysogenum se han identificado algunos reguladores del metabolismo secundario, como AcFKH1 y CPCR1 (Hoff et al., 2005), los cuales tienen un impacto en la formación artrosporas. Del mismo modo, otros genes como AcsepH (Long et al., 2013), AcveA (Dreyer et al., 2007) y cefM (Teijeira et al., 2009) juegan un papel importante en la formación de artrosporas. Por otro lado, en algunos hongos dimórficos también se han identificado algunos reguladores de la formación de células yeast-like, como en Penicillium marneffei (Zuber et al., 2002), Histoplasma capsulatum (Nguyen y Sil, 2008) y Ustilago maydis (Kylie et al., 2005).

La subunidad $G \alpha$ del subgrupo I de las proteínas $G$ heterotriméricas regula la diferenciación celular en varios hongos filamentosos (Bolker, 1998; Schmitt et al., 2004a). Hasta el momento, hay pocos estudios que relacionan la función de la subunidad $\mathrm{G} \alpha$ con el proceso de formación de artrosporas o formación células yeast-like. En el hongo dimórfico P. marneffei se identificó el gen gas $A$, homólogo a fad $A$ de $A$. nidulans (Yu et al., 1996). Mediante análisis funcional se demostró que gas $A$ es un regulador clave del 
desarrollo asexual en P. marneffei, sin embargo, no es requerido para la formación de células yeast-like a $37^{\circ} \mathrm{C}$ (Zuber et al., 2002). Por otro lado, en N. crassa se identificó el gen gna-1, homólogo a fadA y gas $A$, y se demostró que gna-1, junto con gna-3, regulan un estado de artroconidiación, sin embargo, no es claro si las proteínas $\mathrm{G} \alpha$ regulan negativamente la formación de artroconidios (Eaton et al., 2012).

Con el fin de estudiar el papel que desempeña la señalización por la vía de las proteínas $G$ heterotriméricas en el desarrollo de $A$. chrysogenum, se decidió evaluar el efecto de la subunidad $\mathrm{G} \alpha$ Aga1 en el proceso de fragmentación de hifas y formación de artrosporas. Se estudió la morfología y la artrosporación de cuatro cepas mutantes con la función de la subunidad G $\alpha$ Agal alterada, tres de ellas conteniendo en su genoma los alelos dominantes aga $1^{\mathrm{G} 42 \mathrm{R}}$, aga $1^{\mathrm{G} 203 \mathrm{R}}$ y aga Q $^{\mathrm{Q} 204 \mathrm{~L}}$, y la cepa $\Delta a g a 1$ con el gen aga1 delecionado. El proceso de formación de artrosporas en $A$. chrysogenum no ocurre en medio sólido, por lo cual se estudió únicamente en medio líquido.

Durante el cultivo las cuatro cepas mutantes mostraron diferencias en la fragmentación de hifas y formación de artrosporas respecto a la cepa silvestre ATCC 11550. La cepa parental comenzó a formar cadenas de artrosporas a partir de las 48 horas de cultivo y después de las 72 horas la cantidad de artrosporas aumentó considerablemente respecto al resto de las cepas (Fig. 20). Las cepas G42R, G203R y $\Delta a g a 1$ presentaron un comportamiento similar entre sí, comenzaron a generar artrosporas a partir de las 72 horas de cultivo, sin embargo no dejaron de verse filamentos (hifas sin fragmentar) durante todo el tiempo de cultivo (Tabla 8, Fig. 20).

Por su parte, la cepa Q204L tuvo un comportamiento característico respecto al resto de las cepas. Al parecer su micelio mostró menos ramificaciones que en el resto de las cepas, se observaron hifas largas y delgadas en las primeras 96 horas de crecimiento, después de las 96 horas empezaron a aparecer fragmentos pequeños posiblemente debido a una fragmentación mecánica o por la edad del cultivo. Por otro lado, Q204L no formó cadenas de artrosporas, ni células yeast-like unicelulares o bicelulares a lo largo de todo el tiempo de cultivo. Incluso después de las 168 horas se mantuvo en un estado de crecimiento vegetativo sin mostrar alguna diferenciación celular (Tabla 8, Fig. 20).

Un comportamiento similar al de la cepa Q204L fue observado en $A$. chrysogenum A3/2 tras hacerle una deleción del gen $c p c \mathrm{R} 1$ (Hoff et al., 2005). El micelio de la cepa $\Delta_{c p c \mathrm{R} 1}$ no formó artrosporas durante todo el tiempo de cultivo, incluso después de las 168 horas. Con estos resultados se demostró que el factor de transcripción CPCR1 es necesario para la formación de artrosporas y posiblemente regule genes relacionados a la fragmentación de hifas tales como enzimas proteolíticas o quitinolíticas (Hoff et al., 2005). Resultará por tanto de interés comprobar si la expresión del gen $c p c R 1$, así como de otros genes cuya función está relacionada con el proceso de fragmentación de las hifas (cefM, AcsepH, AcveA), se encuentra bajo el control de G $\alpha$ Aga1, para lo cual se analizará en un futuro próximo la expresión de estos genes en los diferentes mutantes del gen aga1. El resultado de este estudio puede arrojar luz sobre 
el mecanismo mediante el cual la activación constitutiva de Aga1 suprime el proceso de formación de artrosporas. Será igualmente muy interesante relacionar el efecto de la activación constitutiva de G $\alpha$ Aga1 sobre la formación de artrosporas y sobre la producción de cefalosporina, procesos que como se ha indicado anteriormente están asociados.

Tabla 8. Resumen de los resultados correspondientes al análisis morfológico de las cepas evaluadas.

\begin{tabular}{|c|c|c|c|c|c|c|c|c|}
\hline Cepa & $\mathbf{O h}$ & $24 \mathrm{~h}$ & $48 \mathrm{~h}$ & $72 \mathrm{~h}$ & $96 \mathrm{~h}$ & $120 \mathrm{~h}$ & $144 \mathrm{~h}$ & $168 \mathrm{~h}$ \\
\hline A. chrysogenum ATCC 11550 & $f$ & $f$ & $f+a$ & $\bar{a}$ & $\bar{a}$ & $\bar{a}$ & $\bar{a}$ & $\bar{a}$ \\
\hline G42R & f & f & $f+a$ & $\mathbf{f}+\mathbf{a}$ & $\mathbf{f + a}$ & $\mathbf{f}+\mathbf{a}$ & $\mathbf{f}+\mathbf{a}$ & $f+a$ \\
\hline G203R & $f$ & f & f & $\mathbf{f}+\mathbf{a}$ & $\mathbf{f}+\mathbf{a}$ & $f-a$ & $f+a$ & $f+a$ \\
\hline Q204L & $\mathbf{f}$ & f & $\mathbf{f}$ & $\mathbf{f}$ & $\mathbf{f}$ & $\mathbf{f}$ & f & f \\
\hline$\Delta$ aga1 & $\mathbf{f}$ & $\mathbf{f}$ & $\mathbf{f}$ & $\mathbf{f}+\mathbf{a}$ & $\mathbf{f}+\mathbf{a}$ & $\mathbf{f + a}$ & $\mathbf{f}+\mathbf{a}$ & $f+a$ \\
\hline
\end{tabular}
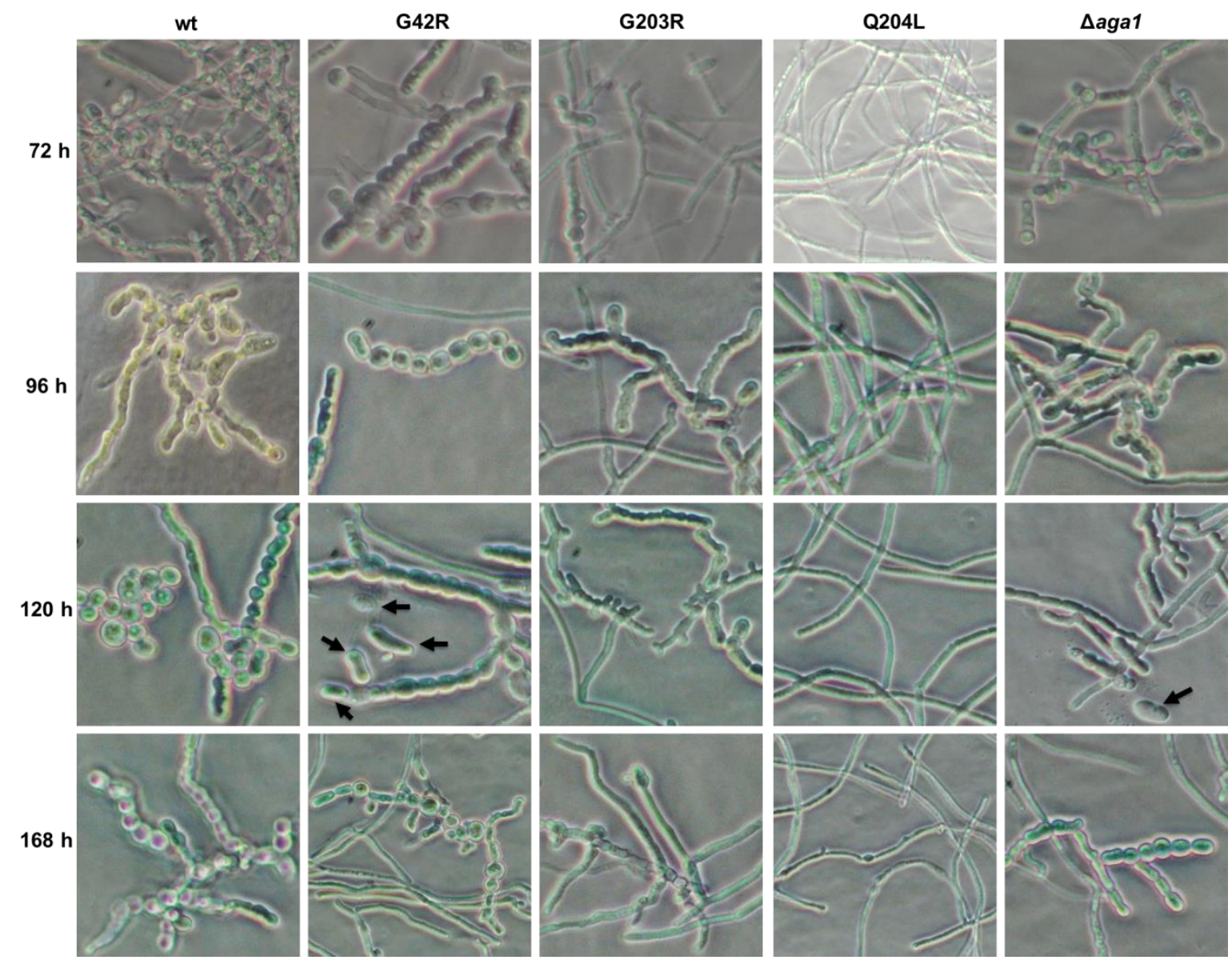

Fig. 20. Morfología de las cepas A. chrysogenum ATCC 11550 (wt), G42R, G203R, Q204L y $\Delta$ aga1. La cepa wt muestra una completa fragmentación de hifas a partir de las 72 horas, mientras que las cepas G42R, G203R y Daga1 muestran una fragmentación reducida. La cepa Q204L no presenta fragmentación incluso hasta las 168 horas del cultivo. Las flechas indican algunas artrosporas 
individuales. Las micrografías fueron tomadas directas del cultivo y observadas a 40X (Ver ANEXO 3 para más micrografías tomadas en estos tiempos).

Por otra parte, se cuantificaron las artrosporas formadas a lo largo del cultivo, y los resultados se representaron como número de artrosporas por miligramo de biomasa (Fig. 21). Se observó que las primeras cadenas de artrosporas comenzaron a aparecer entre las 24 y 48 horas en todas las cepas a excepción de la Q204L (Tabla 8, Fig. 21). El número de artrosporas a las 72 horas de cultivo en la cepa parental fue 4 veces mayor que en las cepas G42R y $\Delta a g a 1$, y 9 veces mayor que en la cepa G203R. El número de artrosporas en la cepa parental aumentó considerablemente después de las 96 horas, hasta llegar a una cuenta de $106 \times 10^{3}$ artrosporas/mg de biomasa a las 168 horas, mientras que el resto de las cepas se mantuvo por debajo de las $30 \times 10^{3}$ artrosporas por mg de biomasa.

$\mathrm{Al}$ parecer, la cepa Q204L perdió la capacidad de formar artrosporas, incluso, después de las 96 horas de cultivo había gran cantidad de micelio vegetativo, largas hifas, poco ramificadas y delgadas. Después de las 144 horas se observaron pequeños fragmentos de hifas, segmentos cortos no hinchados, probablemente generados como parte de la muerte celular. No es claro, pero es posible que este fenómeno se relacione con un efecto específico de esta mutación, ya que en $A$. nidulans se ha descrito que los alelos mutantes de activación constitutiva, incluyendo fad $A^{\mathrm{G} 42 \mathrm{R}}$, fad $A^{\mathrm{R} 178 \mathrm{~L}}$, fad $A^{\mathrm{G} 183 \mathrm{~S}}, \mathrm{fad} A^{\mathrm{R} 178 \mathrm{C}}$ y fad $A^{\mathrm{Q} 204 \mathrm{~L}}$, exhiben un fenotipo autolítico en cultivo sólido y líquido (Yu, 2006; Krijgsheld et al., 2013).

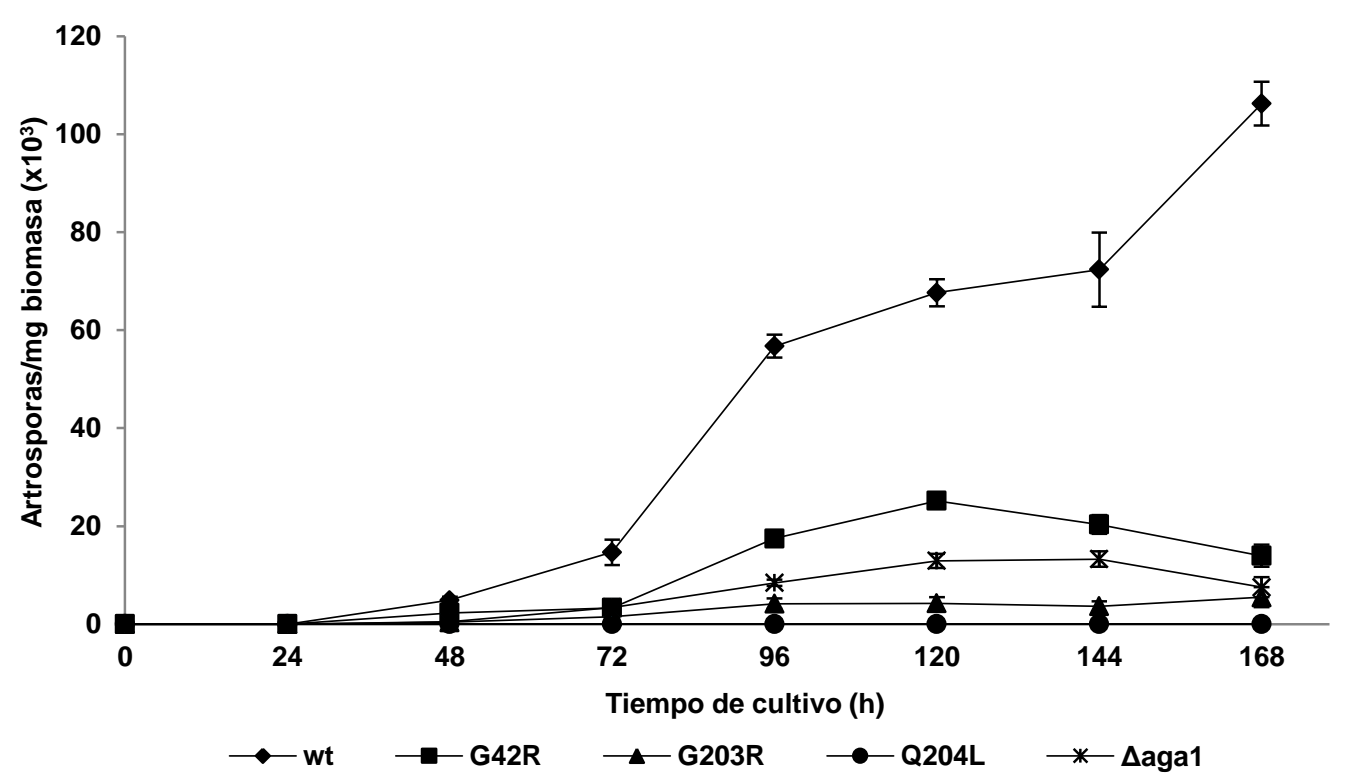

Fig. 21. Formación de artrosporas de las cepas A. chrysogenum ATCC 11550 (wt), G42R, G203R, Q204L y $\triangle a g a 1$, en medio CCM. Las barras de error representan la desviación estándar de tres réplicas. 
En general, estos resultados mostraron que los alelos de activación (aga 1G42R y aga 19204L) e inactivación (aga1G203R) constitutiva, así como la deleción ( $\triangle a g a 1)$ tuvieron un efecto negativo en la formación de artrosporas respecto a la cepa parental, lo cual indica que la subunidad G $\alpha$ Aga1 juega un papel importante en el desarrollo morfológico de $A$. chrysogenum, y que es necesario un ciclo de funcionamiento correcto de G $\alpha$ Aga1 para que el proceso de formación de artrosporas se lleve a cabo eficientemente. Cabe señalar que los alelos aga1G203R y aga1Q204L mostraron el efecto negativo más drástico en este proceso de diferenciación.

En base a lo reportado, se esperaba que las cepas G42R y Q204L tuvieran el mismo fenotipo, ya que ambos alelos (aga1G42R y aga $1^{\mathrm{Q} 204 \mathrm{~L}}$ ) generan teóricamente una subunidad G $\alpha$ Aga1 constitutivamente activa. Sin embargo, se observó que el efecto del alelo aga1Q204L fue mucho más drástico que el de aga1G42R, al bloquear completamente el proceso de formación de artrosporas. Con respecto a lo anterior, la mutante $\mathrm{G} \alpha(\mathrm{G} 42 \mathrm{R})$ se ha venido utilizando en estudios genéticos de algunas especies de hongos, como $A$. nidulans, $M$. oryzae y $P$. chrysogenum, y se ha asumido que la subunidad $G \alpha$ es deficiente en su actividad GTPasa volviéndola constitutivamente activa. Sin embargo, un estudio reciente realizado en $M$. oryzae, que abarca aspectos estructurales, bioquímicos, genéticos y funcionales, sostiene que las mutantes $\mathrm{G} \alpha(\mathrm{G} 42 \mathrm{R})$ conservan su actividad GTPasa y por lo tanto no son constitutivamente activas (Bosch et al., 2012). Además, dos modelos cristalográficos sugieren que el residuo de arginina en la posición 42 previene un cambio conformacional típico en la región del P-loop (Bosch et al., 2012). Así mismo, Bosch y colaboradores (2012) corroboraron estos supuestos con un análisis de dos mutantes $\mathrm{G} \alpha(\mathrm{G} 42 \mathrm{R}$ y $\mathrm{Q} 204 \mathrm{~L})$ de M. oryzae. Sus resultados mostraron diferencias funcionales (morfología y patogenicidad) entre estas dos. La mutante $\mathrm{G} \alpha(\mathrm{Q} 204 \mathrm{~L})$ presentó una reducción drástica de la patogenicidad comparada a la mutante $G \alpha(G 42 R)$. Por otro lado, se ha demostrado que algunas proteínas RGS estimulan la actividad GTPasa en mutantes como G $\alpha(\mathrm{R} 178 \mathrm{C})$, pero no de G $\alpha(\mathrm{Q} 204 \mathrm{~L})$, lo cual indica que la mutante $\mathrm{G} \alpha(\mathrm{Q} 204 \mathrm{~L})$ no posee actividad GTPasa, generando una subunidad $\mathrm{G} \alpha$ constitutivamente activa verdadera (Berman et al., 1996).

Las diferencias funcionales entre los alelos aga1G42R y aga1Q204L, y el hecho de que los mutantes aga $1{ }^{204 \mathrm{~L}}$ presenten un fenotipo más extremo que los mutantes aga 1G42R, parecen apoyar la hipótesis de que los resultados obtenidos por Bosch et al. (2012) en M. oryzae son aplicables a $A$. chrysogenum en cuanto al funcionamiento de estas mutaciones.

Aún no sabemos cómo la subunidad $\mathrm{G} \alpha$ Aga1 regula el proceso de formación de artrosporas, probablemente regule indirectamente genes relacionados con la fragmentación de hifas, tales como enzimas proteolíticas o quitinolíticas, o bien regulando alguno de los genes de efecto pleiotrópico mencionados anteriormente (cpcR1, AcveA, AcsepH). 


\subsection{ESTUDIOS SOBRE EL PROCESO DE CONIDIACIÓN}

\subsubsection{Conidiogénesis en $A$. chrysogenum}

El desarrollo asexual de algunos hongos ascomicetos se da por un proceso conocido como conidiación. Durante la conidiación el hongo produce esporas asexuales llamadas conidios, formadas en estructuras especializadas conocidas como conidióforos (Bayram y Braus, 2012). La conidiación es una respuesta determinada por el estado metabólico del hongo, además de estar influenciada por varios factores como la luz, el pH del medio, calcio extracelular, lesiones físicas del micelio y la presencia de compuestos orgánicos volátiles (Steyaert et al., 2010).

En $A$. chrysogenum la conidiación o esporulación es escasa. La formación de conidios se lleva a cabo por un mecanismo llamado desarrollo conidial blástico. La conidiogénesis comienza con la formación del primer conidio de forma holoblástica a partir de células especializadas llamadas conidiogénicas o fialides. El primer conidio holoblástico se forma a partir de una fiálide compartiendo la misma pared celular. La formación del resto de conidios se da de forma enteroblástica. Durante la formación de los demás conidios la punta de la fialide se rompe, de esta forma el conidio comienza a elongarse y se desarrolla por extensión del contenido citoplasmático encapsulado por una nueva pared celular distinta a la pared de la fialide. El conidio permanece en el cuello de la fiálide hasta que es liberado y alojado en la periferia de la célula conodiogénica, conformando una cabeza mucoide que retiene a los conidios producidos (Fig. 22) (Peberdy, 1987; Summerbell et al., 2011). 


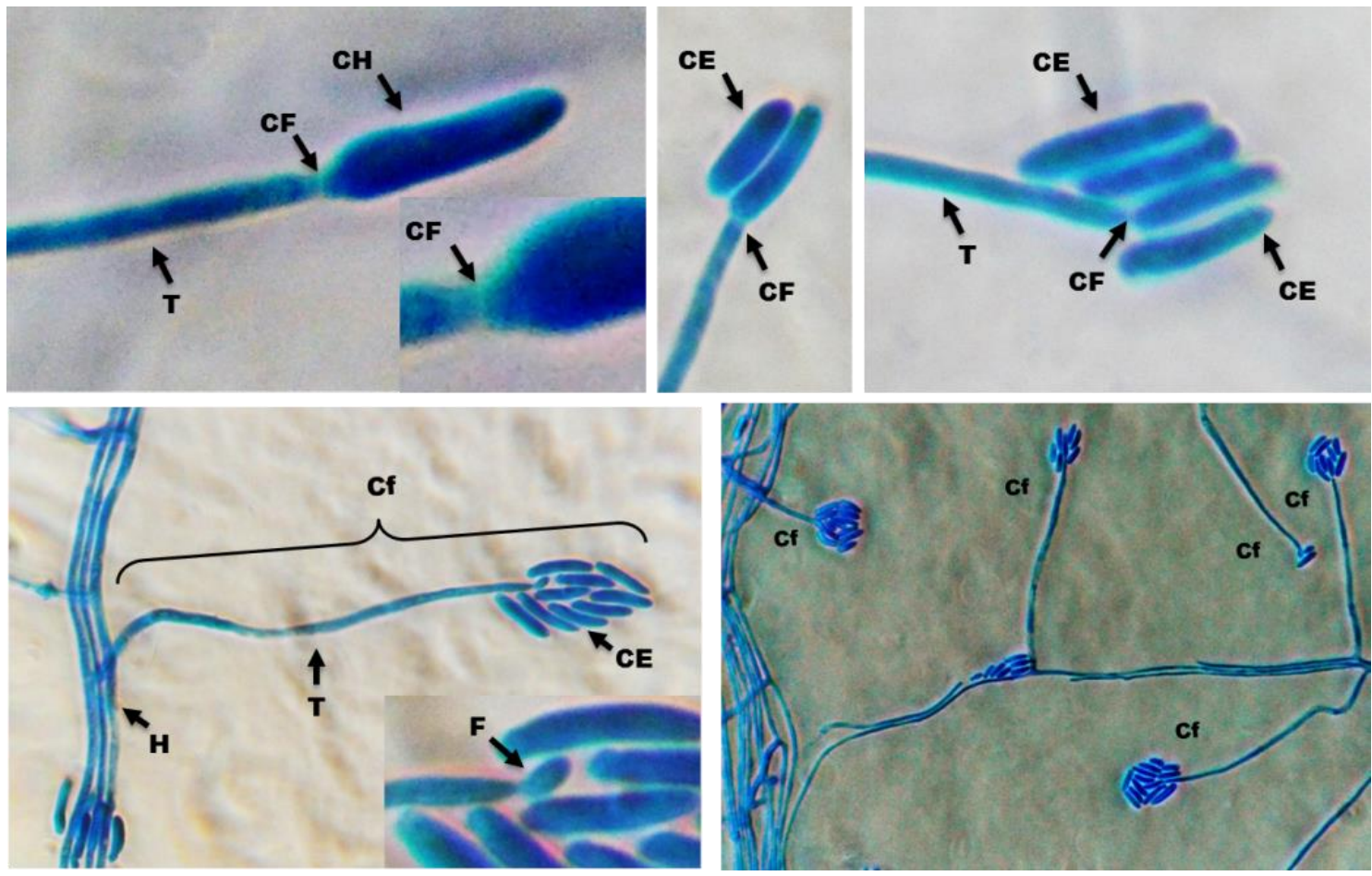

Fig. 22. Estructura conidiogénica (conidióforo) de A. chrysogenum ATCC 11550. T: tallo; CF: cuello de fialide; $\mathrm{CH}$ : conidio holoblástico; $\mathrm{CE}$ : conidio enteroblástico; $\mathrm{H}$ : hifa; Cf: conidióforo; F: fialide. Muestras provenientes de microcultivos. Tinción con azul de bromofenol.

\subsubsection{Estructuras conidiogénicas en las cepas G42R, G203R, Q204L y $\Delta$ aga1}

La figura 23 muestra las estructuras conidiogénicas obtenidas a partir de microcultivos en medio sólido LPE después de 168 horas de incubación. El medio sólido para los microcultivos fue inoculado con conidios de las diferentes cepas, y en el caso de la cepa Q204L, se inoculó con micelio vegetativo ya que no produce conidios. En las micrografías se aprecian los componentes típicos de un conidióforo de $A$. chrysogenum como mostró en la figura 21.

Aparentemente, entre las cepas se observan ligeras diferencias en el tamaño de los conidióforos y cantidad de conidios en los mismos. La cepa silvestre y la G42R presentan conidióforos de tamaño regular, mientras que las cepas G203R y $\Delta a g a 1$ muestran conidióforos más grandes y con mayor número de conidios rodeando la fialide. La cepa G42R presenta cabezas mucoides conidiogénicas irregulares, mientras que en las cepas G203R y $\Delta a g a 1$ se encuentran más ordenadas. Por su parte, la cepa Q204L no tuvo la capacidad para formar conidióforos, incluso después de las 168 horas de incubación se siguió observando sólo micelio vegetativo sin ramificar. Un efecto similar fue observado en N. crassa (Yang y Borkovich, 1999), aunque no se inhibió completamente la conidiación. El efecto negativo sobre la conidiación que mostró la cepa Q204L coincide con lo reportado en P. chrysogenum 
portando el alelo aga 1942R, el cual reduce drásticamente la conidiación hasta un 5\% del número de conidios de la cepa parental (García-Rico et al., 2007; García-Rico et al., 2008a). Cabe señalar que los alelos de activación constitutiva $m a g B^{\mathrm{G} 183 \mathrm{~S}}$, $m a g B^{\mathrm{G} 42 \mathrm{R}}$ y magB ${ }^{\mathrm{Q} 204 \mathrm{~L}}$ en $M$. grisea presentaron una hiperconidiación (Liu et al., 2007), efecto contrario al alelo aga1 ${ }^{204 L}$ en $A$. chrysogenum.

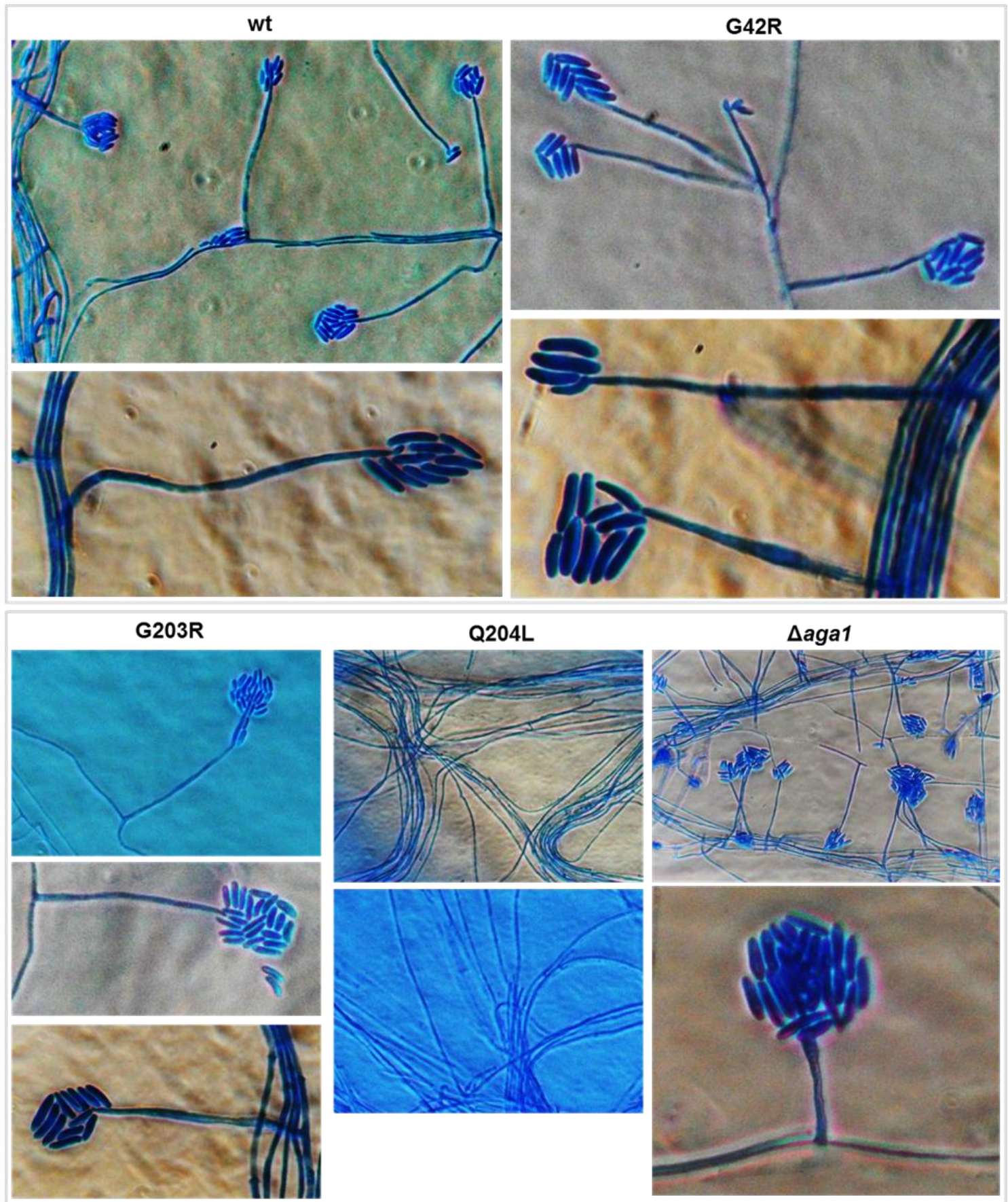

Fig. 23. Estructuras conidiogénicas de las cepas A. chrysogenum ATCC 11550 (wt), G42R, G203R, Q204L y $\Delta a g a 1$. 


\subsubsection{Efecto de la subunidad G $\alpha$ Aga1 en la conidiación}

La conidiación en $A$. chrysogenum es muy baja y se conoce poco sobre la regulación de este proceso (Schmitt et al., 2004a). En los últimos dos años, un par de publicaciones abordaron el tema de la conidiación en $A$. chrysogenum como proceso crucial de su diferenciación y desarrollo. Long y colaboradores (2012) identificaron la proteína AcSEPH relacionada a la septación, producto del gen AcsepH y homóloga de SEPH de A. nidulans (Harris et al., 1994). Este grupo observó que al interrumpir AcsepH $(\triangle A$ csepH $)$ se redujo significativamente la conidiación, 6 veces menos que la cepa tipo silvestre A. chrysogenum CGMCC 3.3795, lo cual indica que $A$ csepH es requerido para la conidiación. Por otro lado, Wang y colaboradores (2014) identificaron una proteína serina/treonina cinasa (AcATG1) implicada en la autofagia, esencial para la formación del autofagosoma en ausencia de nutrientes. Este grupo observó que al interrumpir el gen $\operatorname{Acatg1}(\Delta$ Acatg1) se reduce significantemente la formación de conidios en el medio de esporulación LPE, sin embargo, la adición de 1\% de alguna fuente de carbono (glucosa, sacarosa, manitol, inositol) restaura la conidiación casi a niveles de la cepa parental.

En nuestro caso se probaron los siguientes tres medios: CCM (medio complejo de Cephalosporium [Minuth et al., 1982]), PDA (medio agar-papa-dextrosa) y LPE (Medio de esporulación y mantenimiento; modificado de LePage y Campbell, 1946). El medio CCM (Minuth et al., 1982) es altamente complejo y contiene $1.5 \%$ de glucosa como principal fuente de carbono, fue diseñado como medio de mantenimiento y se usa generalmente para caracterizaciones fenotípicas y genotípicas. El medio PDA es un medio rico para el crecimiento de un amplio rango de hongos, es usado para el mantenimiento y caracterización de cepas fúngicas, también se usa como medio de esporulación, este medio contiene $2 \%$ de glucosa como principal fuente de carbono. El medio LPE fue diseñado exclusivamente para la esporulación de $A$. chrysogenum. Su formulación proviene de un medio de esporulación de la bacteria filamentosa Actinomyces griseus (LePage y Campbell, 1946). El medio LPE contiene $0.1 \%$ de glucosa y una elevada cantidad de $\mathrm{CaCl}_{2}(1 \%)$ como estimulante de la esporulación.

En CCM la cepa parental alcanzó una producción de $51 \times 10^{2}$ conidios $/ \mathrm{mm}^{2}$, mientras que las cepas G42R, G203R y $\Delta a g a 1$ produjeron 26, 202 y $83 \times 10^{2}$ conidios $/ \mathrm{mm}^{2}$, respectivamente. La cepa G42R presentó una reducción significativa en el número de conidios, sólo produjo el 50\% respecto a la cepa parental (Fig. 24). La mutante G42R presentó una reducción en el número de conidios, y estos resultados coinciden con los ya reportados en otros hongos filamentosos. Se ha visto que la disminución o represión de la conidiogénesis es uno de los principales efectos de una subunidad $\mathrm{G} \alpha$ constitutivamente activa como ocurre en $A$. nidulans ( $\mathrm{Yu}$ et al., 1996), C. parasitica (Segers y Nuss, 2003), P. marneffei (Zuber et al., 2002) y P. chrysogenum (García-Rico et al. 2008). Este antecedente explica el comportamiento de la mutante Q204L, incapaz de producir conidios. 
Cabe señalar que la cepa G42R produjo un pigmento amarillo a partir de las 96 horas de incubación, el cual se observa en la parte inferior de la placa de Petri (Fig. 25). Por otra parte, las cepas G203R y $\Delta a g a 1$ tuvieron mayor producción de conidios. Sin embargo, la cepa G203R mostró una hiperconidiación en este medio, ya que produjo 4 veces más conidios que la cepa parental y 8 veces más que la cepa G42R. Este comportamiento coincide con el efecto que mostró el alelo pga1G203R en P. chrysogenum alcanzando altos niveles de conidiación (García-Rico et al., 2008a; García-Rico et al., 2007). Este resultado demuestra que la subunidad G $\alpha$ Aga1 regula negativamente la conidiación.

En PDA todas las cepas mostraron diferencias significativas $(P<0.05)$. En general, la conidiación en PDA fue más reducida que en CCM, de tal forma que la cepa parental y las tres cepas mutantes G42R, G203R y $\Delta a g a 1$ formaron sólo el 6.8\%, 32\%, 5.5\% y 15\% de conidios $/ \mathrm{mm}^{2}$, respectivamente, respecto al número de conidios obtenidos en CCM (Fig. 24). Estos resultados nos muestran una disminución drástica de la conidiación en PDA, en contraste con los otros medios probados. Aún no es claro, pero al parecer los componentes del medio no favorecen ni la conidiación, ni el crecimiento radial como se describió en la sección 6.4. Resultó interesante observar que la cepa G42R alcanzó niveles de conidiación similares a la cepa G203R y $\Delta a g a 1$ superando incluso a la parental. Cabe señalar que en PDA se estimuló la producción de un pigmento amarillo difusible sólo en la cepa parental y G42R, aunque en esta última la pigmentación fue baja (Fig. 25).

Aunque está reportado otro medio complejo de esporulación (Nash y Pieper, 1974) para A. chrysogenum, el medio LPE es el más usado para la obtención de conidios. El medio LPE es característico debido a que contiene poca glucosa $(0.1 \%)$ y una elevada cantidad de $\mathrm{CaCl}_{2}(1 \%=90 \mathrm{mM})$, el cual puede estimular la conidiación. Se ha descrito que la conidiación puede ser inducida por niveles de calcio extracelular (Hadley y Harrold, 1958), el tipo de fuente de nitrógeno (Morton, 1961) y por agotamiento de glucosa (Pitt y Mosley, 1986). La conidiación inducida por calcio se describe como un proceso que consta de dos fases, una fase de crecimiento inicial en la cual el hongo alcanza la capacidad para inducir la conidiación y la segunda fase después de la inducción por calcio, que consiste de una secuencia de cambios morfogénicos que conducen a la formación de conidios (Foster et al., 1945). Respecto a lo anterior, se observó en $P$. notatum que la conidiación puede ser inducida con la adición de calcio (0.5 5.0\%) al medio sumergido (Foster et al., 1945). También, se demostró en P. cyclopium que el calcio no actúa como inductor directo de la conidiación, sino que acelera la acción de un autoinductor llamado conidiogenona (Roncal et al., 2002). Por otro lado, en P. camemberti fue demostrado que las condiciones más favorables para la conidiación en medio sólido fueron la ausencia de nitrógeno y la adición de calcio $\left(15 \mathrm{mM} \mathrm{CaCl}_{2}\right.$ ) al medio (Krasniewski et al., 2006). 
Estos resultados parecen indicar que el calcio desempeña un papel directo e indirecto en la producción de conidios, al menos en algunos hongos, por lo tanto, resultó interesante estudiar la conidiación en $A$. chrysogenum portando alelos implicados en este proceso.

Al estudiar la conidiación de $A$. chrysogenum en LPE, se observó una gran diferencia entre la cepa parental y las cepas mutantes. La cepa parental produjo $36 \times 10^{2}$ conidios $/ \mathrm{mm}^{2}$, lo cual corresponde al 33, 26 y 28\% de los conidios producidos por las cepas G42R, G203R y $\Delta$ aga1, respetivamente (Fig. 24). Las cepas G203R y $\Delta a g a 1$ no mostraron diferencias significativas, y como era de esperarse, y observado en otros hongos filamentosos, mostraron un fenotipo hiperesporulado.

En lo que respecta a la cepa G42R, cabe señalar que alcanzó niveles de conidiación inesperados, incluso mayor a la cepa parental. Este resultado contrasta con lo reportado en algunos hongos ya que el alelo aga1G42R de activación constitutiva debería regular negativamente la formación de conidios. Sin embargo, coincide con un estudio realizado en $M$. grisea, donde el alelo mag $B^{\mathrm{G} 42 \mathrm{R}}$ muestra altos niveles de conidiación respecto a la cepa silvestre (Liu et al., 2007).

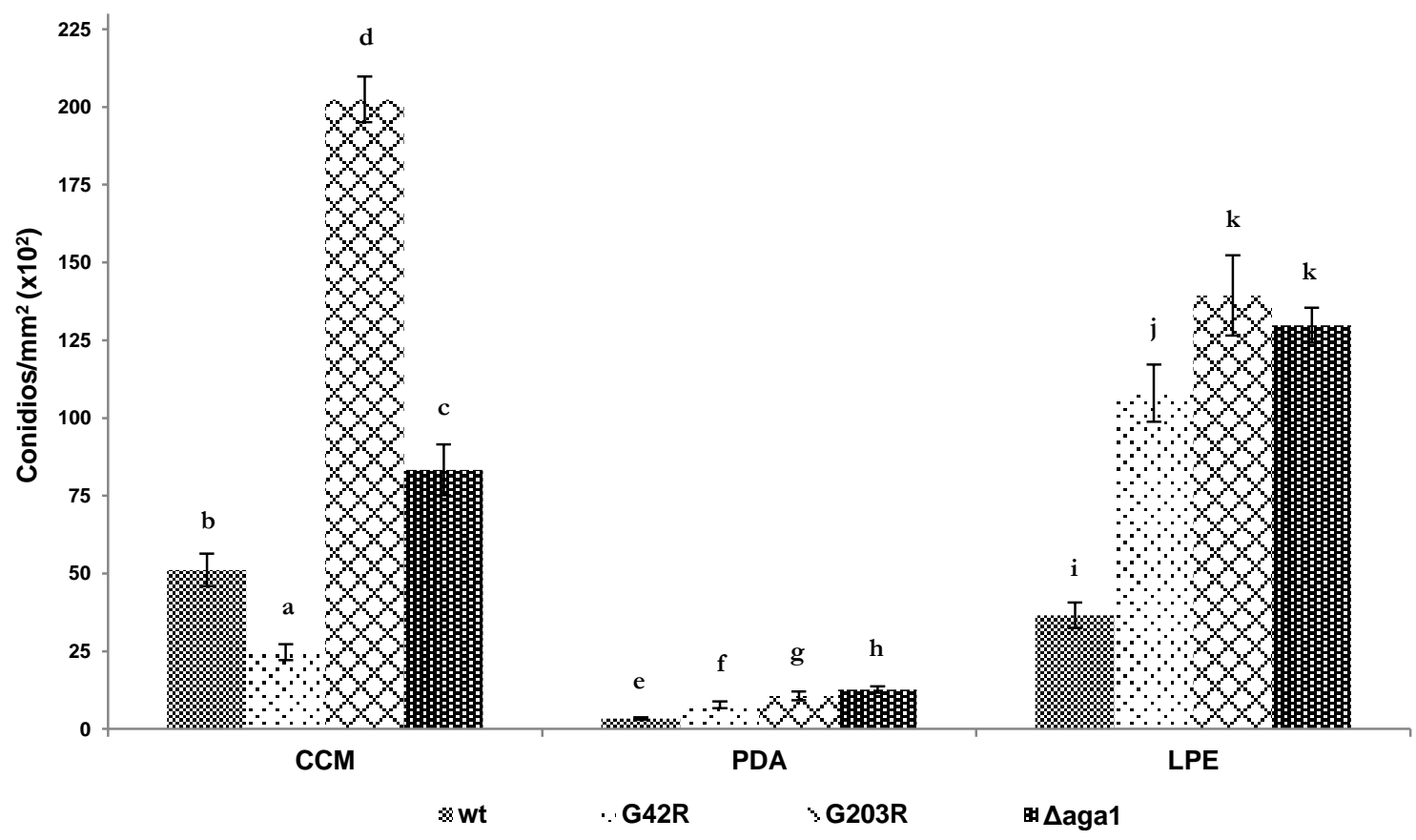

Fig. 24. Formación de conidios en A. chrysogenum ATCC 11550 (wt) y las cepas mutantes G42R, G203R y $\Delta a g a 1$ en los medios CCM, PDA y LPE después de 7 días de incubación. Las barras de error representan la desviación estándar de tres réplicas. Diferentes letras por medio de cultivo indican diferencias significativas $(P<0.05)$. 


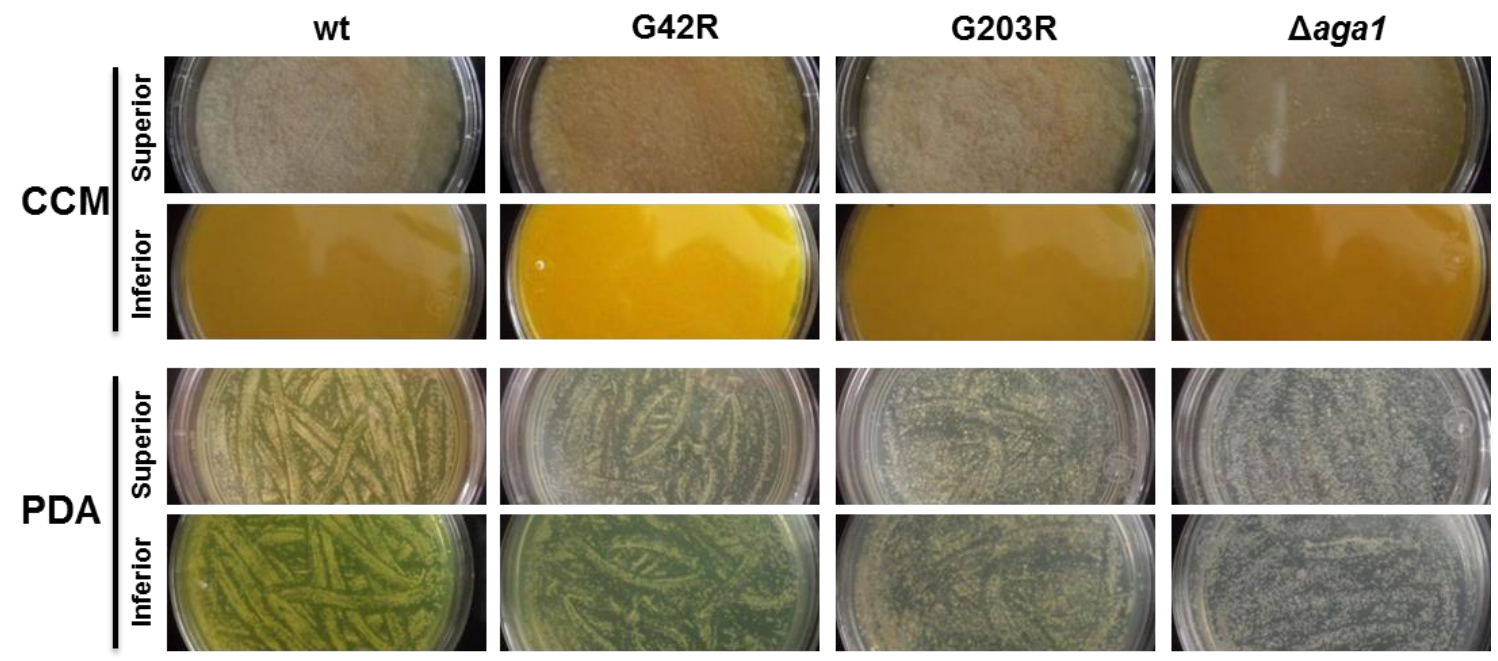

Fig. 25. Fenotipo de $A$. chrysogenum ATCC 11550 y las cepas mutantes G42R, G203R y $\Delta$ aga1 en medio CCM y PDAE después de 7 días de incubación.

Al comparar el comportamiento de la cepa silvestre con el de las cepas G203R y $\Delta a g a 1$ queda claro que la subunidad $\mathrm{G} \alpha$ Aga1 tiene un efecto negativo sobre la conidiación, ya que su funcionamiento normal provoca una conidiación reducida con respecto a las cepas G203R y $\Delta a g a 1$, donde G $\alpha$ Aga1 no es funcional. Por otro lado, la cepa G42R presentó el fenotipo esperado sólo en el medio CCM, una reducción en el número de conidios respecto a la cepa parental, mientras que en LPE mostró una hiperconidiación. Este contraste en la cepa G42R, nos llevó a realizar otro análisis en el cual se ensayaron dos cambios al medio LPE, esto con el fin de observar si la cepa G42R es sensible al calcio o su efecto negativo mostrado en CCM sobre la conidiación es disfrazado por un efecto represor debido a la cantidad de glucosa. Se ha descrito que la conidiación puede ser regulada por carbono, ya que puede ser inducida o inhibida por la disponibilidad de glucosa. Esta regulación puede ocurrir a nivel transcripcional ejerciendo un efecto represor sobre genes relacionados con la conidiación (Ebbole, 1998).

Se le hicieron dos modificaciones al medio LPE, la primera consistió en eliminar el calcio (medio M2) y en la segunda al medio M2 se le cambió el porcentaje de glucosa (medio M3), de 0.1\% a 1.5\% (misma cantidad de glucosa que en CCM donde la G42R mostró una conidiación reducida). Cabe señalar que la composición de LPE es muy simple (glucosa $0.1 \%$, extracto de levadura $0.2 \%, \mathrm{NaCl} 0.15 \%$ y $\mathrm{CaCl}_{2}$ $1 \%$ ) y la complejidad es dada por el extracto de levadura, que tiene una concentración de sólo un $0.2 \%$, por lo tanto, el medio LPE en sí tiene bajo contenido de nutrientes.

Como se muestra en la figura 26, la conidiación en la cepa parental puede ser inducida por calcio y posiblemente reprimida por glucosa. En LPE la cepa parental alcanzó niveles de 36.5 x102 conidios $/ \mathrm{mm}^{2}$, mientras que en M2 produjo $8 \times 10^{2}$ conidios $/ \mathrm{mm}^{2}$, aproximadamente el $22 \%$ respecto a 
LPE (Fig. 26), lo cual muestra una disminución de conidios de más del 70\% en ausencia de calcio (M2). En M3 también presentó una conidiación reducida $\left(6.8 \times 10^{2}\right.$ conidios $\left./ \mathrm{mm}^{2}\right)$, mostrando una ligera diferencia significativa con respecto a M2 (Ver ANEXO 4). Con respecto a lo anterior, Wang y colaboradores (2014) observaron que algunas fuentes de carbono, incluyendo la glucosa (1\%), reprimen ligeramente la formación de conidios. Por otro lado, las cepas G42R, G203R y Daga1 también mostraron un descenso de la conidiación en M2, sin embargo, siguen conservando la hiperconidiación respecto a la cepa parental (Fig. 26). Las cepas G203R y $\Delta$ aga1 mantuvieron su comportamiento hiperesporulado en los tres medios probados (LPE, M2 y M3) mientras que la cepa G42R lo mantuvo sólo en LPE y M2.

En M3 la cepa G42R presentó una reducción drástica de la conidiación, produciendo aproximadamente $2 \times 10^{2}$ conidios $/ \mathrm{mm}^{2}$, una cantidad extremadamente baja equivalente al $1.8 \%$ de los conidios producidos en LPE $\left(111 \times 10^{2}\right.$ conidios $\left./ \mathrm{mm}^{2}\right)$. Cabe señalar que el fenotipo de G42R en M3 se corresponde con los resultados publicados en otros hongos, sin embargo, parece ser que G42R se comporta de forma similar a las cepas G203R y $\Delta a g a 1$, porque en presencia de calcio alcanza altos niveles de conidiación, incluso en LPE produce una gran cantidad de conidióforos como el resto de las cepas (Fig. 27). Con estos resultados podría concluirse que el efecto negativo en la conidiación mostrado en G42R es regulado por la cantidad de glucosa en el medio y no por la mutación.

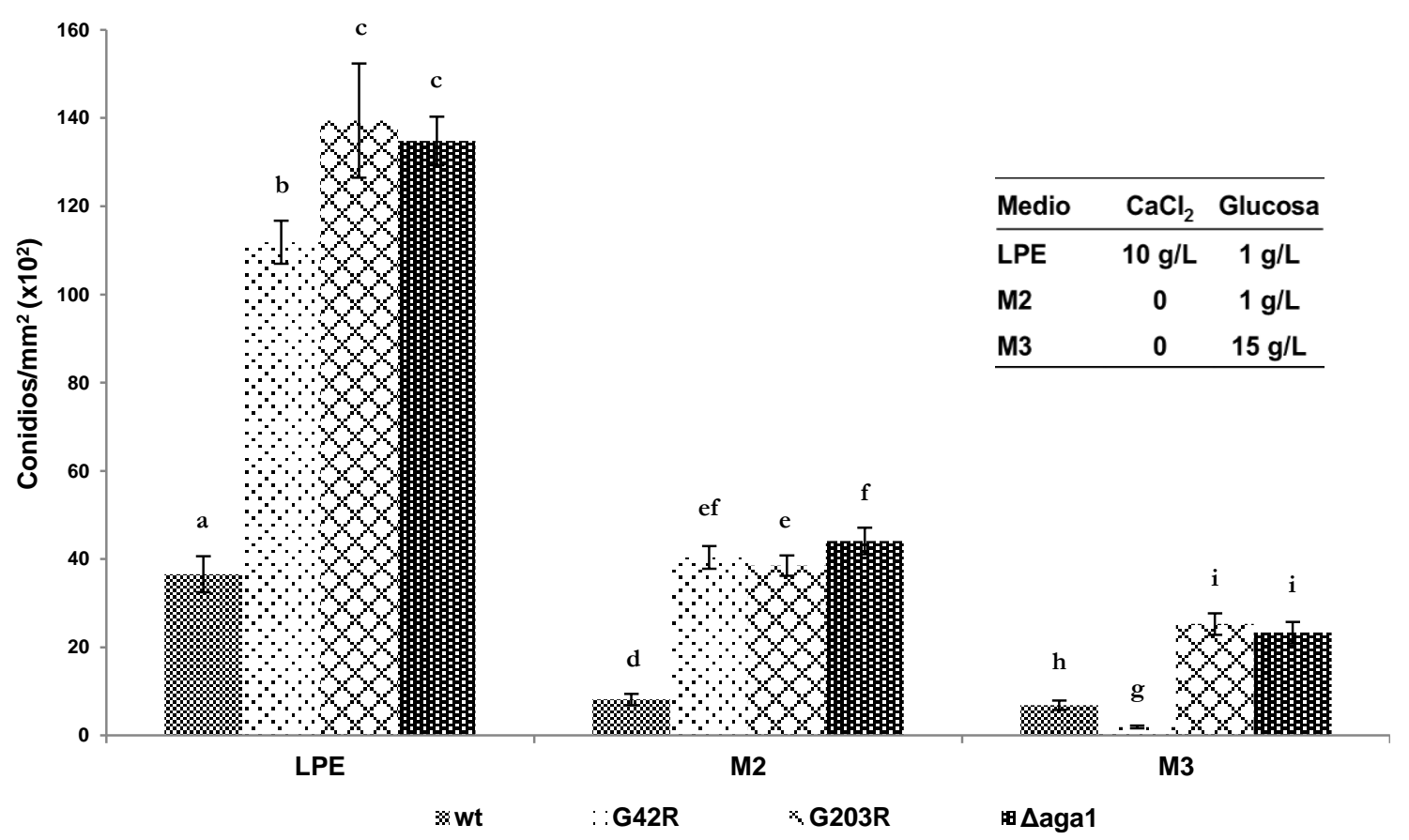

Fig. 26. Producción de conidios en A. chrysogenum ATCC 11550 (wt) y las cepas mutantes G42R, G203R y $\Delta a g a 1$ en los medios LPE, M2 y M3 después de 7 días de incubación. Las barras de error 
representan la desviación estándar de tres réplicas. Diferentes letras por medio de cultivo indican diferencias significativas $(P<0.05)$.
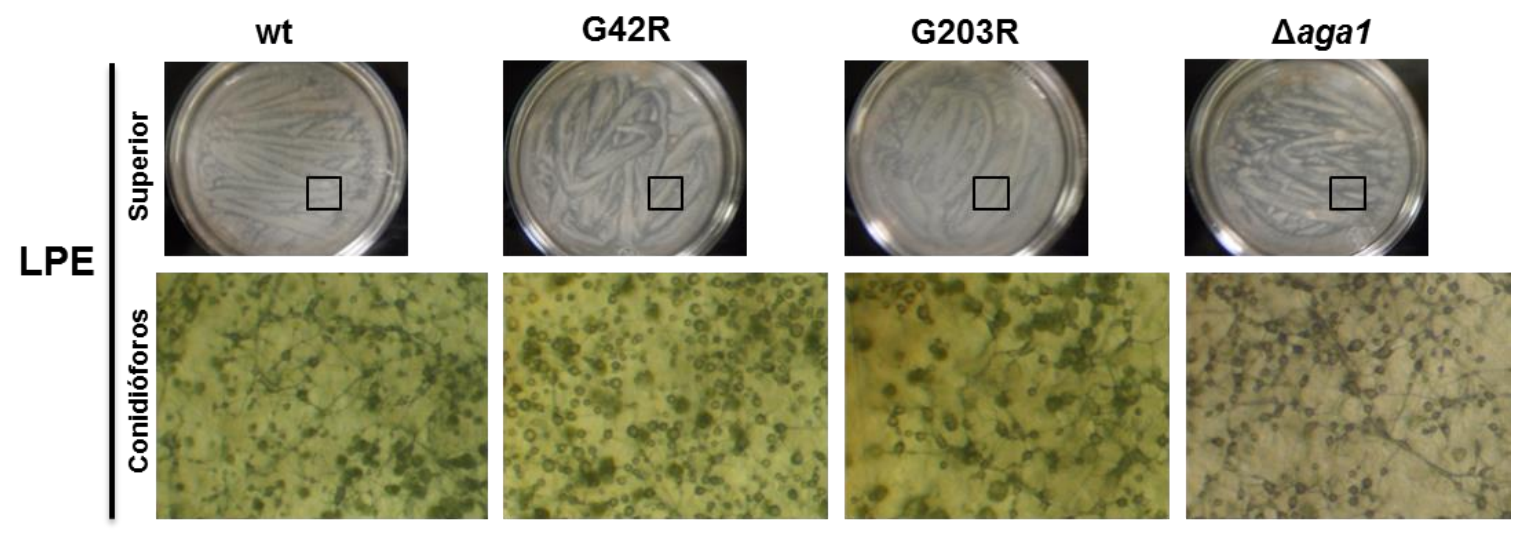

Fig. 27. Formación de conidióforos en A. chrysogenum ATCC 11550 (wt) y las cepas mutantes G42R, G203R y $\Delta a g a 1$ en medio LPE después de 7 días de incubación.

En general la subunidad $\mathrm{G} \alpha$ del subgrupo I ha sido estudiada ampliamente y ha mostrado tener diversas funciones en los hongos filamentosos. Hay ejemplos claros sobre activación o represión del metabolismo secundario, aumento o reducción de los niveles de conidiación, inducción o bloqueo de la patogénesis, en fin, esto es resultado de un efecto pleiotrópico. Los mecanismos que regulan estos procesos aun no son claros, y éstos pueden llegar a ser diferentes en cada microorganismo. Incluso, dentro de la misma especie la regulación del metabolismo secundario, el desarrollo y la patogenicidad han llegado a ser diferentes como se ha descrito ya en varias publicaciones. 


\section{CONCLUSIONES}

- Se obtuvo el alelo de activación constitutiva aga1Q204L.

- Se obtuvieron cepas transformantes de A. chrysogenum que expresan una subunidad G $\alpha$ Aga1 constitutivamente activa (G42R y Q204L) o constitutivamente inactiva (G203R).

- El efecto de los alelos aga 1942R, aga 1204L y aga $1^{\mathrm{G} 203 \mathrm{R}}$ mostró diferencias significativas en la tasa de crecimiento radial en los medios ensayados, lo que indica que $\mathrm{G} \alpha$ Aga1 regula el desarrollo vegetativo del hongo.

- Ga Aga1 regula el proceso de formación de artrosporas, siendo necesario un ciclo normal de funcionamiento de esta subunidad $G \alpha$ para que el proceso se desarrolle de manera eficiente.

- Ga Aga1 regula negativamente la conidiación, ya que la ausencia de actividad en G $\alpha$ Aga1 incrementa los niveles de conidiación, mientras que la activación constitutiva la suprime.

- Las mutaciones G42R y Q204L de G $\alpha$ Aga1 no son equivalentes, siendo Q204L aparentemente una mutación auténtica de activación constitutiva, mientras que G42R no muestra un efecto claro. 


\section{REFERENCIAS}

1. Abraham E. 1990. Selective reminiscences of beta-lactam antibiotics: early research on penicillin and cephalosporins. Bioessays. 12(12):601-606.

2. Alexopoulos C. J., y C. W. Mims. 1979. Introductory mycology, third edition. John Wiley \& Sons, Inc., New York.

3. Barr F. A, A. Leyte, y W. B. Huttner. 1992. Trimeric G proteins and vesicle formation. Trends. Cell. Biol. 2(4):91-4.

4. Bartnicki G. S., y W. J. Nickerson. 1962a. Induction of yeast-like development in Mucor by carbon dioxide. J. Bacteriol. 84:829-840.

5. Bartnicki G. S., y W. J. Nickerson. 1962b. Nutrition, growth, and morphogenesis of Mucor rouxii. J. Bacteriol. 84:841-852

6. Bartoshevich Y. E., P. L. Zaslavskaya, M. J. Novak, y O. D. Yudina. 1990. Acremonium chrysogenum differentiation and biosynthesis of cephalosporin. J. Basic. Microbiol. 30:313-320.

7. Bayram Ö., y G. H. Braus. 2012. Coordination of secondary metabolism and development in fungi: the velvet family of regulatory proteins. FEMS Microbiol. Rev. 36(1):1-24.

8. Berman D. M., T. M. Wilkie, y A. G. Gilman. 1996. GAIP and RGS4 are GTPaseactivating proteins for the $G_{i}$ subfamily of $G$ protein alpha subunits. Cell. 86:445-452.

9. Bibel D. J., D. A. Crumrine, K. Yee, y R. D. King. 1977. Development of arthrospores of Trichophyton mentagrophytes. Infect. Immun. 15:958-971.

10. Bok J. W., y N. P. Keller. 2004. LaeA, a regulator of secondary metabolism in Aspergillus spp. Eukaryot. Cell. 3:527-535.

11. Bok J. W., S. A. Balajee, K. A. Marr, D. Andes, K. F. Nielsen, J. C. Frisvad, y N. P. Keller. 2005. LaeA, a regulator of morphogenetic fungal virulence factors. Eukaryot. Cell. 4:15741582.

12. Bok J. W., D. Noordermeer, S. P. Kale, y N. P. Keller. 2006. Secondary metabolic gene cluster silencing in Aspergillus nidulans. Mol. Microbiol. 61:1636-1645.

13. Bolker M. 1998. Sex and crime: heterotrimeric $G$ proteins in fungal mating and pathogenesis. Fungal Genet. Biol. 25:143-156.

14. Bosch D. E., F. S. Willard, R. Ramanujam, A. J. Kimple, M. D. Willard, N. I. Naqvi, y D. P. Siderovski. 2012. A P-loop mutation in $\mathrm{G} \alpha$ subunits prevents transition to the active state: implications for G-protein signaling in fungal pathogenesis. PLoS Pathog. 8(2):e1002553.

15. Brotzu G. 1948. Ricerche Su di un Nuovo Antibiotico. LavoriDell'Instituto D'Igiene du Cagliari. 1-11.

16. Campbell P. M., y C. J. Der. 2004. Oncogenic Ras and its role in tumor cell invasion and metastasis. Semin. Cancer. Biol. 14:105-114. 
17. Cole G. T., y W. B. Kendrick. 1969. Conidium ontogeny in hyphomycetes. The arthrospores of Oidiodendron and Geotrichum, and the endoarthrospores of Sporendonema. Can. J. Bot. 47:1773-1780.

18. Coleman D. E, A. M. Berghuis, E. Lee, M. E. Linder, A. G. Gilman, y S. R. Sprang. 1994. Structures of active conformations of $\mathrm{G}_{\mathrm{i} \alpha 1}$ and the mechanism of GTP hydrolysis. Science 265:1405-1412.

19. Dreyer J, H. Eichhorn, E. Friedlin, H. Kürnsteiner, y U. Kück. 2007. A homologue of the Aspergillus velvet gene regulates both cephalosporin $\mathrm{C}$ biosynthesis and hyphal fragmentation in Acremonium chrysogenum. Appl. Environ. Microbiol. 73(10):3412-22.

20. Eaton C. J., I. E. Cabrera, J. A. Servin, S. J. Wright, M. P. Cox, y K. A. Borkovich. 2012. The guanine nucleotide exchange factor RIC8 regulates conidial germination through $\mathrm{G} \alpha$ proteins in Neurospora crassa. PLoS One. 7(10):e48026

21. Ebbole D. J. 1998. Carbon catabolite repression of gene expression and conidiation in Neurospora crassa. Fungal Genet. Biol. 25:15-21.

22. Fang E. G., y R. A. Dean. 2000. Site-directed mutagenesis of the magB gene affects growth and development in Magnaporthe grisea. Mol. Plant. Microbe. Interact. 13:1214-1227.

23. Fischer R., y U. Kües. 2006. Asexual Sporulation in Mycelial Fungi, p. 263-285. U. Kües y R. Fischer (Ed.). The Mycota. vol. I: growth, differentiation and sexuality. Springer, Berlin, Germany.

24. Foster J. W., L. E. McDaniel, H. B. Woodruff, y J. L. Stokes. 1945. Microbiological aspects of penicillin. V. Conidiospore formation in submerged cultures of Penicillium notatum. J. Bacteriol. 50:365-368.

25. Gams W. 1971. Cephalosporium-artige Schimmelpilze (Hyphomycetes). Fischer Verlag G (Ed.). Stuttgart, 262 pp.

26. Gao S., y D. Nuss. 1996. Distinct role for two $G \propto \alpha$ subunits in fungal virulence, morphology, and reproduction revealed by targeted gene disruption. Proc. Natl. Acad. Sci. 93:14122-14127.

27. García-Rico R. O., J. F. Martín, y F. Fierro. 2007. The pga1 gene of Penicillium chrysogenum encodes a heterotrimeric $G$ protein alpha subunit that controls growth and development. Res. Microbiol. 158:437-446.

28. García-Rico R. O., F. Fierro, y J. F. Martín. 2008a. Heterotrimeric G $\alpha$ protein Pga1 of Penicillium chrysogenum controls conidiation mainly by a cAMP-independent mechanism. Biochem. Cell. Biol. 86:57-69.

29. García-Rico R. O., F. Fierro, E. Mauriz, A. Gómez, M. A. F. Bodega, y J. F. Martín. 2008b. The heterotrimetic $\mathrm{G} \alpha$ protein Pga1 regulates biosynthesis of penicilin, chrysogenin and roquefortin in Penicillium chrysogenum. Microbiol. 154:3567-3578.

30. García-Rico R.O., R. Chávez, F. Fierro, y J.F. Martín. 2009. Effect of a heterotrimeric G protein alpha subunit on conidia germination, stress response, and roquefortine $\mathrm{C}$ production in Penicillium roqueforti. Inter. Microbiol. 12(2):123-129. 
31. García-Rico R. O., J. F. Martín, y F. Fierro. 2011. Heterotrimeric G $\alpha$ protein Pga1 from Penicillium chrysogenum triggers germination in response to carbon sources and affects negatively resistance to different stress conditions. Fungal Genet. Biol. 48(6):641-649.

32. Giraldo A., J. Gené, J. Cano, S. de Hoog, y J. Guarro. 2014. Acremonium with catenate elongate conidia: phylogeny of Acremonium fusidioides and related species. Mycologia. 106(2):328-338.

33. Glenn A. E., C. W. Bacon, R. Price, y R. T. Hanlin. 1996. Molecular phylogeny of Acremonium and its taxonomic implications. Mycol. 88:369-383.

34. Guarro J., W. Gams, I. Pujol, y J. Gené. 1997. Acremonium species: new emerging fungal opportunists in vitro antifungal susceptibilities and review. Clin. Infect. Dis. 25:1222-1229.

35. Guarro J., J. Gené, y A. M. Stchigel. 1999. Developments in fungal taxonomy. Clin. Microbiol. Rev. 12(3):454-500.

36. Gupta V. K, y M. Ayyachamy. 2012. Biotechnology of Fungal Genes. Science Publishers, U.S., pp 123.

37. Gutiérrez S., J. Velasco, A. T. Marcos, F. J. Fernández, F. Fierro, J. L. Barredo, B. Díez, y J. F. Martín. 1997. Expression of the $e^{e f} G$ gene is limiting for cephalosporin biosynthesis in Acremonium chrysogenum. Appl. Microbiol. Biotechnol. 48:606-614.

38. Gutiérrez S., F. Fierro, J. Casqueiro, y J. F. Martín. 1999. Gene organization and plasticity of the $\beta$-lactam genes in different filamentous fungi. Antonie van Leeuwenboek. 75:81-94.

39. Hadley G., y C. E. Harrold. 1958. The sporulation of Penicillium notatum Westling in submerged liquid culture. I. The effect of calcium and nutrients on sporulation intensity. $J$. Exp. Bot. 9(27):408-17.

40. Harris S. D., J. L. Morrell, y J. E. Hamer. 1994. Identification and characterization of Aspergillus nidulans mutants defective in cytokinesis. Genet. 136:517-532.

41. Hayter A. J. 1984. A Proof of the conjecture that the Tukey-Kramer multiple comparisons procedure is conservative. Annal. Statist. 12(1):61-75.

42. Hengen P. N. 1996. Methods and reagents: Preparing ultra-competent Escherichia coli. Trends in Biochem. Science. 21(2):75-76.

43. Hicks J. K., J. H. Yu, N. P. Keller, y T. H. Adams. 1997. Aspergillus sporulation and mycotoxin production both require inactivation of the FadA $G \alpha$ protein-dependent signaling pathway. EMBO J. 16:4916-4923.

44. Hoff B, E. K. Schmitt, y U. Kück. 2005. CPCR1, but not its interacting transcription factor AcFKH1, controls fungal arthrospore formation in Acremonium chrysogenum. Mol. Microbiol. 56:1220-1233.

45. Hoff B, y U. Kück. 2005. Use of bimolecular fluorescence complementation to demonstrate transcription factor interaction in nuclei of living cells from the filamentous fungus Acremonium chrysogenum. Curr. Genet. 47(2):132-138. 
46. Horwitz B. A., A. Sharon, S. W. Lu, V. Ritter, T. Sandrock, O. C. Yoder, y B. G. Turgeon. 1999. A G protein asubunit from Cocbliobolus beterostrophus involved in mating and appressorium formation. Fungal Genet. Biol. 26:19-32.

47. Inoue H, H. Nojima, y H. Okayama. 1990. High efficiency transformation of Escherichia coli with plasmids. Gene. 96:23-28.

48. Ivey F. D., P. N. Hodge, G. E. Turner, y K. A. Borkovich. 1996. The G $\alpha_{i}$ homologue gna-1 controls multiple differentiation pathways in Neurospora crassa. Mol. Biol. Cell. 7:1283-1297.

49. Jain S., K. Akiyama, K. Mae, T. Ohguchi, y R. Takata. 2002. Targeted disruption of a G protein $\alpha$ subunit gene results in reduced pathogenicity in Fusarium oxysporum. Curr. Genet. 41:407-413.

50. Jekosch K., y U. Kück. 2000a. Glucose dependent transcriptional expression of the cre1 gene in Acremonium chrysogenum strains showing different levels of cephalosporin C production. Curr. Genet. 37(6):388-95.

51. Jekosch K., y U. Kück. 2000b. Loss of glucose repression in an Acremonium chrysogenum $\beta$ lactam producer strain and its restoration by multiple copies of the cre1 gene. Appl. Microbiol. Biotechnol. 54:556-563.

52. Jicinska E. 1974. Dimorphic and yeast-like mutants of the genus Cephalosporium Cda. Folia Microbiol.19:1-4.

53. Käfer E. 1965. Origins of translocations in Aspergillus nidulans. Genet. 52:217-232.

54. Käfer E. 1977. Meiotic and mitotic recombination in Aspergillus and its chromosomal aberrations. Adv. Genet. 19:33-131.

55. Karaffa L., E. Sándor, J. Kozma, y A. Szentirmai. 1997. Methionine enhances sugar consumption, fragmentation, vacuolation and cephalosporin $\mathrm{C}$ production in Acremonium chrysogenum. Process. Biochem. 32:495-499.

56. Keller N. P., G. Turner, y J.W. Bennett. 2005. Fungal secondary metabolism from biochemistry to genomics. Nat. Rev. Microbiol. 3:937-947.

57. Krasniewski I., P. Molimard, G. Feron, C. Vergoignan, A. Durand, J. F. Cavin, y P. Cotton. 2006. Impact of solid media composition on the conidiation in Penicillium camemberti. Process Biochem. 41(6):1318-1324.

58. Krijgsheld P., R. Bleichrodt, G. J. van Veluw, F. Wang, W. H. Müller, J. Dijksterhuis, y H. A. B. Wösten. 2013. Development in Aspergillus. Stud Mycol. 74(1):1-29.

59. Kylie J. B., H. Chang, C. A. D’Souza, y J. W. Kronstad. 2005. An Ustilago maydis septin is required for filamentous growth in culture and for full symptom development on maize. Eukaryot. Cell. 4:2044-2056.

60. Larkin M. A., G. Blacshields, N.P. Brown, R. Chenna, P. A. McGettigan, H. McWilliam, F. Valentin, I. M. Wallace, A. Wilm, R. López, J.D. Thompson, T. J. Gibson, y D. G. Higgins. 2007. Clustal W y Clustal X version 2.0. Bioinformatics. 23(21):2947-2948. 
61. Le Page G. A., y E. Campbell. 1946. Preparation of streptomycin. J. Biol. Chem. 162:163171.

62. Li L., S.J. Wright, S. Krystofova, G. Park, y K. A. Borkovich. 2007. Heterotrimeric G protein signaling in filamentous fungi. Annu. Rev. Microbiol. 61:423-452.

63. Liras P. y J. F. Martín. 2006. Gene clusters for $\beta$-lactam antibiotics and control of their expression: why have clusters evolved, and from where did they originate? Int. Microbiol. 9:919.

64. Liu S., y R. A. Dean. 1997. G protein alpha subunit genes control growth, development, and pathogenicity of Magnaporthe grisea. Mol. Plant. Microbe. Interact. 10:1075-1086.

65. Liu H., A. Suresh, F. S. Willard, D. P. Siderovski, S. Lu, y N. I. Naqvi. 2007. Rgs1 regulates multiple $\mathrm{G} \alpha$ subunits in Magnaporthe pathogenesis, asexual growth and thigmotropism. EMBO J. 26:690-700.

66. Long L. K., Y. Wang, Y. Jing, X. Xinxin, y L. Gang. 2013. A septation related gene AcsepH in Acremonium chrysogenum is involved in the cellular differentiation and cephalosporin production. Fungal Genet. Biol. 50:11-20.

67. Mah J. H., y J. H. Yu. 2006. Upstream and downstream regulation of sexual development in Aspergillus fumigatus. Eukaryot. Cell. 5(10):1585-1595.

68. Malbon C. C. 2005. G proteins in development. Nat. Rev. Mol. Cell. Biol. 6(9):689-701.

69. Martín J. F., C. García-Estrada, y R. V. Ullán. 2012. Genes encoding penicillin and cephalosporin biosinthesis in Acremonium chrysogenum: Two separate clusters are required for cephalosporin production, p. 113-138. Gupta V. K., y M. Ayyachamy. Biotechnology of Fungal Genes. Science Publishers.

70. Meletiadis J., J. F. G. M. Meis, J. W. Mouton, y P. E. Verweij. 2001. Analysis of growth characteristics of filamentous fungi in different nutrient media. J. Clin. Microbiol. 39(2):478484.

71. Milligan G., y E. Kostenis. 2006. Heterotrimeric G-proteins: a short history. British J. Pharmacol. 147:S46-S55.

72. Mooney J. L., y L. N. Yager. 1990. Light is required for conidiation in Aspergillus nidulans. Genes Dev. 4:1473-1482.

73. Morton A. G. 1961. The induction of sporulation in mould fungi. Proc. R. Soc. Lond. B 153:548-69.

74. Mukherjee P. K., J. Latha, R. Hadar, y B. A. Horwitz. 2004. Role of two G-protein alpha subunits, TgaA and TgaB, in the antagonism of Trichoderma virens against plant pathogens. Appl. Environ. Microbiol. 70:542-549.

75. Nash C. H, F. M. Huber. 1971. Antibiotic synthesis and morphological differentiation of Cephalosporium acremonium. Appl. Microbiol. 22(1):6-10.

76. Nash C. H, y R. L. Pieper. 1974. Physiology of spore germination in Cephalosporium acremonium. Mycopathol. Mycol. Appl. 54(3):369-75. 
77. Neer E. J. 1995. Heterotrimeric G proteins: organizers of transmembrane signals. Cell. 80:249-257.

78. Nguyen V. Q., y A. Sil. 2008. Temperature-induced switch to the pathogenic yeast form of Histoplasma capsulatum requires Ryp1, a conserved transcriptional regulator. Proc. Natl. Acad. Sci. 105:4880-4885.

79. Oldham W. M., y H. E. Hamm. 2006. Structural basis of function in heterotrimeric G proteins. Quaterly Rev. Biophys. 39(2):117-66.

80. Oldham W. M., y H. E. Hamm. 2008. Heterotrimeric G protein activation by G-proteincoupled receptors. Nat. Rev. Mol. Cell. Biol. 9(1):60-71.

81. Peberdy J. F. 1987. Penicillium and Acremonium. En: Biotechnology Handbooks. Peberdy J. F. (Ed.). Plenum Press, Springer, vol. 1, New York.

82. Pitt D., y M. J. Mosley. 1986. Oxidation of carbon sources via tricarboxylic acid cycle during calcium-induced conidiation of Penicillium notatum. Antonie Leeunenboek. 52:467-82.

83. Queener S. W., y D. L. F. Ellis. 1975. Differentiation of mutants of Cephalosporium acremonium in complex medium: the formation of unicellular arthrospores and their germination. Can. J. Microbiol. 21:1981-1996.

84. Queener S. W., T. D. Ingolia, P. L. Skatrud, J. L. Chapman, K. R. Kaster. 1985. A system for genetic transformation of Cephalosporium acremonium. En: "Microbiology". Leive L (Ed.). American society for microbiology, Washington DC, pp: 468-472.

85. Raw A. S., D. E. Coleman, A. G. Gilman, y S. R. Sprang. 1997. Structural and biochemical characterization of the GTP gammaS-, GDP.P. ${ }^{-}$, and GDP-bound forms of a GTPasedeficient Gly42 $\rightarrow$ Val mutant of Gialpha1. Biochem. 36:15660-15669.

86. Reithner B., K. Brunner, R. Schuhmacher, I. Peissl, V. Seidl, R. Krska, y S. Zeilinger. 2005. The $G$ protein alpha subunit Tga1 of Trichoderma atroviride is involved in chitinase formation and differential production of antifungal metabolites. Fungal Genet Biol. 42:749-760.

87. Rens-Domiano S., y H. E. Hamm. 1995. Structural and functional relationships of heterotrimeric G-proteins. The FASEB Journal, 9:1059-1066.

88. Rodríguez Q. F, y V. J. Benedí. 1993. Escherichia coli strain DH5 $\alpha^{\mathrm{TM}}$ is a suitable host for the study of pho A insertions. Focus. 15:110-112.

89. Roncal T., S. Cordobés, O. Sterner, y U. Ugalde. 2002. Conidiation in Penicillium cyclopium is induced by conidiogenone, an endogenous diterpene. Eukaryot. Cell. 1(5):823-829.

90. Samson S. M., J. E. Dotzlaf, M. L. Slisz, G. W. Becker, R. M. van Frank, L. E. Veal, W. K. Yeh, J. E. Miller, S. W. Queener, y T. D. Ingolia. 1987. Cloning and expression of the fungal expandase/hidroxylase gene involved in cephalosporin biosynthesis. Bio/Technology. 5:12071214.

91. Schell W. A. y J. R. Perfect. 1996. Fatal, disseminated Acremonium strictum infection in a neutropenic host. J. Clinical Microbiol. 34(5):1333-1336. 
92. Schmitt E. K., y U. Kück. 2000. The fungal CPCR1 protein, which binds specifically to beta-lactam biosynthesis genes, is related to human regulatory factor $\mathrm{X}$ transcription factors. J. Biol. Chem. 275(13):9348-57.

93. Schmitt E. K., R. Kempken, y U. Kück. 2001. Functional analysis of promoter sequences of cephalosporin C biosynthesis genes from Acremonium chrysogenum specific DNA-protein interactions and characterization of the transcription factor PACC. Mol. Genet. Genom. 265(3):508-18.

94. Schmitt E. K., B. Hoff, y U. Kück. 2004a. Regulation of Cephalosporin Biosynthesis. Adv. Biochem. Engin/Biotechnol. 88:1-43.

95. Schmitt E. K., B. Hoff, y U. Kück. 2004b. AcFKH1, a novel member of the forkhead family, associates with the RFX transcription factor CPCR1 in the cephalosporin Cproducing fungus Acremonium chrysogenum. Gene. 342:269-281.

96. Schmitt E. K., A. Bunse, D. Janus, B. Hoff, E. Friedlin, H. Kürnsteiner, y U. Kück. 2004c. Winged helix transcription factor CPCR1 is involved in regulation of beta-lactam biosynthesis in the fungus Acremonium chrysogenum. Eukaryot. Cell. 3(1):121-34.

97. Segers G. C., y D. L. Nuss. 2003. Constitutively activated $G \alpha$ negatively regulates virulence, reproduction and hydrophobin gene expression in the chestnut blight fungus Cryphonectria parasitica. Fungal Genet. Biol. 38:198-208.

98. Shimizu K., y N. P. Keller. 2001. Genetic involvement of a cAMP-dependent protein kinase in a $G$ protein signaling pathway regulating morphological and chemical transitions in Aspergillus nidulans. Genetics. 157:591-600.

99. Shwab E. K., J. W. Bok, M. Tribus, J. Galehr, S. Graessle, y N. P. Keller. 2007. Histone deacetylase activity regulates chemical diversity in Aspergillus. Eukaryot. Cell. 6:1656-1664.

100. Simon M. I., M. P. Strathmann, y N. Gautam. 1991. Diversity of G proteins in signal transduction. Science. 252:802-808.

101. Skatrud P. L., y S. W. Queener. 1989. An electrophoretic molecular karyotype for an industrial strain of Cephalosporium acremonium. Gene. 78:331-338.

102. Sprang S. R. 1997. G protein mechanisms: insights from structural analysis. Annu. Rev. Biochem. 66:639-678.

103. Steinberg G. 2007. Hyphal growth: a tale of motors, lipids, and the Spitzenkörper. Eukaryot. Cell. 6:351-360.

104. Steyaert J. M., R. J. Weld, A. M. Mendoza, y A. Stewart. 2010. Reproduction without sex: conidiation in the filamentous fungus Trichoderma. Microbiol. 156:2887-2900.

105. Studt L., H. U. Humpf y B. Tudzynski. 2013. Signaling governed by g proteins and cAMP is crucial for growth secondary metabolism and sexual development in Fusarium fijikuroi. PLoS One. 8(2):e58185.

106. Sugui A., J. Pardo, Y. C. Chang, A. Müllbacher, K. A. Zarember, E. M. Galvez, L. Brinster, P. Zerfas, J. I. Gallin, M. M. Simon, y K. J. Kwon-Chung. 2007. Role of laeA in the 
regulation of alb1, gliP, conidial morphology, and virulence in Aspergillus fumigatus. Eukaryot. Cell. 6:1552-1561.

107. Summerbell R. C., C. Gueidan, H. J. Schroers, G. S. de Hoog, M. Starink, Y. A. Rosete, J. Guarro, y J. A. Scott. 2011. Acremonium phylogenetic overview and revision of Gliomastix, Sarocladium, and Trichothecium. Studies in Mycol. 68:139-62.

108. Teijeira F, R. V. Ullán, S. M. Guerra, C. García-Estrada, I. Vaca, y J. F. Martín. 2009. The transporter CefM involved in translocation of biosynthetic intermediates is essential for cephalosporin production. Biochem. J. 418:113-124.

109. Teijeira F., R. V. Ullán, M. F. Aguado, y J. F. Martín. 2011. CefR modulates transporters of beta-lactam intermediates preventing the loss of penicillins to the broth and increases cephalosporin production in Acremonium chrysogenum. Metabol. Engineering. 13:532-543.

110. Turner G. E, y K. A. Borkovich. 1993. Identification of a G protein alpha subunit from Neurospora crassa that is a member of the $G_{i}$ family. J. Biol. Chem. 268(20):14805-11.

111. Ullán R. V, G. Liu, J. Casqueiro, O. Bañuelos, F. J. Fernández, S. Gutiérrez, y J. F. Martín. 2002a. A novel epimerization system in fungal secondary metabolism involved in the conversion of isopenicillin $\mathrm{N}$ into penicillin $\mathrm{N}$ in Acremonium chrysogenum. J. Biol. Chem. 277:46216-46225.

112. Ullán, R., G. Liu, J. Casqueiro, S. Gutiérrez, O. Bañuelos, y J. F. Martín. 2002b. The cefT gene of Acremonium chrysogenum $\mathrm{C} 10$ encodes a putative multidrug efflux pump protein that significantly increases cephalosporin C production. Mol. Genet. Genomics. 267:673-683.

113. Ullán R. V, J. Casqueiro, L. Naranjo, I. Vaca, y J. F. Martin. 2004. Expression of cefD2 and the conversion of isopenicillin $\mathrm{N}$ into penicillin $\mathrm{N}$ by the two-component epimerase system are rate limiting steps in cephalosporin biosynthesis. Mol. Genet. Genom. 272(5):562-70.

114. Ullán R. V, F. Teijeira, y J. F. Martín. 2008. Expression of the Acremonium chrysogenum cefT gene in Penicillium chrysogenum indicates that it encodes an hydrophilic beta-lactam transporter. Current. Genetics. 54:153-161.

115. Ullán R. V, F. Teijeira, S. M. Guerra, I. Vaca, y J. F. Martín. 2010. Characterization of a novel peroxisome membrane protein essential for conversion of isopenicillin $\mathrm{N}$ to cephalosporin C. Biochem. J. 432:227-236.

116. Wang H., Y. Pan, P. Hu, Y. Zhu, J. Li, X. Jiang, y G. Liu. 2014. The autophagy-related gene Acatg1 is involved in conidiation and cephalosporin production in Acremonium chrysogenum. Fungal Genet. Biol. 69:65-74.

117. Wettschureck N., y S. Offermanns. 2005. Mammalian G proteins and their cell type specific functions. Physiol. Rev. 85(4):1159-204.

118. Yang Q., y K. A. Borkovich. 1999. Mutational activation of a $G \alpha_{i}$ causes uncontrolled proliferation of aerial hyphae and increased sensitivity to heat and oxidative stress in Neurospora crassa. Genetics. 151:107-117. 
119. Yu, J. H., J. Wieser, y T. H. Adams. 1996. The Aspergillus FlbA RGS domain protein antagonizes $G$ protein signaling to block proliferation and allow development. EMBO J. 15:5184-5190.

120. Yu J. H., S. Rosen, y T. H. Adams. 1999. Extragenic suppressors of loss-of-function mutations in the Aspergillus FlbA regulator of G-protein signaling domain protein. Genetics. 151:97-105.

121. Yu J. H. 2006. Heterotrimeric G protein signaling and RGSs in Aspergillus nidulans. J. Microbiol. 44:145-154.

122. Yu H. Y., J. A. Seo, J. E. Kim, K. H. Han, W. B. Shim, S. H. Yun, y Y. W. Lee. 2008. Functional analyses of heterotrimeric $G$ protein $G \alpha$ and $G \beta$ subunits in Gibberella zeae. Microbiol. 154:392-401.

123. Zhang H, W. Tang, K. Liu, Q. Huang, X. Zhang, X. Yan, Y. Chen, J. Wang, Z. Qi, Z. Wang, X. Zheng, P. Wang, y Z. Zhang. 2011. Eight RGS and RGS-like proteins orchestrate growth, differentiation, and pathogenicity of Magnaporthe oryzae. PLoS Pathog. 7(12):e1002450.

124. Zhou C., Y. Yujun, y Y. J. Ambrose. 1990. Mini-Prep in Ten Minutes. Biotechniques. 8(2):172-173.

125. Zuber S., M. J. Hynes, y A. Andrianopoulos. 2002. G-protein signaling mediates asexual development at $25^{\circ} \mathrm{C}$ but has no effect on yeast-like growth at $37^{\circ} \mathrm{C}$ in the dimorphic fungus Penicillium marneffei. Eukaryot. Cell. 1:440-447. 
ANEXOS 
9. ANEXOS

\subsection{ANEXO 1. Soluciones y buffers}

TENS-Mini Prep (Zhou et al., 1990)

TENS: 10 mM Tris-HCl (pH 8), 1 mM EDTA (pH 8), $0.1 \mathrm{~N} \mathrm{NaOH}, 0.5 \%$ (p/v) SDS.

MEGAPREP POR LISIS ALCALINA Y FENOLIZACIÓN (método modificado)

Buffer P1: 50 mM Tris-HCl (pH 8), 10 mM EDTA (pH 8).

Buffer P2: $200 \mathrm{mM} \mathrm{NaOH}, 0.5 \%$ (p/v) SDS.

Buffer P3: 3.0 M Acetato de sodio pH 5.2.

PREPARACIÓN Y TRANSFORMACIÓN DE CÉLULAS ULTRA-COMPETENTES (Inoue et al., 1990; Hengen, 1996)

TB: $10 \mathrm{mM}$ Pipes; $15 \mathrm{mM} \mathrm{CaCl}$; $250 \mathrm{mM} \mathrm{KCl}$. Mezclar estos componentes y ajustar a $\mathrm{pH} 6.7$ con $\mathrm{KOH}(1 \mathrm{M})$ y esterilizar en autoclave. Después adicionar $55 \mathrm{mM} \mathrm{MnCl}_{2}$ previamente estéril. DMSO: Antes de la elaboración de células ultra-competentes se preparan alícuotas de $1.5 \mathrm{~mL}$ en microtubos y se almacenan a $-20^{\circ} \mathrm{C}$ hasta el momento de su uso.

\section{TRANSFORMACIÓN DE A. CHRYSOGENUM}

CCM: 50 mM CaCl, 10 mM MOPS pH 7, 18\% (p/v) PEG 8000.

NCM: $0.8 \mathrm{M} \mathrm{NaCl}, 50 \mathrm{mM} \mathrm{CaCl}_{2}, 10 \mathrm{mM}$ MOPS pH 7 .

TPC: $0.8 \mathrm{M} \mathrm{NaCl}, 50 \mathrm{mM}$ Buffer de fosfato potásico pH 7, Después de esterilizar añadir $0.02 \mathrm{M}$ $\mathrm{MgSO}_{4}$.

\section{ESTUDIOS DE CONIDIACIÓN}

Buffer NT: $0.9 \% \mathrm{NaCl}, 0.05 \%$ Tritón X100. 


\subsection{ANEXO 2. Medición de la extensión radial}

Este método de medición se montó para reducir el error con una regla de Vernier. Es un método sencillo y muy rápido de realizar.

1. Capturar las fotos de las colonias con una cámara digital SAMSUNG ST80 acoplada a un estereoscopio Southern Precision Instrument Modelo 1839. Las fotos se toman cuidando las condiciones de la cámara y del estereoscopio (zoom, resolución, lentes, objetivos, escala de referencia, etc.).

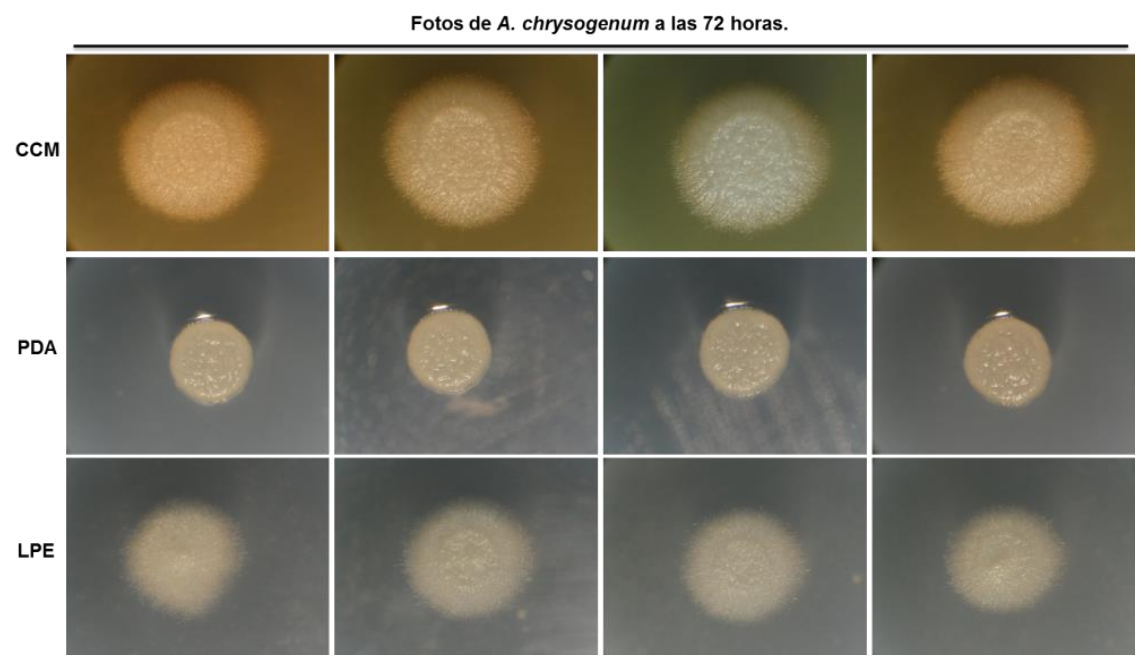

2. Abrir ImageJ $>$ File $>$ Open $>$ seleccionar foto con escala de referencia $>$ Straight $>$ ajustar escala con referencia conocida
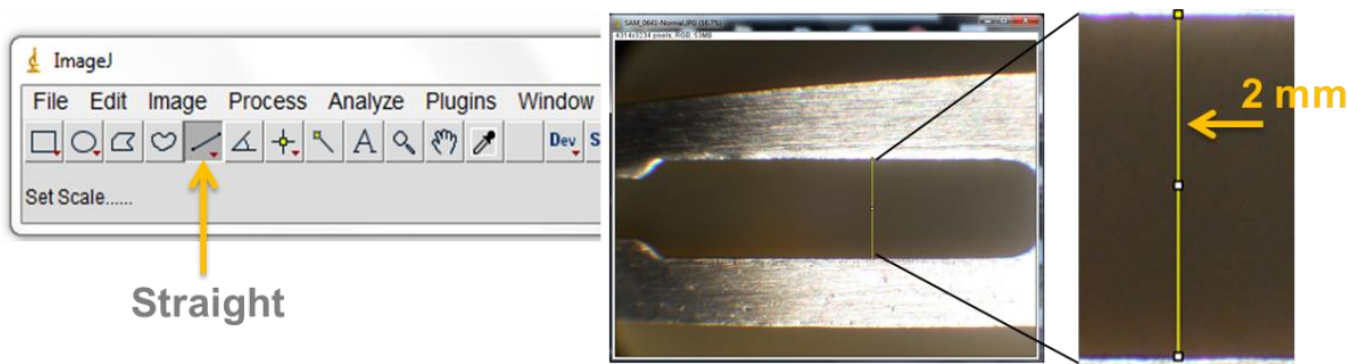

3. Analize $>$ Set Scale $>$ Known distance $>$ Unit of length $>$ Global $>$ Ok
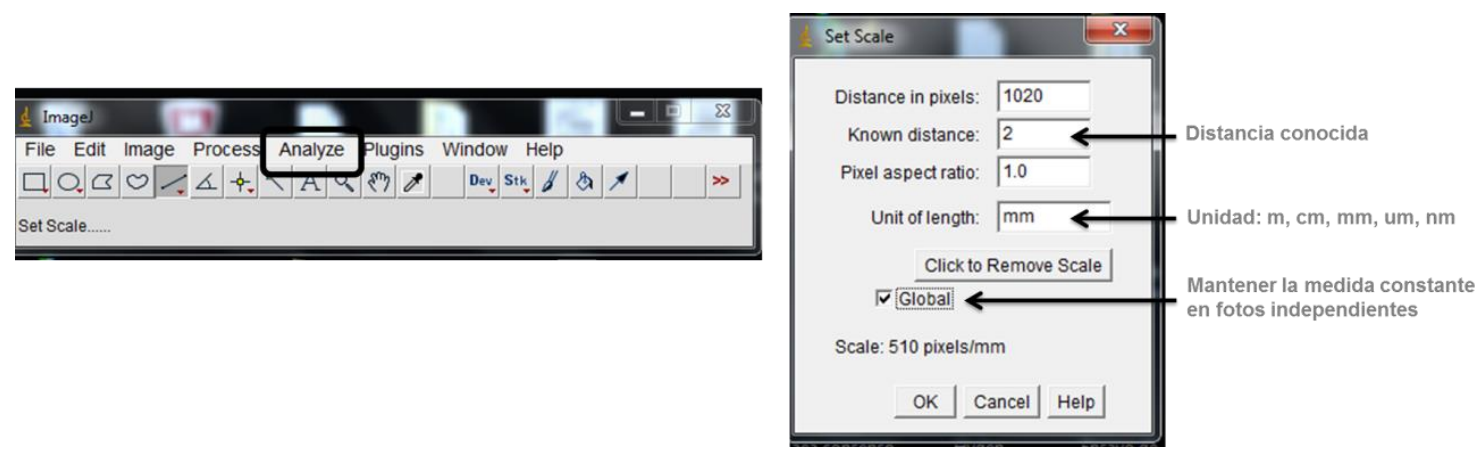
4. Registro de las mediciones. File $>$ Open $>$ Imagen a analizar $>$ Analize $>$ Measure $(\mathrm{Ctrl}+\mathrm{M})$
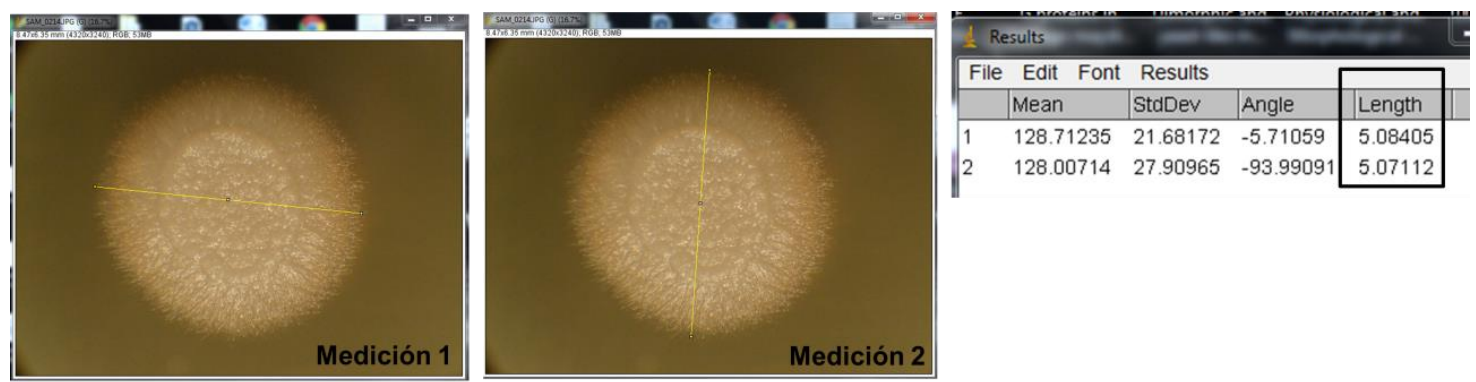

5. Análisis de los datos. Analize>Summarize. Estas opciones arrojan los valores de la media y desviación estándar de las mediciones realizadas. Se suelen hacer dos mediciones perpendiculares por colonia. Los datos son capturados y procesado en Excel.

\begin{tabular}{|c|c|}
\hline Analyze Plugins & Window \\
\hline Measure & Ctrl $+\mathrm{M}$ \\
\hline Analyze Particles. & \\
\hline Summarize & \\
\hline Distribution... & \\
\hline Label & \\
\hline Clear Results & \\
\hline Set Measurement & \\
\hline Set Scale... & \\
\hline Calibrate... & \\
\hline Histogram & $\mathrm{Ctrl}+\mathrm{H}$ \\
\hline Plot Profile & $\mathrm{Ctrl}+\mathrm{K}$ \\
\hline Surface Plot... & \\
\hline Gels & . \\
\hline Tools & , \\
\hline
\end{tabular}

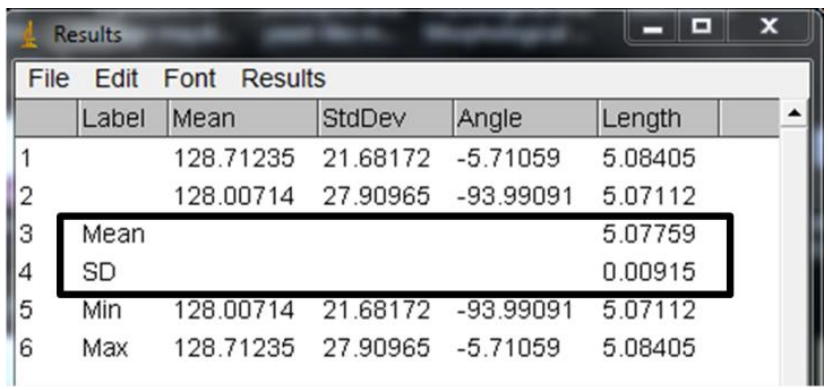


Extensión radial. Se muestran algunas fotos tomadas a partir de un Estereoscopio usadas para el estudio de la extensión radial. Sólo se muestra la comparación del diámetro de colonia desde las $72 \mathrm{~h}$ hasta las $168 \mathrm{~h}$ de crecimiento. Barras negras: $1 \mathrm{~mm}$. Barras blancas: $2 \mathrm{~mm}$.

wt

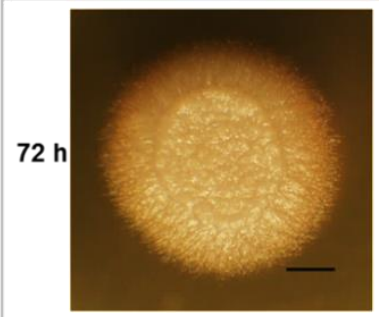

CCM
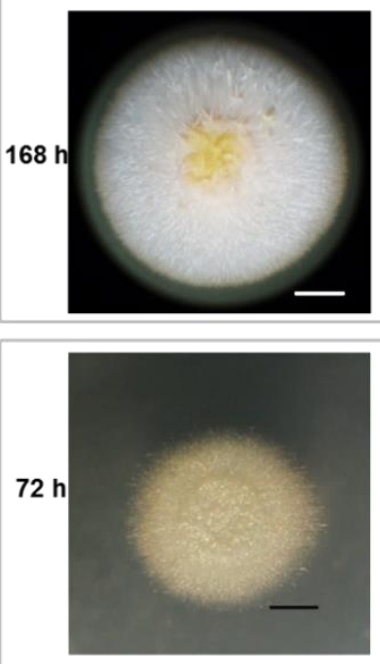

LPE
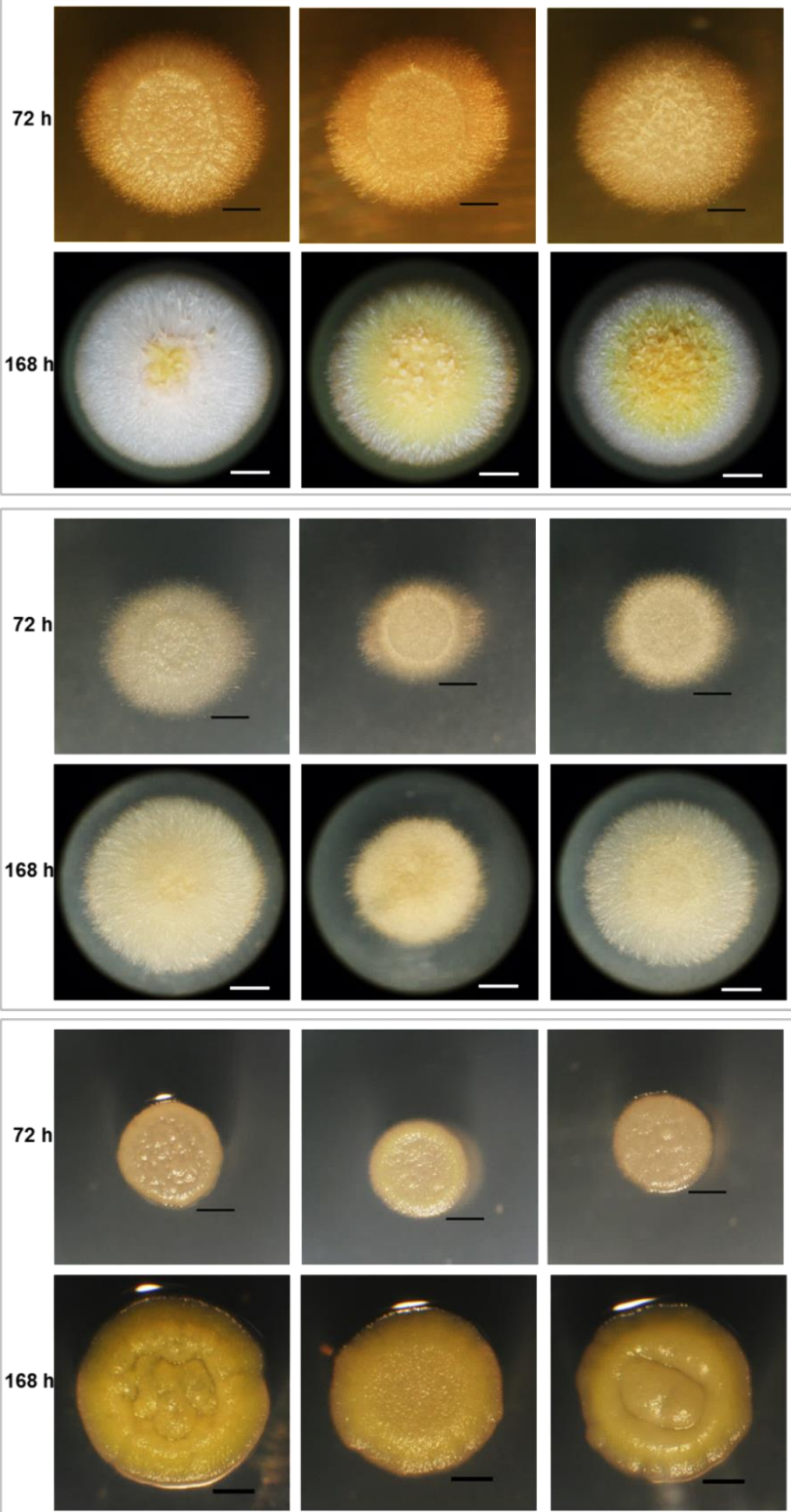
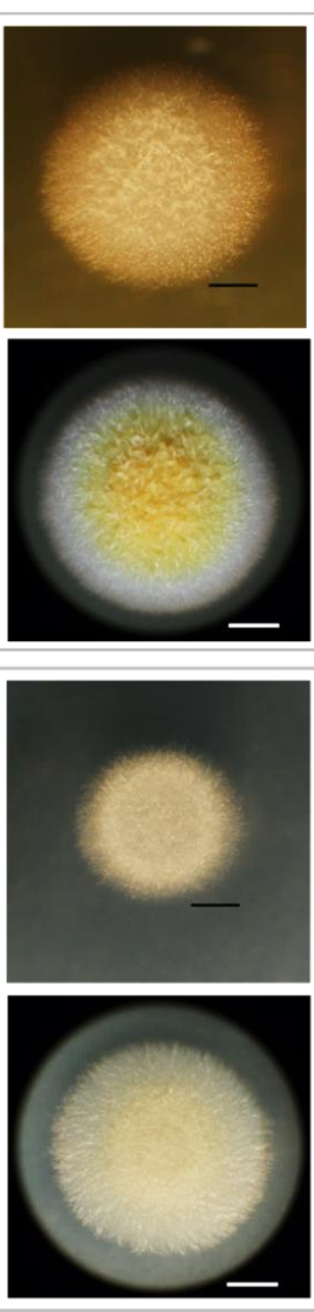

$\Delta$ aga1
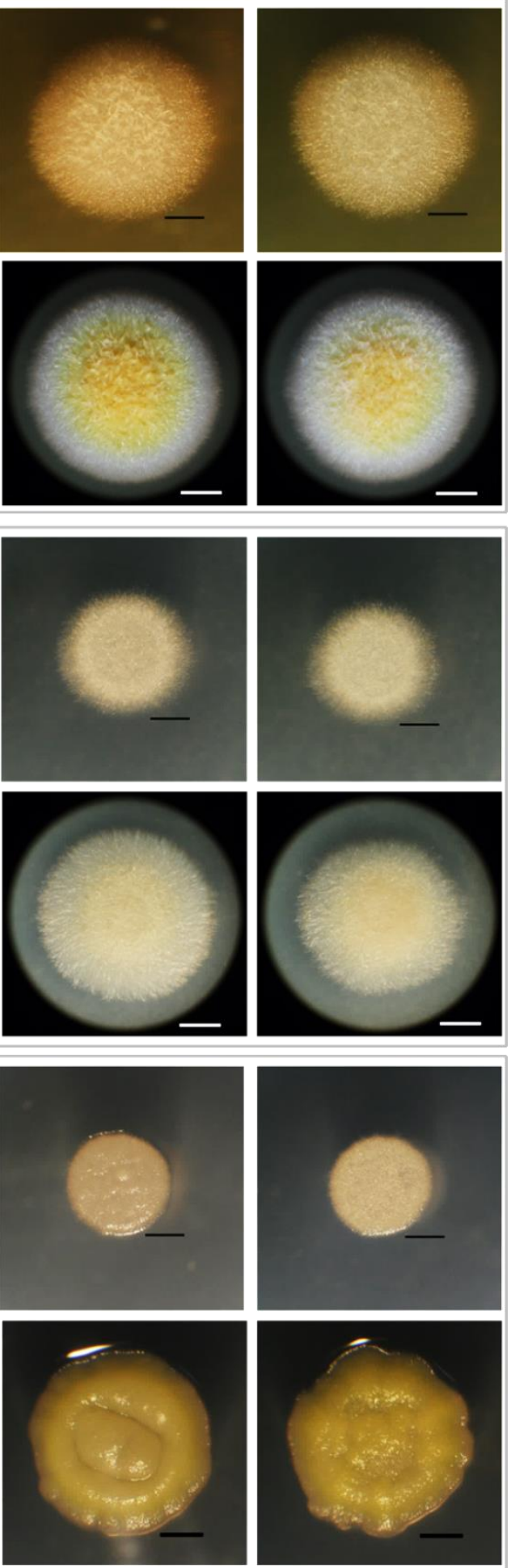
Resumen de la morfología de colonia de las cepas $A$. chrysogenum ATCC 11550, G42R, G203R y $\Delta$ aga1. Se describen características físicas que se observan en las colonias.

\begin{tabular}{|c|c|c|c|c|c|c|}
\hline \multirow{2}{*}{$\begin{array}{l}\text { Característica } \\
\text { Cepa }\end{array}$} & \multicolumn{6}{|c|}{ Morfología } \\
\hline & wt & wt & wt & G42R & G42R & G42R \\
\hline Medio $^{a}$ & CCM & LPE & PDA & CCM & LPE & PDA \\
\hline Tamaño $^{b}$ & 10.3 & 9.0 & 4.7 & 9.8 & 7.1 & 4.1 \\
\hline Forma & Circular & Circular & Regular & Circular & Circular & Regular \\
\hline Coloración & Blanca & Café claro & Amarilla & $\begin{array}{l}\text { Blanca/ } \\
\text { amarilla }\end{array}$ & Café claro & Amarilla \\
\hline Textura & Aterciopelado & Vellosa & Cremosa & Aterciopelado & Vellosa & Cremosa \\
\hline Superficie & Elevada & Plana & Elevada & Elevada & Plana & Elevada \\
\hline Aspecto & Crateriforme & Radiado & Cerebriforme & Crateriforme & Radiado & Cerebriforme \\
\hline Borde & Regular & Regular & Regular & Regular & Regular & Regular \\
\hline $\begin{array}{l}\text { Tasa de } \\
\text { crecimiento }^{c}\end{array}$ & 0.056 & 0.0531 & 0.019 & 0.053 & 0.0424 & 0.014 \\
\hline Cepa & G203R & G203R & G203R & Daga1 & $\Delta$ agal & Daga1 \\
\hline Medio $^{\text {a }}$ & CCM & LPE & PDA & CCM & LPE & PDA \\
\hline Tamaño $^{b}$ & 9.7 & 8.6 & 4.5 & 9.7 & 7.8 & 4.2 \\
\hline Forma & Circular & Circular & Irregular & Circular & Circular & Irregular \\
\hline Coloración & $\begin{array}{l}\text { Blanca/ } \\
\text { amarilla }\end{array}$ & Café claro & Amarilla & $\begin{array}{l}\text { Blanca/ } \\
\text { amarilla }\end{array}$ & Café claro & Amarilla \\
\hline Textura & Aterciopelado & Vellosa & Cremosa & Aterciopelado & Vellosa & Cremosa \\
\hline Superficie & Elevada & Plana & Elevada & Elevada & Plana & Elevada \\
\hline Aspecto & Crateriforme & Radiado & Cerebriforme & Crateriforme & Radiado & Cerebriforme \\
\hline Borde & Regular & Regular & Irregular & Regular & Regular & Irregular \\
\hline $\begin{array}{l}\text { Tasa de } \\
\text { crecimiento }^{c}\end{array}$ & 0.052 & 0.051 & 0.016 & 0.052 & 0.045 & 0.015 \\
\hline
\end{tabular}




\subsection{ANEXO 3. Micrografías}

Micrografías tomadas a partir de cultivo líquido CCM. Se muestran las diferencias en la formación de artrosporas en todas las cepas.
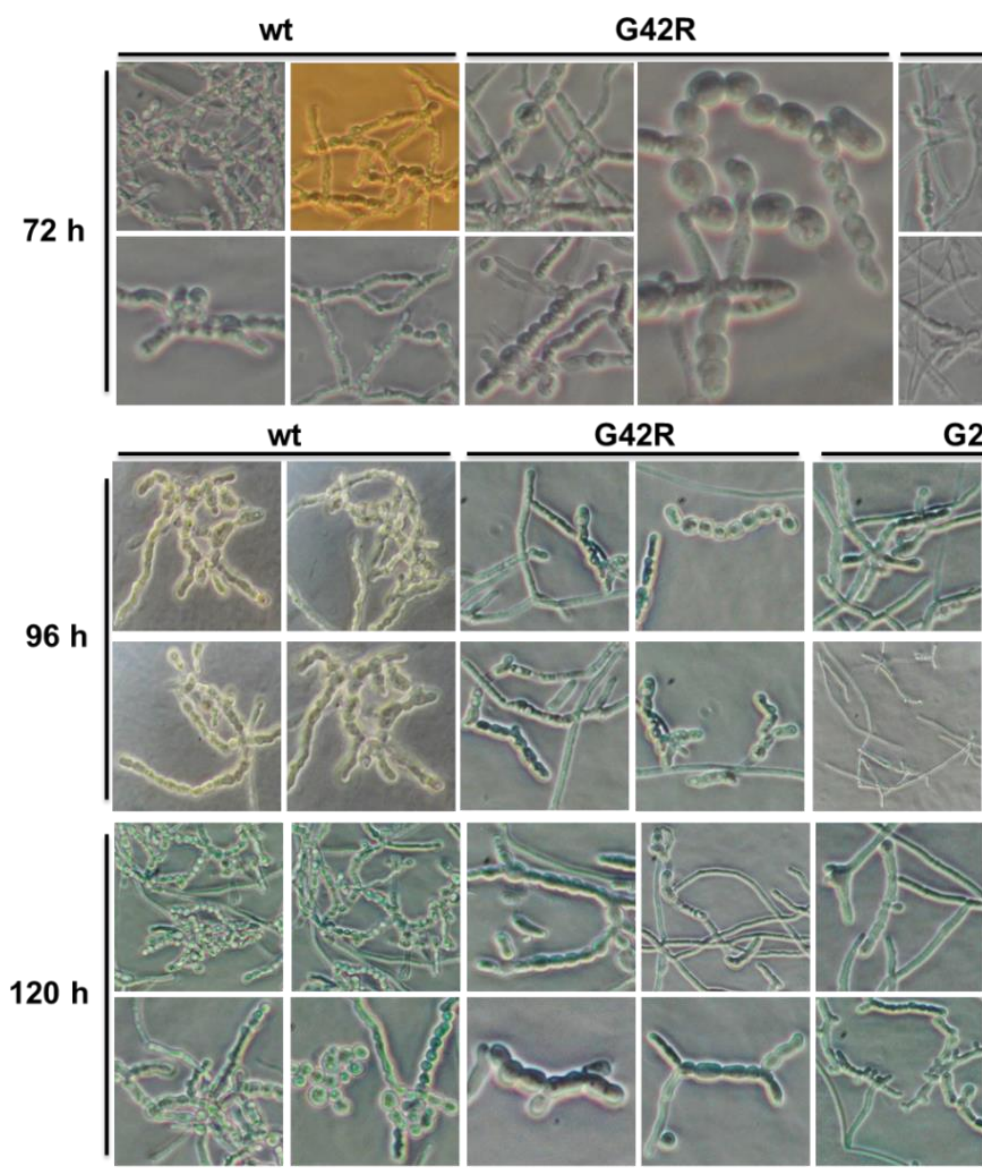

G203R
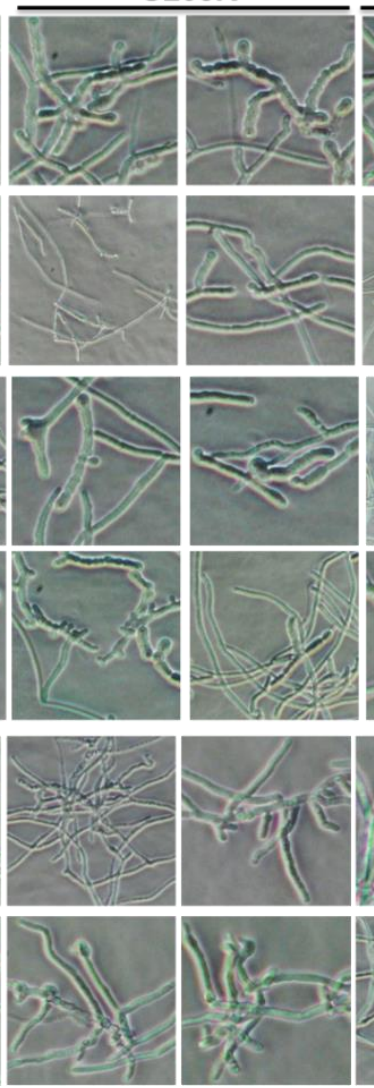

Q204L

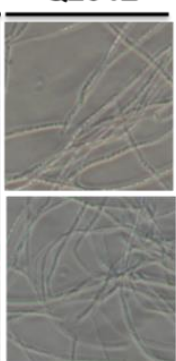

Q204L
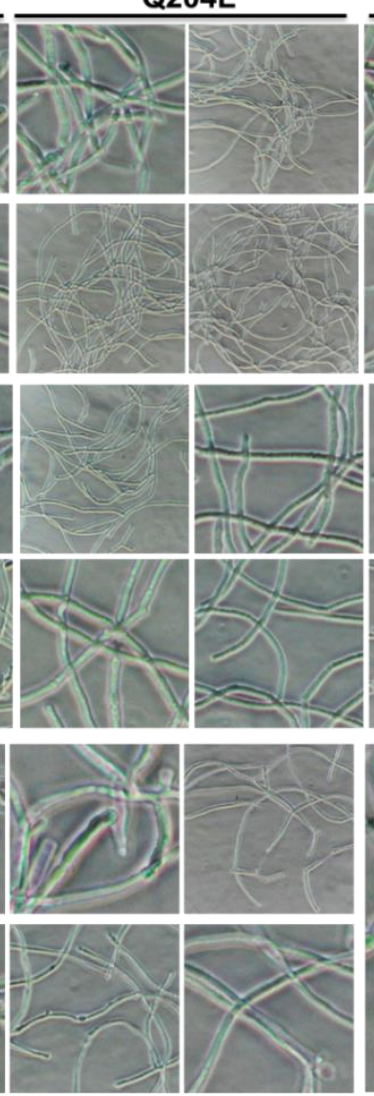

هaga1

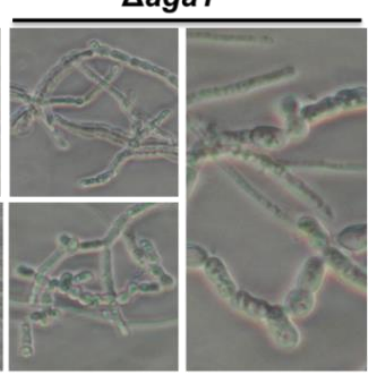

Daga1
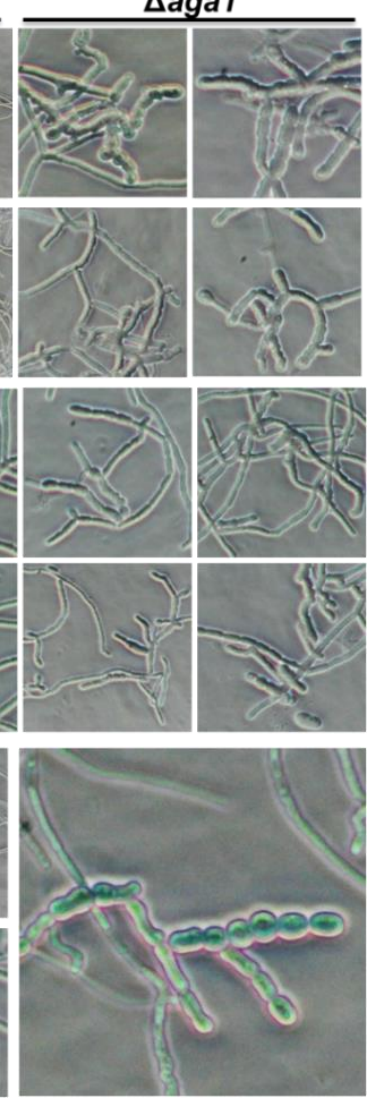


\subsection{ANEXO 4. Análisis estadísticos}

Tablas de ANOVA mostrando las diferencias significativas entre cepas y pruebas de comparación múltiple de Tukey.

\section{CONIDIACIÓN}

\section{CCM}

\begin{tabular}{|l|r|r|r|r|r|}
\hline CCM & $\begin{array}{c}\text { Suma de } \\
\text { cuadrados }\end{array}$ & gl & $\begin{array}{c}\text { Media } \\
\text { cuadrática }\end{array}$ & F & Sig. \\
\hline Inter-grupos & 110731.326 & 3 & 36910.442 & 950.959 & .000 \\
\hline Intra-grupos & 776.279 & 20 & 38.814 & & \\
\hline Total & 111507.605 & 23 & & & \\
\hline
\end{tabular}

\begin{tabular}{|c|c|c|c|c|c|}
\hline \multicolumn{6}{|c|}{ HSD de Tukeya } \\
\hline \multirow[t]{2}{*}{ Cepas } & \multirow[b]{2}{*}{$\mathbf{N}$} & \multicolumn{4}{|c|}{ Subconjunto para alfa $=0.05$} \\
\hline & & 1 & 2 & 3 & 4 \\
\hline G42R & 6 & 24.7037 & & & \\
\hline wt & 6 & & 51.1111 & & \\
\hline Daga1 & 6 & & & 83.3333 & \\
\hline G203R & 6 & & & & 202.4074 \\
\hline Sig. & & 1.000 & 1.000 & 1.000 & 1.000 \\
\hline \multicolumn{6}{|c|}{$\begin{array}{l}\text { Se muestran las medias para los grupos en los subconjuntos } \\
\text { homogéneos. }\end{array}$} \\
\hline
\end{tabular}

\section{PDA}

\begin{tabular}{|l|r|r|r|r|r|}
\hline PDA & $\begin{array}{c}\text { Suma de } \\
\text { cuadrados }\end{array}$ & gl & $\begin{array}{c}\text { Media } \\
\text { cuadrática }\end{array}$ & F & Sig. \\
\hline Inter-grupos & 289.767 & 3 & 96.589 & 89.279 & .000 \\
\hline Intra-grupos & 21.637 & 20 & 1.082 & & \\
\hline Total & 311.404 & 23 & & & \\
\hline
\end{tabular}

\begin{tabular}{|c|c|c|c|c|c|}
\hline \multicolumn{6}{|c|}{ HSD de Tukeya } \\
\hline \multirow[t]{2}{*}{ Cepas } & \multirow[b]{2}{*}{$\mathbf{N}$} & \multicolumn{4}{|c|}{ Subconjunto para alfa $=0.05$} \\
\hline & & 1 & 2 & 3 & 4 \\
\hline wt & 6 & 3.4074 & & & \\
\hline G42R & 6 & & 7.7778 & & \\
\hline G203R & 6 & & & 10.6296 & \\
\hline$\Delta$ aga1 & 6 & & & & 12.6667 \\
\hline Sig. & & 1.000 & 1.000 & 1.000 & 1.000 \\
\hline
\end{tabular}

\section{LPE}

\begin{tabular}{|l|r|r|r|r|r|}
\hline LPE & $\begin{array}{c}\text { Suma de } \\
\text { cuadrados }\end{array}$ & gl & $\begin{array}{c}\text { Media } \\
\text { cuadrática }\end{array}$ & F & Sig. \\
\hline Inter-grupos & 38900.755 & 3 & 12966.918 & 177.588 & .000 \\
\hline Intra-grupos & 1460.339 & 20 & 73.017 & & \\
\hline Total & 40361.094 & 23 & & & \\
\hline
\end{tabular}

\begin{tabular}{|c|c|c|c|c|}
\hline \multicolumn{5}{|c|}{ HSD de Tukeya } \\
\hline \multirow[t]{2}{*}{ Cepas } & \multirow[b]{2}{*}{$\mathbf{N}$} & \multicolumn{3}{|c|}{ Subconjunto para alfa $=0.05$} \\
\hline & & 1 & 2 & 3 \\
\hline wt & 6 & 36.5741 & & \\
\hline G42R & 6 & & 107.9630 & \\
\hline$\Delta$ agal & 6 & & & 129.8148 \\
\hline G203R & 6 & & & 139.4445 \\
\hline Sig. & & 1.000 & 1.000 & .239 \\
\hline \multicolumn{5}{|c|}{$\begin{array}{l}\text { Se muestran las medias para los grupos en los subconjuntos } \\
\text { homogéneos. }\end{array}$} \\
\hline
\end{tabular}

\section{M2}

\begin{tabular}{|l|r|r|r|r|r|}
\hline M2 & $\begin{array}{c}\text { Suma de } \\
\text { cuadrados }\end{array}$ & g1 & $\begin{array}{c}\text { Media } \\
\text { cuadrática }\end{array}$ & F & Sig. \\
\hline Inter-grupos & 4948.971 & 3 & 1649.657 & 288.809 & .000 \\
\hline Intra-grupos & 114.239 & 20 & 5.712 & & \\
\hline Total & 5063.210 & 23 & & & \\
\hline
\end{tabular}

\begin{tabular}{|c|c|c|c|c|}
\hline \multicolumn{5}{|c|}{ HSD de Tukeya } \\
\hline \multirow{2}{*}{ Cepas } & \multirow[b]{2}{*}{$\mathbf{N}$} & \multicolumn{3}{|c|}{ Subconjunto para alfa $=0.05$} \\
\hline & & 1 & 2 & 3 \\
\hline wt & 6 & 8.1482 & & \\
\hline G203R & 6 & & 38.5185 & \\
\hline G42R & 6 & & 40.3704 & 40.3704 \\
\hline$\Delta$ aga1 & 6 & & & 44.0741 \\
\hline Sig. & & 1.000 & .548 & .063 \\
\hline \multicolumn{5}{|c|}{$\begin{array}{l}\text { Se muestran las medias para los grupos en los subconjuntos } \\
\text { homogéneos. }\end{array}$} \\
\hline \multicolumn{5}{|c|}{ a. Usa el tamaño muestral de la media armónica $=6.000$} \\
\hline
\end{tabular}

\section{M3}

\begin{tabular}{|l|r|r|r|r|r|}
\hline \multicolumn{7}{|c|}{ ANOVA } \\
\hline M3 & $\begin{array}{c}\text { Suma de } \\
\text { cuadrados }\end{array}$ & gl & $\begin{array}{c}\text { Media } \\
\text { cuadrática }\end{array}$ & F & Sig. \\
\hline Inter-grupos & 2467.273 & 3 & 822.424 & 251.636 & .000 \\
\hline Intra-grupos & 65.366 & 20 & 3.268 & & \\
\hline Total & 2532.640 & 23 & & & \\
\hline
\end{tabular}

\begin{tabular}{|c|c|c|c|c|}
\hline \multicolumn{5}{|c|}{ HSD de Tukeya } \\
\hline \multirow[t]{2}{*}{ Cepas } & \multirow[b]{2}{*}{$\mathbf{N}$} & \multicolumn{3}{|c|}{ Subconjunto para alfa $=0.05$} \\
\hline & & 1 & 2 & 3 \\
\hline G42R & 6 & 1.8889 & & \\
\hline wt & 6 & & 6.8519 & \\
\hline$\Delta$ aga1 & 6 & & & 23.3333 \\
\hline G203R & 6 & & & 25.2593 \\
\hline Sig. & & 1.000 & 1.000 & .283 \\
\hline \multicolumn{5}{|c|}{$\begin{array}{l}\text { Se muestran las medias para los grupos en los subconjuntos } \\
\text { homogéneos. }\end{array}$} \\
\hline
\end{tabular}


TASA DE EXTENSIÓN RADIA

\section{CCM}

\begin{tabular}{|l|r|r|r|r|r|}
\hline CCMmm.h & $\begin{array}{c}\text { Suma de } \\
\text { cuadrados }\end{array}$ & g1 & $\begin{array}{c}\text { Media } \\
\text { cuadrática }\end{array}$ & F & Sig. \\
\hline Inter-grupos & .000 & 3 & .000 & 10.158 & .000 \\
\hline Intra-grupos & .000 & 28 & .000 & & \\
\hline Total & .000 & 31 & & & \\
\hline
\end{tabular}

\begin{tabular}{|c|c|c|c|}
\hline \multicolumn{4}{|c|}{ HSD de Tukey ${ }^{\mathrm{a}}$} \\
\hline \multirow[t]{2}{*}{ Grupo } & \multirow[b]{2}{*}{$\mathbf{N}$} & \multicolumn{2}{|c|}{ Subconjunto para alfa $=0.05$} \\
\hline & & 1 & 2 \\
\hline G203R & 8 & .0517230 & \\
\hline$\Delta$ aga1 & 8 & .0527571 & \\
\hline G42R & 8 & .0539112 & \\
\hline wt & 8 & & .0565713 \\
\hline Sig. & & .108 & 1.000 \\
\hline \multicolumn{4}{|c|}{ Se muestran las medias para los grupos en los subconjuntos homogéneos. } \\
\hline \multicolumn{4}{|c|}{ a. Usa el tamaño muestral de la media armónica $=8.000$. } \\
\hline
\end{tabular}

\section{PDA}

\begin{tabular}{|l|r|r|r|r|r|}
\hline \multicolumn{7}{|l|}{ PDAmm.h } & $\begin{array}{c}\text { Suma de } \\
\text { cuadrados }\end{array}$ & g1 & $\begin{array}{c}\text { Media } \\
\text { cuadrática }\end{array}$ & F & Sig. \\
\hline Inter-grupos & .000 & 3 & .000 & 50.807 & .000 \\
\hline Intra-grupos & .000 & 28 & .000 & & \\
\hline Total & .000 & 31 & & & \\
\hline
\end{tabular}

\begin{tabular}{|c|c|c|c|c|}
\hline \multicolumn{5}{|c|}{ HSD de Tukeya } \\
\hline \multirow{2}{*}{ Grupo } & \multirow[b]{2}{*}{$\mathbf{N}$} & \multicolumn{3}{|c|}{ Subconjunto para alfa $=0.05$} \\
\hline & & 1 & 2 & 3 \\
\hline G42R & 8 & .014601865 & & \\
\hline$\Delta$ aga1 & 8 & .015687415 & & \\
\hline G203R & 8 & & .016980606 & \\
\hline wt & 8 & & & .019265435 \\
\hline Sig. & & .050 & 1.000 & 1.000 \\
\hline
\end{tabular}

\section{LPE}

\begin{tabular}{|l|r|r|r|r|r|}
\hline LPEmm.h & $\begin{array}{c}\text { Suma de } \\
\text { cuadrados }\end{array}$ & g1 & $\begin{array}{c}\text { Media } \\
\text { cuadrática }\end{array}$ & F & Sig. \\
\hline Inter-grupos & .001 & 3 & .000 & 89.147 & .000 \\
\hline Intra-grupos & .000 & 28 & .000 & & \\
\hline Total & .001 & 31 & & & \\
\hline
\end{tabular}

\begin{tabular}{|c|c|c|c|c|}
\hline \multicolumn{5}{|c|}{ HSD de Tukey ${ }^{\mathrm{a}}$} \\
\hline \multirow[t]{2}{*}{ Grupo } & \multirow[b]{2}{*}{$\mathbf{N}$} & \multicolumn{3}{|c|}{ Subconjunto para alfa $=0.05$} \\
\hline & & 1 & 2 & 3 \\
\hline G42R & 8 & .0424334 & & \\
\hline$\Delta$ aga1 & 8 & & .0454299 & \\
\hline G203R & 8 & & & .0513401 \\
\hline wt & 8 & & & .0531966 \\
\hline Sig. & & 1.000 & 1.000 & .087 \\
\hline \multicolumn{5}{|c|}{ Se muestran las medias para los grupos en los subconjuntos homogéneos. } \\
\hline \multicolumn{5}{|c|}{ a. Usa el tamaño muestral de la media armónica $=8.000$. } \\
\hline
\end{tabular}

